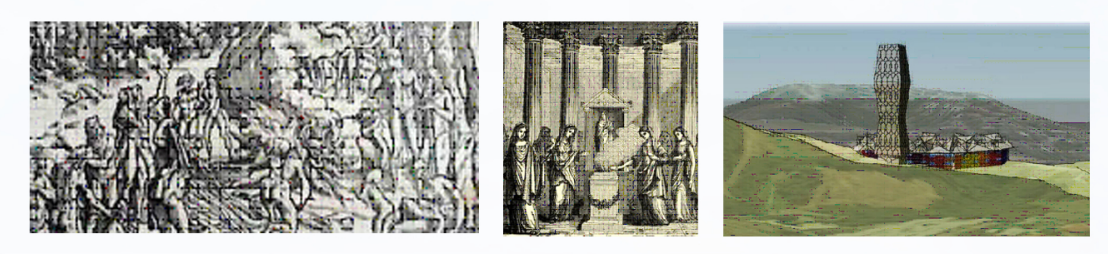

\title{
Playing with Fire: \\ Analysing the Role of Fire in Architecture
}

Submitted in partial fulfilment of the Master of Architecture (Professional) At Victoria University of Wellington School of Architecture

By Joanita Goei

2011

Supervised by Dr. Peter Wood 


\section{Table of Contents}

Table of Contents 1

Introduction

Chapter 1: Myth as History

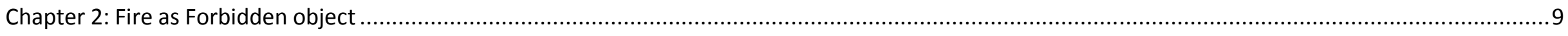

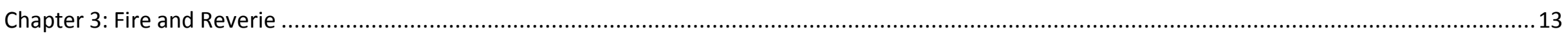

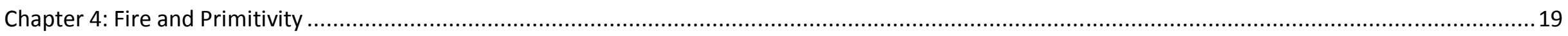

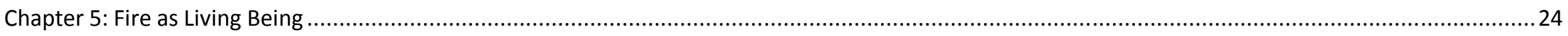

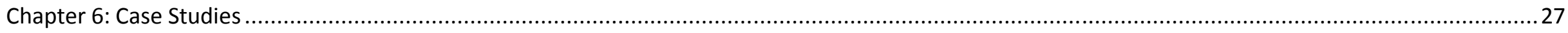

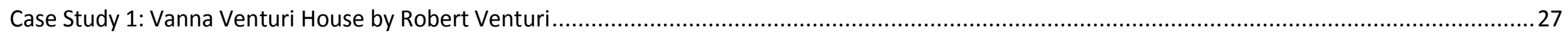

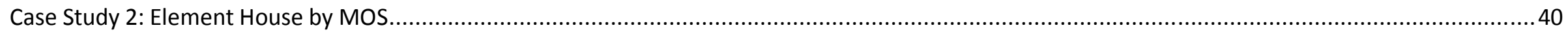

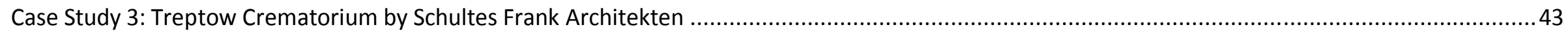

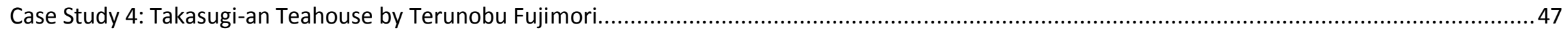

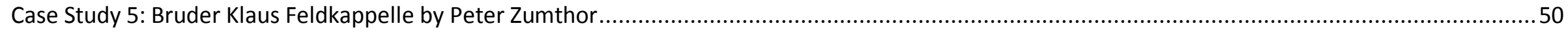

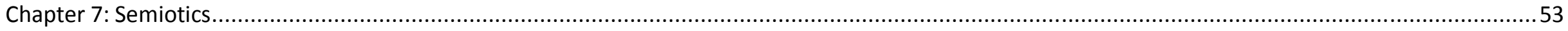

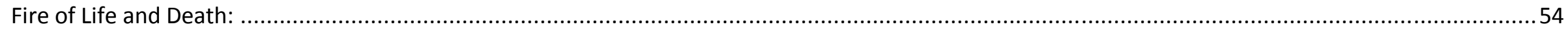

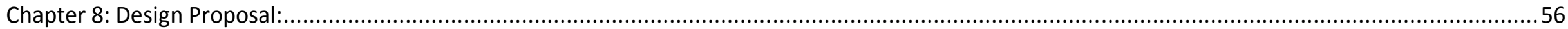


Drawing Experiments:

I. Fire as Life

II. Fire of death.

III. Fire of Violence

IV. Fire of Power

Conclusion

Appendix A - History of fireplace:

Bibliography

Illustration reference: 


\section{Introduction}

Architecture acts not only as a framework to society but also to reinforce our way of life and existence. Outside pragmatics, architecture serves to fulfil psychological and spiritual needs. Fire is one architectural element which serves both pragmatics as well as the poetic needs. It provides us with warmth while also allowing us to tap into our subconscious. When we find ourselves lost in thought while gazing at burning fire we find one of our first experiences with architecture.

Fire is ancient. Gottfried Semper viewed the discovery of fire as the beginning of architecture. In his Four Elements of Architecture, Semper writes: "Before men thought of erecting tents, fences or huts, they gathered around an open flame." ${ }^{1}$ At the very moment people first gathered around an open fire, architecture was born. The architecture he spoke of is not a 'building' per se, but a ritualized space. Fire creates a centre point in which space is organized around. The circumference of its warmth and light is a threshold. Those within the threshold are considered part of a community, and those outside are not. In other words, this division of space defined fire as an important focal point in architecture. It is the key element in which architecture revolves around.

Fire's ability to gather a community is present within crematoriums, which are examples where fire is used as a ritual vessel at which people gather around, a kind of civic beacon. It is there to bring together the community in remembrance of a beloved one. Not only does fire have a central role in the function of the architecture, it also provides poetic meaning. Fire's duality in character has resulted in its connection with contradicting ideas. It is the symbol of life and death, a creator and destructor. This research proposes a crematorium for Wellington that operates with these motives and psychological ambiguities. As the fireplace is decreasingly popular within the homes due to sustainability, a 'civic ritual fire' like the crematorium can replace it. The architecture of the crematorium is an extended symbol of the fire, bringing together people and celebrating the life,

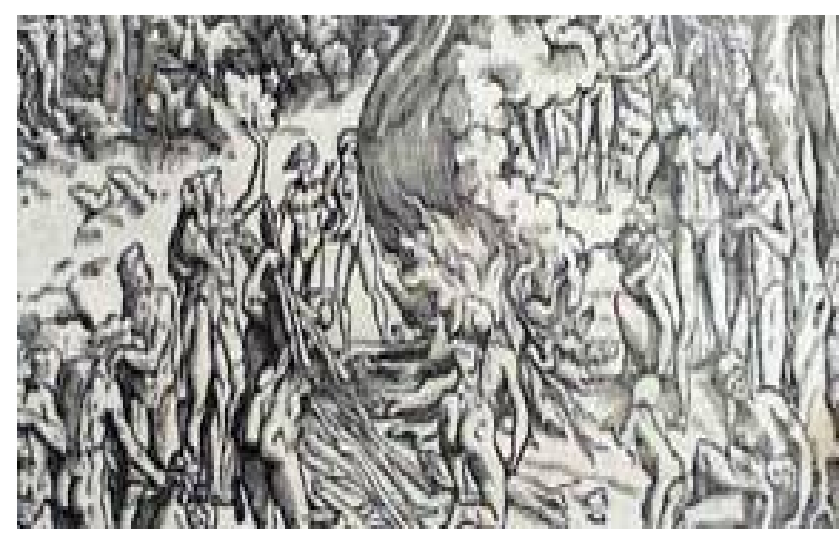

Figure 1:

Fernandez-Galiano, Luis, Fire and Memory: On Architecture and Energy, Cambridge: MIT Press, 2000, pp15

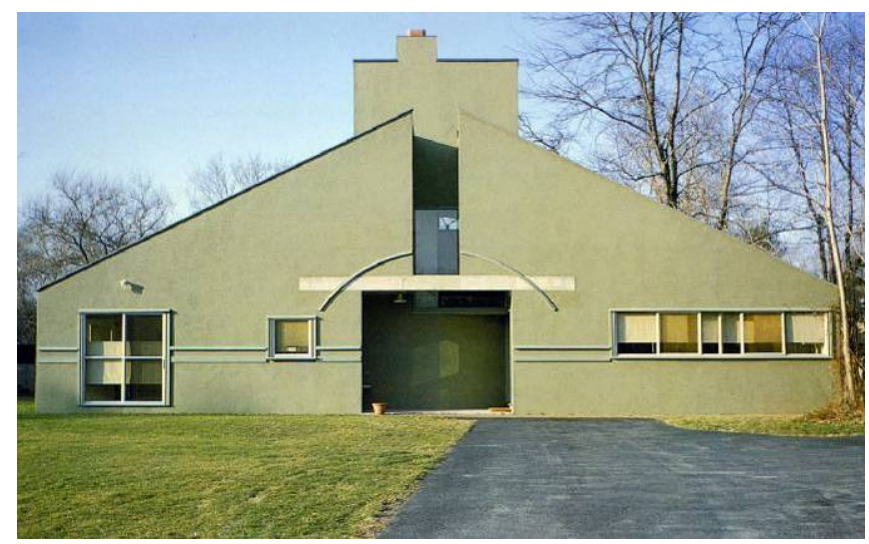

Figure 2:

Vanna Venturi House by Robert Venturi in Philadelphia. (1962)

${ }^{1}$ Herrmann, Wolfgang, Gottfried Semper: in search of architecture, USA: MIT Press, 1984, pp. 198 
death and rebirth of a loved one. The aim here is to serve our primal need for contact with fire architecturally, but allowing it to fit into today's conditions.

This research addresses the four inherent themes within fire. Fire has an association with myth due to its complexity in nature and existence long before modern science. Even today these myths live on as a way to describe the characteristics of fire as an architectural element. Bachelard's book The Psychoanalysis of Fire looks at how fire connects with our primitive self through reverie. Fire's contemplative character allows us to escape the surrounding world, and transport us to a kind of subconscious level. An extension of the reverie of fire is fire's relation to the primitive. Although we have evolved into advance species, at a basic level we are all still animals. There are certain primal needs inherent within us such as sense of safety and community. Fire fulfils these needs architecturally by providing the setting for 'primitive experiences.' The last theme I will look at has to do with fire's association with living beings. Even though fire is not scientifically a living organism, it is often compared to a living being due to its complexity in character. Moreover, it often symbolises life in many levels of society such as the civic hearth during the Greco-Roman era.

Several case studies are looked at to see the application of the ideas represented within the themes of fire. A range of contemporary architecture is chosen to show how the ideals associated with fire are still applicable in architecture even today. In the case studies fire has either been excluded physically but present symbolically, or its presence has been reduced to the bare minimum. The case studies aim to show how fire can be addressed architecturally using other architectural elements that are traditionally associated with fire, such as chimneys and hearth. Due to current issues such as sustainability, having fire physically within a space is becoming more difficult. Many places around the world have banned open fires. An option to continue celebrating fire within architecture is through the symbolic representation of the element. This can be done by using other architectural elements that we traditionally associate with fire. The first case study will be the Vanna Venturi House by Robert Venturi (1962). This house is important in the way it uses the existence of fire within domestic architecture as a symbol of the heart of the home. Element House by MOS (2010) is another version, where the same symbolic approach can be manipulated to create a different message, while still fulfilling the same needs. Treptow Crematorium by Axel Schultes (2008) is then

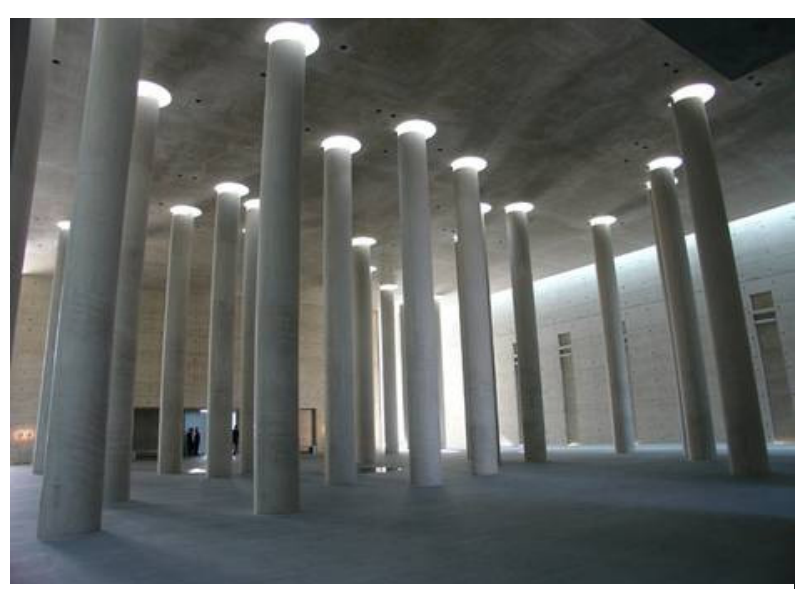

Figure 3:

Treptow Crematorium by Axel Schultes in Berlin. (2008)

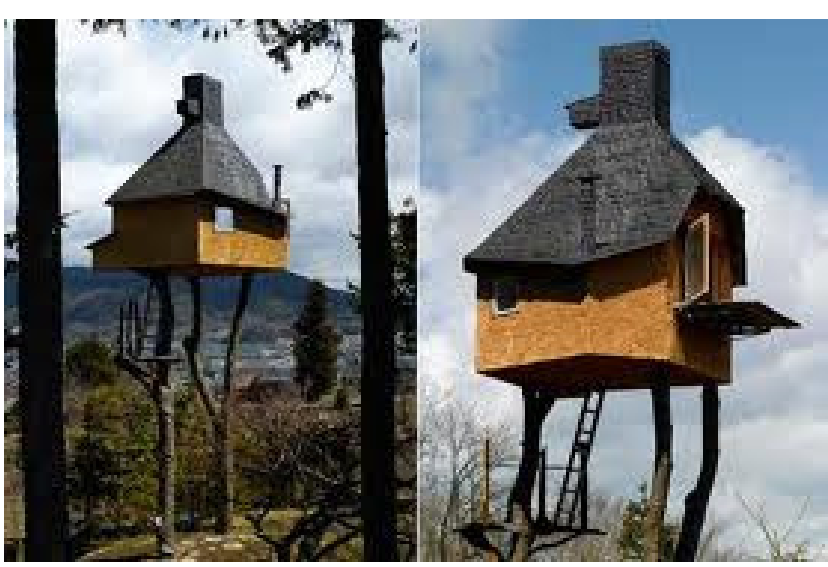

Figure 4:

Takasugi-an by Terunobu Fujimori in Chino. (2004) 
looked at as an example where fire as an architectural element is used for civic purposes. Takasugian Teahouse by Terunobu Fujimori (2004) also explores how fire is used as a ritual vessel in architecture, in the ultra modern society. It is important in the way it has kept tradition even, when technology reins the everyday life. Lastly, Peter Zumthor's Bruder Klaus Feldkappelle (2007) is an example where fire is the creative means in making architecture. Zumthor literally uses fire to create his architecture and allow traces of it to linger so that our reveries will connect with fire's association with life, death, rebirth and cleansing. These case studies are then taken as precedents for the design of the Wellington crematorium.

With the influence of semiotics in architecture, images are derived which symbolize fire in its characteristics of life, death, power and violence. These images are put through a series of drawing experiments in order to create an abstract image that is later used as the basis of form making for the crematorium. The design proposal of a crematorium highlights fire's relation to the duality of life and death. The design explores this idea of duality through geometrical relationships as well as other compositional techniques. The design aims to create a focus on a more celebratory nature of funeral rites, following those of oriental religions and historical societies.

Fire's presence within architecture has spanned over millennia. Gottfried Semper believes that fire has been a central focal point for architecture since the beginning. ${ }^{2}$ It is one of the humanising elements' which provide the poetic elements within architecture. Although the use of fire literally is diminishing today in architecture, it is important the element is still implied or included one way or another. In looking to the past uses of fire, we may be able to find an alternative way to use this architectural element that fits with today's society while continuing the binary characteristics of fire. In other words, we should search for the primal impulses within our modern world.

\footnotetext{
${ }^{2}$ Semper, Gottfried, Four Elements of Architecture and Other Writings, Cambridge: Cambridge University Press, 1989, pp. 102
}

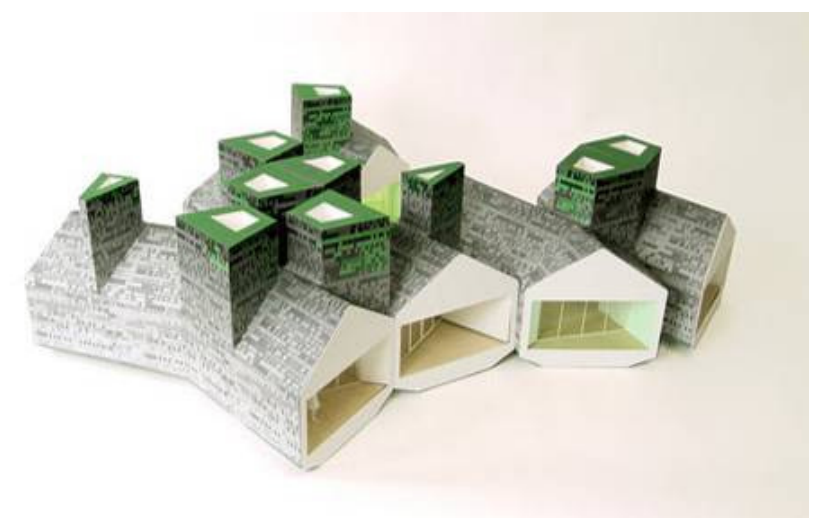

Figure 5:

Element House by MOS in Colorado. (2010)

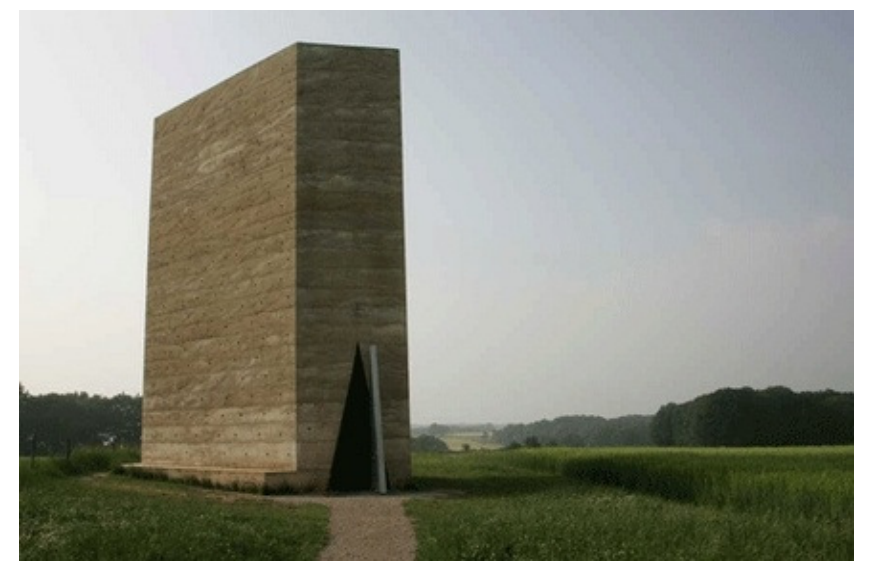

Figure 6:

Bruder Klaus Feldkappelle by Peter Zumthor in Wachendorf. (2007) 


\section{Chapter 1: Myth as History}

Robert Segal writes that "philosophy grows out of myth; that myth is philosophy." ${ }^{3}$ For him, myth is a primitive form of philosophy. Many philosophers often use myths to help explain their ideas. One example is where Bachelard used Prometheus, the Greek God of fire, as the basis of his theory on fire discovery.

Myths can be considered to be a type of historical account. It often tells tales of creation "typically involving supernatural beings or events." ${ }^{14}$ Anthropologist Stanley Hyman believes that myths are the primitive form of science due to its attempts at explaining natural phenomena or, as Roland Barthes writes in Mythologies, "myth is a type of speech." ${ }^{5}$ Similarly, architecture, too, can be considered a tool for communication. Both are used as a way to transmit ideas regarding our environments as well as the spiritual needs. Although exaggerated, we must not forget that myth is also an account of the past. In essence myth can therefore be seen as a type of history. ${ }^{6}$ There are a number of myths that have to do with fire. Architecture communicates the importance of fire within these myths. In ancient Greek temples, fire is often used as the climactic centre of religious buildings. Ancient Greece believed fire to be the centre of community, and therefore represented in the centre of architecture.

Prometheus, the god of fire, was the one who gifted humans with fire. ${ }^{7}$ He was a second generation Titan, a giant race "who inhabited earth before man." ${ }^{8}$ Prometheus was said to have stolen fire from

${ }^{3}$ Schilbrack, Kevin Ed., Thinking Through Myths: Philosophical Perspective, London: Routledge, 2002, pp. 19

4 "Myth", Oxford Dictionaries, April 2010, Oxford University Press, visited 1 November 2010

<http://english.oxforddictionaries.com/view/entry/m_en_gb0545790>.

${ }^{5}$ Barthes, Roland, Mythologies, Canada: HarperCollins Canada Ltd., 1972, pp, 109

${ }^{6}$ Heehs, Peter, 'Myth, History and Theory', History and Theory vol. 33. No.1, pp. 3

${ }^{7}$ Raggio, Olga, 'The Myth of Prometheus', Journal of the Warburg and Courfauld Institutes vol. 21 no. 1/2, Warburg Institute, 1958

${ }^{8}$ Bulfinch, Thomas, Bulfinch's Mythology, London: Spring Books, 1964, pp. 14

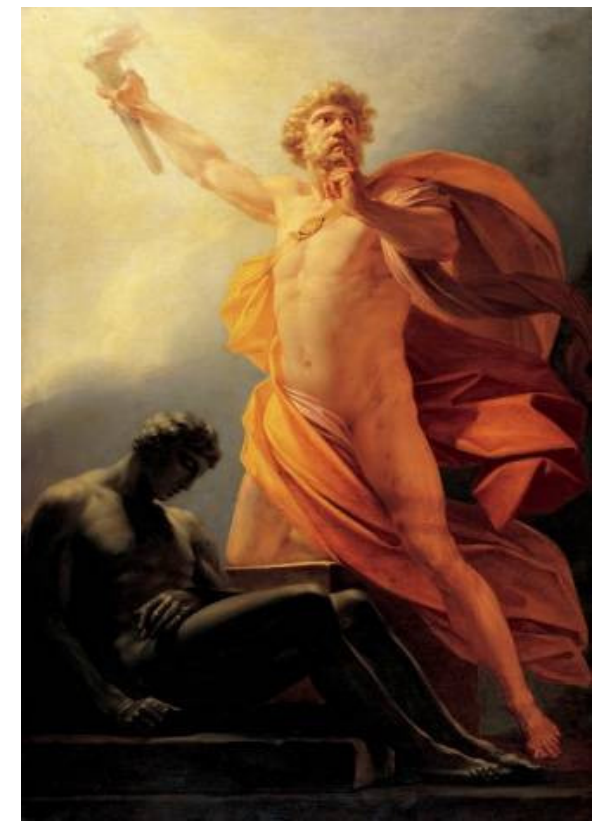

Figure 7:

'Prometheus Bring Fire to Mankind', Heinrich Fueger 1817. 
Zeus, the god who created man. ${ }^{9}$ According to the legend, Prometheus not only began the existence of fire for human kind, but he was also the source of our curiosity. Fire in Greek mythologies is represented as a forbidden element, out of bounds for humans, the sons and daughters of Zeus. As a parent figure, Zeus wished that man to be forever inferior, thus ensuring their worship of him. Prometheus showed man knowledge as a way of being independent. As a result, the myth explains how curiosity became inherent in all human. Bachelard compares children wishing to better their parents to Prometheus wishing that humans be equal or better than the Gods. According to the Greek mythology, fire was seen as a power that belongs only to the Gods. In attaining it, humans were able to become more independent from the gods. As a result, fire became a respected element and was celebrated throughout classical architecture, as it is seen as the element that catalyzed progress by the Greeks.

The legend of Prometheus is central to Gaston Bachelard's Prometheus Complex. Bachelard saw the similarities between Prometheus and humans. Both have inherent curiosity and a desire of advancement. Bachelard's Prometheus Complex describes the tendencies to "know as much as our fathers, more than our fathers, as much as our teachers, more than our teachers." ${ }^{10}$ As a result of this we constantly develop the technologies that we have. The development of our society has been reliant on our curiosity. For example as fire became domesticated as fireplace, it has over time gone under several evolutions. It has grown from the primitive open fire, to the open hearth within a shelter to its current location within the wall. ${ }^{11}$ The reason for evolution is mainly driven by pragmatics such as smoke control. Due to this constant evolution, the mobile fire has now become static. $^{12}$

Another Greek God associated with fire is Hestia. Hestia was the virgin god of the hearth - a static form of fire. As a goddess, her job was to keep the fire of Olympus alive. ${ }^{13}$ In respect of the gods the

\footnotetext{
${ }^{9}$ Bulfinch, Thomas, pp. 9

${ }^{10}$ Bachelard, Gaston, The Psychoanalysis of Fire, Boston: Beacon Press, 1964, pp. 12

${ }_{11}$ McDonald, Roxana, The Fireplace Book, England: Architectural Press Ltd., 1984, pp. 3

${ }^{12}$ See Appendix A for a detail description of the evolution of fireplace.

${ }^{13}$ Kajava, Mika, 'Hestia: Hearth, Goddess and Cult', Harvard Studies in Classical Philology, vol. 102, 2004, pp. 1
}

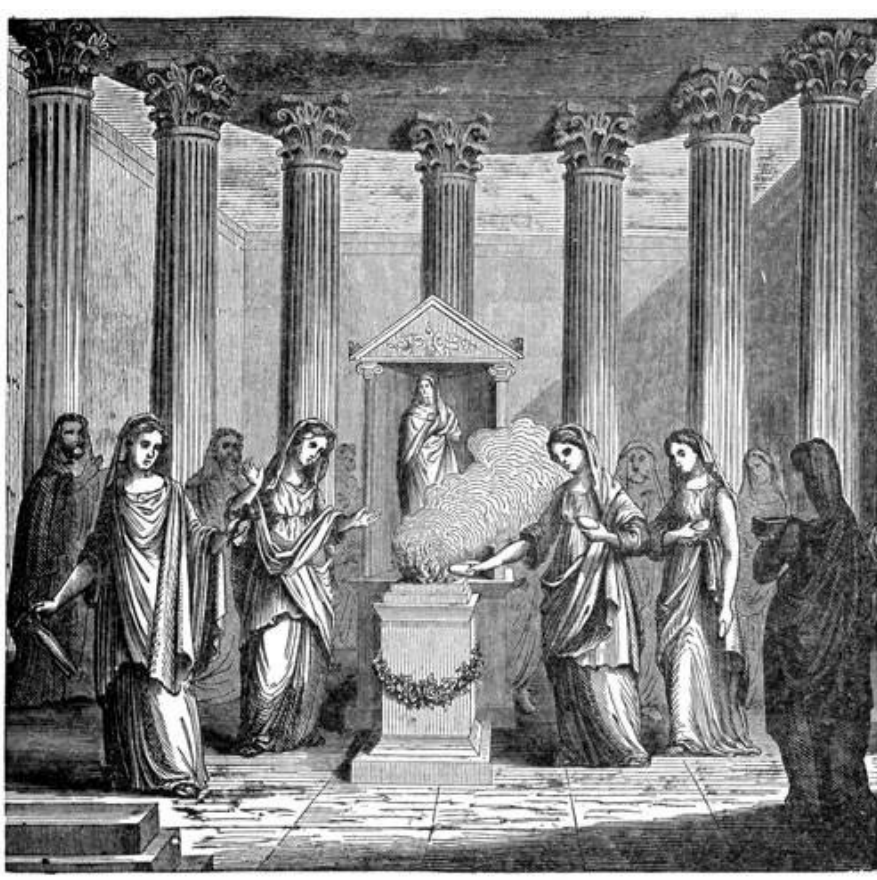

Figure 8:

Image of vestal virgins in the temple from Bulfinch's Mythology-Age of Fable 1903. 
Greeks too had a civic hearth which was kept constantly alive. An equivalent of Hestia for the Romans was Vesta and their civic hearth was referred to as the Vestal. The Greeks and Romans arranged their ancient cities and architecture around this hearth and its flames represented the life of the city. As an architectural element, fire became closely related with the "the city in foundation rites." ${ }^{14}$ Important to life as a citizen were rituals that involve the central hearth that is the civic fire. Ceremonies of celebration as well as tribulation were situated around and often included the fire. A ritual of sacrifice to the gods was often conducted at the location of the hearth; this ritual will be explained later on in chapter 2.

The civic fire is a public hearth lit to symbolize the life of the Roman or Greek city. It is a reflection of the hearth Hestia or Vesta kept in Olympus. It is therefore considered to be sacred due to its connections with the Gods. The remnants of ritual and presence of this civic hearth shows the importance of fire as a mythical element during the age of classicism. It is one reason the domestic fireplace is considered to be the element of sanctity in the home. ${ }^{15}$ This is parallel to the way civic fire, or Vestal as the Romans call it, is the symbol of the city's life. In this case the city is comparable to the home just as the Vestals are comparable to fireplaces. Both uses of fire as an architectural element create a threshold separating the sacred inside from the outside. The civic fire symbolically creates a threshold around the perimeter of the city. Whoever is within the threshold is part of the community and is protected by the city. It also acts as a focal point at which the citizens gather around, thus reinforcing a sense of community and producing a kind of transcendental architectural experience. Fire as an architectural element is essential due to its ability to fulfil the poetic needs such as a sense of physical and spiritual warmth. Its ability to gather people, and thus create a sense of community and safety makes it a focal point within space.

\footnotetext{
${ }^{14}$ Fernàndez-Galiano, Fire and Memory: On Architecture and Energy, Cambridge: MIT Press, 2000, pp. 13

${ }^{15}$ Fernàndez-Galiano, pp. 10
} 


\section{Chapter 2: Fire as Forbidden object}

In Bachelard's writing, our first experience of fire is that of prohibition. If our animalistic nature attracts us to fire, as children we are denied of this attraction. Children often try to touch fire. In order to protect their children from harm, parents automatically prevent this contact. In saying so our curiosity of fire often increases when we are forbidden from interacting with it. As a result, we often find children 'stealing fire' from their parents. Even Jung recalls:

"I recall from this period (seven to nine) that I was fond of playing with fire... I used to tend a little fire in one of these caves, with other children helping me; a fire that had to burn forever therefore had to be constantly maintained by our united efforts, which consisted in gathering the necessary wood. No one but myself was allowed to tend this fire... My fire alone was living and had an unmistakable aura of sanctity." ${ }^{16}$

Jung's memory of fire supports the fact that fire is naturally attractive for us. Even as children we sense fire's importance and acknowledge it as being a focus at which we gather around. Jung believes that we inherently see something sacred in fire. Architecturally its ancient connection with the Gods reinstates its position as a 'sacred element.' As a result, it is inherent that we feel the space around fire is special. In saying so, as children we are forbidden to interact with it and our curiosity towards fire grows stronger because we are denied it.

Fire's association with the legend of Prometheus is one of the reasons it is considered forbidden. Its forbidden nature in turn is one of the reasons why it is considered sacred. Observing the way fire is treated, we can see a duality in its character. Though it is believed to be the source of life and creation in Greek mythology, it is also the symbol and cause of destruction. "The quickness of fire offers... problems," ${ }^{17}$ which means it is also destructive. This duality provides a certain complexity to the element, and is represented in the way fire is used as a ritual vessel during Greek times. George Hersey writes that ancient Greek sacrificial ritual involves the "the deconstruction and reconstruction

${ }^{16}$ Jung, Carl G., Memories Dreams Reflections, London: Collins, 1961, pp. 35

${ }^{17}$ Bachelard, Gaston, 1964, pp. 63

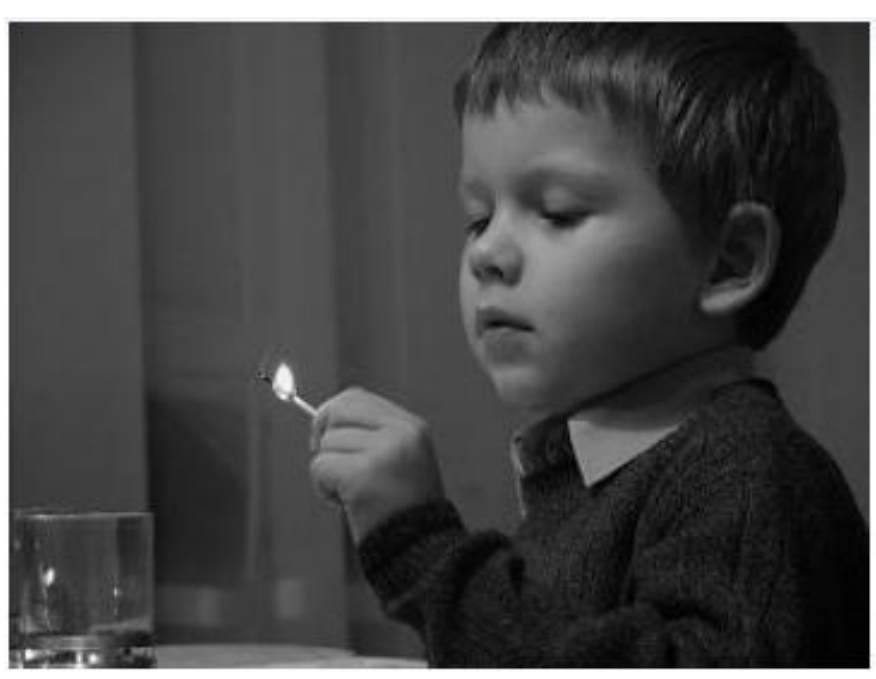

Figure 9:

Typical advert showing a child stealing matches to play with fire. 
of the victim's body." ${ }^{18}$ This description is due to the act of progressive cutting of the animal sacrifice's body, and throwing it into the sacred fire. The reconstruction is done after all parts of the sacrifice are in the fire. The remains of the body are laid to resemble its original form, as if to remind the congregation of the nobility of the act of sacrifice. ${ }^{19}$ The use of fire in sacrifices shows the positivity of the communal life by representing the idea of sacrifice for the greater good. It reflects the life giving characteristics of fire in the way sacrifices are believed to be a way of securing the Gods protection for the city. When used during mourning, it reflects fire's power to destroy, a darker view of the element. However it is important to see that in both dialectics of safety and danger fire is still an element which gathers people. The fire marks a space that is considered to be sacred through the way it is viewed as special by the occupants. Therefore fire divides the private space from the common space by marking the area with its light and warmth. Ironically today, we invite fire into the home only to defend ourselves against its intrusion.

Respect for its destructive power also means that there is a distance associated with it. This can be observed in the way fireplaces are treated in the home thus highlighting the first dialectic of saviour and danger. For safety and aesthetic reasons it is often raised up from the floor level. While the aesthetic reasons can be observed, the raising is also to create a kind of threshold separating the powerful element from the rest of the house. Parents with children will often put safety gates around the fireplace. This way, children can engage with the fireplace safely - at a distance. Furthermore, this allows parents to feel safe knowing their child will be unable to hurt themselves by playing with the fire. Here, even though children are able to interact with fire visually, in a sense they are still denied fire as they are unable to truly interact with the element and discover its properties.

In contrast to children, who are attracted to fire, animals are naturally fearful of it. This is the reason why fire was often used at night to repel predators. It seems while wild animals are aware of fire's destructive nature, domesticated animals and children are more familiar with its positive characteristics. Domesticated animals will comfortably lie in front of a fireplace embracing its

\footnotetext{
${ }^{18}$ Hersey, George, The Lost Meaning of Classical Architecture, Massachusetts: MIT Press, 1988, pp. 16

${ }^{19}$ Hersey, George, pp. 15-16
}

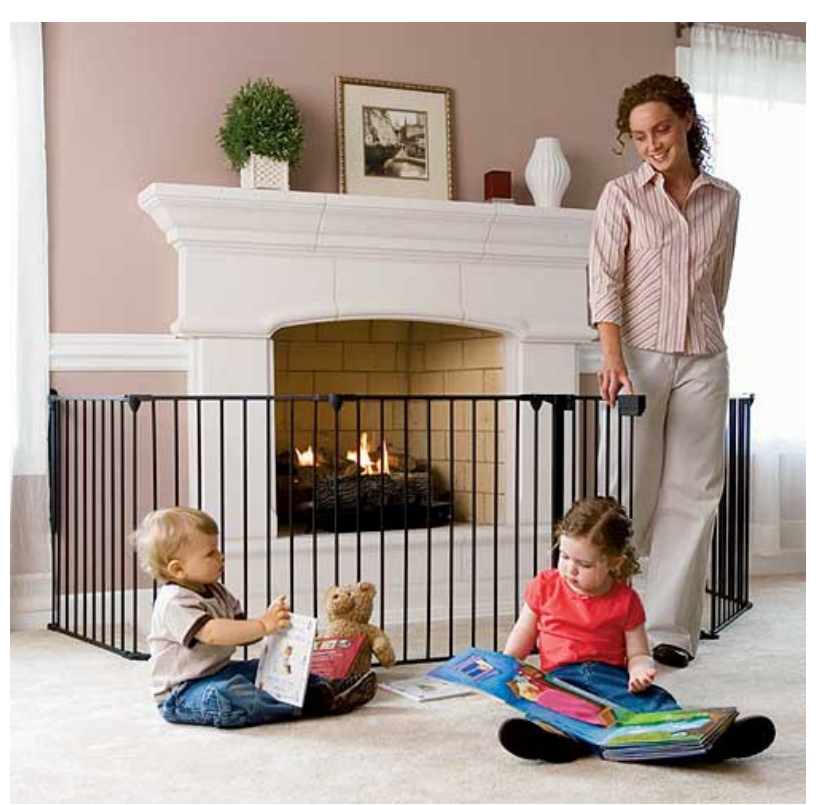

Figure 10:

Protective gates are often installed within the home in order to prevent children from getting too close to the fire. This act of 'protection' is what Jung and Bachelard interpreted as a way of depriving children of one of the primal needs of being a human being. 
warmth, while wild animals will keep their distance whenever they see fire. Wild animals come in contact with wild fire in the form of lightning and forest fires. From this kind of experience, we see why wild animals are fearful of fire. They are only familiar with its destructive nature. The opposite applies to domesticated animals. Humans often 'control' fire well thus utilizing it only for its positive functions. Therefore they are familiar only with the good characteristics of fire. This opposing treatment of fire between the wild and domesticated truly represents fire's double personality. While it is caring and protective, it is also destructive and dangerous.

In conclusion, many ancient societies represented the human fascination with fire with rituals based upon a variety of myths. The Greeks in particular associated fire with two Gods: Prometheus and Hestia. Prometheus represents the male side of fire, the human curiosity and desire to improve. This 'male' side of fire is adopted by Bachelard in his Prometheus Complex. Hestia, the 'female' side, represents the protective power of fire. This particular association is expressed architecturally through the civic fire of ancient Greece and Rome. This fire is a beacon for the city.

The architecture of ancient cities was built around fire and its life was representative of the city's life. The civic hearth was the first 'architecture' to be built within a new settlement, and its flames from Apollo equal the community's vitality. ${ }^{20}$ Semper writes in his Four Elements of Architecture that the civic fire was important architecturally as it was a point of gathering for the occupants and the way fire was treated in these ancient cities show how fire is a kind of focal point for community. The civic fire's connection to Hestia, the Greek goddess of Hearth, and use for sacrificial rituals for the gods is the reason it is seen as an important and sacred element. In respecting its sacredness comes the knowledge of fire's destructive power. Fire's violent power is often used to cleanse a city of its former past. The element's ability to eradicate everything in its path made it a dangerous weapon in battle. This aspect of fire will be discussed further in chapter 7 . This destructive nature also highlights fire's dialectic nature. For example, the fireplace is present within the home to provide comfort and warmth. However, due to safety reasons gates are often placed around the fireplace to prevent children from getting too close. Children are encouraged to observe and engage with fire -

${ }^{20}$ Zaidman, Louise \& Pauline Pantel, Religion in the Ancient Greek City, Cambridge: Cambridge University Press, 1992, pp. 93 
Joey Goei - Playing with Fire: Analysing the role of Fire in Architecture

at a distance. Even though society has evolved in so many ways, fire's meaning in architecture and its dangers remain the same. 


\section{Chapter 3: Fire and Reverie}

"The dream is stronger than experience." 21 - Bachelard

Bachelard believes that fire is closely related to our reverie. He writes: "reverie works in a star pattern. It returns to its centre to shoot out new beams." ${ }^{22}$ From this he means that reverie is connected to a variety of things - fire is but one. These abstract connections fire has with various elements of life, such as community, are the reason fire is a semiological symbol (further discussed in Chapter 7). ${ }^{23}$ Our need to be part of a community is also considered by Bachelard to be primal. Gathering around an open fire, or fireplace, we are able to return to the central reverie. This includes our respect for fire and the way fire is dialectic of both life as well as death.

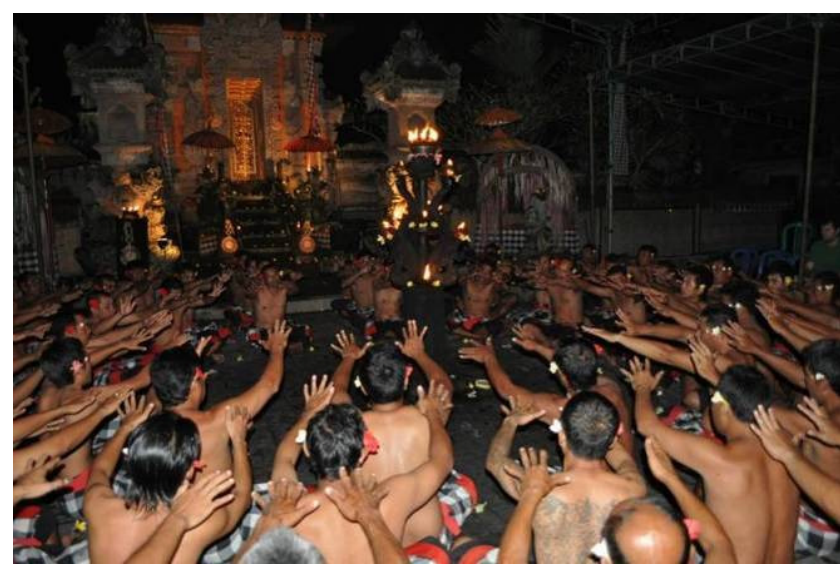

Figure 11:

'Kecak originated in Balinese Hindu culture as a sort of exorcism, a trance ritual that was meant to keep evil spirits away.

\footnotetext{
${ }^{21}$ Bachelard, Gaston, 1964, pp. 19

22 Bachelard, Gaston, 1964, pp. 14

${ }^{23}$ Walker, Paul, Semiotics and the Discourse of Architecture, Auckland: University of Auckland, 1987, pp. 43
} 
Bachelard coined the term Empedocles Complex to explain our "respect for fire, the instinct for living, and the instinct for dying" 24 The term is based upon the Greek philosopher Empedocles, who first established the four classical elements of fire, water, earth and air as being the base of balance in the universe. Empedocles also connected these elements to the idea of love and strife, love being the connecting force and strife the separating force. ${ }^{25}$ This relates to Bachelard's theory that fire ignites the inherent reverie of "love and death," ${ }^{26}$ which connects and separates all human beings. Our reverie connects us to each other at a subconscious level where a kind of primal blueprint exists in all minds. It especially addresses the way we subconsciously prepare ourselves for the end of our life. Within this particular idea, the natural way to part with the dead is by cremation. Bachelard writes that "death in flame is the least of lonely deaths." ${ }^{\prime 2}$ The western approach to cremation is the opposite to that of the east. For western society, cremation is a lonely process, where the dead undergoes their final transformation alone, without the presence of their loved ones. In religions such as Hinduism, fire brings community together, its presence act as a focal point to architecture and society. The mourners gather around a central ritual fire while they pray and watch the body being consumed by fire. In other words, when cremated, loved ones will be gathered around the fire, they will be with you in spirit. The fire acts as a kind of gateway to the next realm and as the body is incinerated, their loved ones are present to see them pass through that gateway. The fire will mark a space of primitive reverie symbolising community through the way people gather in celebration of this transformation.

In Bachelard's writing reverie is a principal element of life. It is considered to be the $\mathrm{x}$-factor we seek for in architecture. In other words, Bachelard believes that architecture should aim to ignite our reverie so that people will be attracted to the space and receive a sense of fulfilment from it. For example, a burning log fire taps into our reverie in the way it brings us back to past moments we have had with the fireplace. Many families gather around a fireplace at home during winter.

\footnotetext{
${ }^{24}$ Bachelard, Gaston, 1964, pp. 16

${ }^{25}$ Russell, Bertrand, History of Western Philosophy, New York: Routledge, 2004, pp. 62

${ }^{26}$ Chimisso, Christina, Gaston Bachelard: critic of science and imagination, New York: Routledge, 2001, pp. 205

${ }^{27}$ Bachelard, Gaston, 1964, pp. 15
}

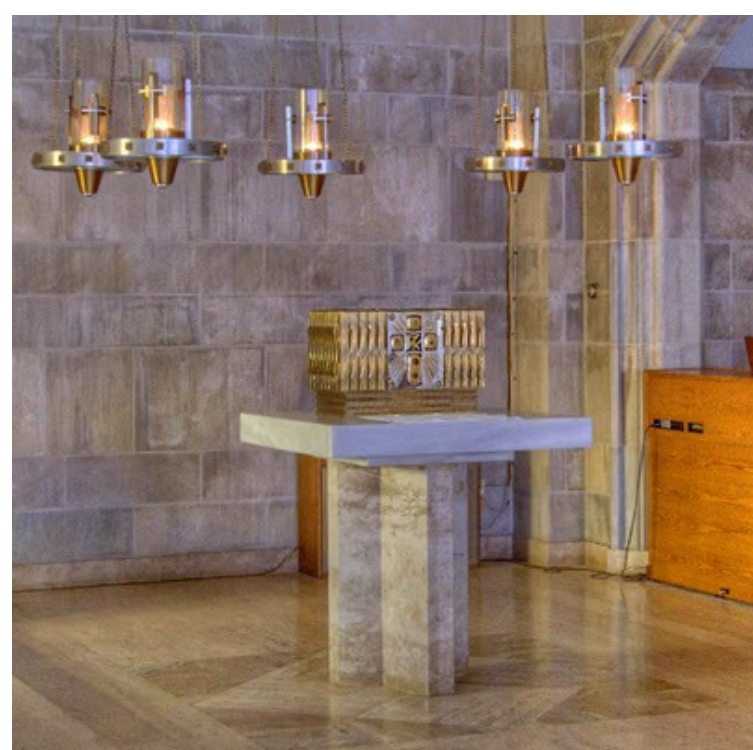

Figure 12:

The candles around the Tabernacle are lit in order to symbolize the presence of Christ's body. 
Memories, such as the reverie of community achieved through the gathering of family around the fireplace, link to our idea of safety and community.

Bachelard writes: "One only receives comfort from the fire when one leans his elbows on his knees and holds his head in his hands." ${ }^{28}$ Here Bachelard speaks of the deep meditative state and sense of repose achieved when we interact with fire. We often find ourselves staring deeply into a burning fire. As people we seem to have an uncanny fascination towards fire. This fascination with fire is often used to create transcendental experiences in architecture. The creation of this deep reflective state aims to cut out our surrounding world and place us elsewhere mentally. In religion many escape their present world to be in touch with what they considered sacred. As a result, fire is often incorporated within religious architecture. ${ }^{29}$ Whether the role is small like within the light of a Tabernacle, or large, fire has a strong symbolic presence. The Tabernacle is the place where the Holy Communion is stored at churches. Flames of the candles act as a symbol showing the presence of Christ's body inside, when empty the flame is put out (figure 12). Fire acts as a vessel that sheds the distraction of materiality and the congregation come together to focus on spirituality. For example Hindu temples in Bali often perform 'Kecak', a trance state dance that is achieved through praying around a central hearth at the temple. Though the temple itself is adorned with ornaments of many gods, it is the ritualistic fire that provides the extra spirituality. Fire is central to the transcendental experience due to its ability to gather people and enhance their sacred experience.

Jung and Bachelard both agree that being in touch with our reverie is important, but ritual may be losing its place in western society. Kevin Schilbrack writes that ritual processes in western society have declined since the Industrial Revolution. As architecture reflects the ideals of society, architecture too has gone under "a radical secularization of life." ${ }^{\prime 30}$ For example, Modernism focuses on the pragmatics of architecture and incorporates architectural machines to ensure efficiency.

\footnotetext{
${ }^{28}$ Bachelard, Gaston, 1964, pp. 14

${ }^{29}$ Stegers, Rudolf \& Dorothea Baumann, Sacred Buildings: a design manual, New York: Springer, 2008, pp. 33

${ }^{30}$ Schilbrack, Kevin, pp. 72
} 
Today's focus on efficiency is also influenced by the increasing interest in environmental sustainability. The earth's environment has become a big issue in the past decade. Architecture and technology now strives to improve the environment by producing less pollutant to the air. Fireplaces therefore have been banned in some areas around the world in order to decrease the amount of pollutants released into the earth's atmosphere. This too has a major part in the declining number of fireplaces within the home, as they have to comply with legislation and social trends. With the disappearance of fireplaces comes the disappearance of mantelpieces. The mantelpiece is where families often place their treasured mementoes as a way to connect with their past and origin. Nothing has yet to replace the mantelpiece's role in the home. If anything the new focus inside the home is the television. Furniture and room arrangements are now based upon the location of the TV whereas it used to be arranged around the mantelpiece. As a result for some there is a decrease in connection with our past and origin.

In terms of fire, the fireplace is being replaced by systems such as heat pumps. The fireplace is proven to be inefficient as a heating mechanism due to the amount of heat loss from cracks and the flue. ${ }^{31}$ Therefore it is replaced by a machine which provides efficient heating. These new machines do not have the ability to tap into our reverie. Even the Romans had efficient central heating systems, and yet fire is still a principal element within their architecture for civic purposes. It can be said that today architecture is losing its connection with poetics due to the move towards efficiency.

Our interest in fire is more than pragmatic. Fire, as an architectural element, connects us with ourselves through reverie. Bachelard's theory states that fire ignites our thoughts of life and death due to its both warming and destructive powers. Fire, being a symbol of passion is often used in funerary rituals. Bachelard believes that when cremated we are enveloped in the love of those who we leave. The fact that there is nothing left means we are virtually transferred to the next realm. Architecturally reverie is important because it allows us to connect with our subconscious. Fire entrances us when we look at it, slowly drowning the present world out. It brings people together

${ }^{31}$ Louisiana Department of Natural Resources, 'Fireplaces: Energy Dollars Up in Smoke', Energy Efficiency Resource Gateway, http://dnr.louisiana.gov/sec/execdiv/techasmt/educational resources/bgbb/7/energy/index.html, visited 9 December 2010 
and provides us with our inherent desire for company. When we design buildings we hope that it will provide the occupant with a chance to reflect and enjoy both in groups and at a personal level. Similarly, the fireplace is a focus for introspection. It is one of the many elements in architecture that creates a sense of transcendence, allowing us to be lost in its presence. While deep in our thought, we are able to be in touch with our subconscious. Unfortunately, since Modernism, this relation to our poetic dimension is often seen as an indulgence. Previous styles such as classicism and Gothic are seen as frivolous due to the high use of ornamentation. Modernism as a style reduces ornamentation to the bare minimum. For example Adolf Loos is famous for his quote "ornament is a crime" and Mies van der Rohe's, "less is more." Due to 'form follows function,' architects are encouraged not to focus on the poetics but rather the pragmatics. Joseph Rykwert mentions that many designers today have opted to follow "the light of reason 'functionality'." "32 This act of pragmatism is thought to be the solution to modern societal problems such as pollution. As a result our society has become more and more mechanized, and fire as poetic element is no longer seen as important. Architects are seen as the solver or societal problems, as a result, architecture followed the trend. ${ }^{33}$ What used to be an essential element within architecture is now seen as unnecessary due to sustainability or is legislated out.

Even fire's functions of providing light and cooking is replaced by more efficient machines. Saving energy has become an important part of daily life. Rather than using candlelight or even traditional light bulbs, eco-efficient bulbs are used to maximise capacity while minimising energy use. The amount of light created by electric light is simply a lot more powerful than that of fire. Nevertheless, the type of light it creates is different to fire. A fire's light 'warms' the heart in a way artificial lights do not. Also due to convenience and better safety, cooking is now often done with electric stoves. Though there is less chance of house fire when cooking with an electric stove, the experience differs. I feel this is the reason why families often find it special to gather around a bonfire and roast marshmallows.

\footnotetext{
${ }^{32}$ Rykwert, Joseph, The Necessity of Artifice, New York: Rizzoli, 1982, pp. 59

${ }^{33}$ Rykwert, Joseph, pp. 58
} 
In Psychoanalysis of Fire, Bachelard writes that fire as an architectural element has the ability to tap into our subconscious. It has an ability to drown out our present surrounding, and bring us into a state of deep contemplation. Bachelard deems this experience an essential need for humans; he writes that fire provides a psychological connection to our eminent death as well as love. Architecture often seeks to give the message of these emotions. Fire is often used as an architectural element to achieve the state of contemplation that relates us to the ideas of love and death. However, over time due to mechanization and other technologies, fire is seen as an unnecessary element within architecture. Its pragmatic function of heating is replaced by other systems. Architects, (who are so often seen as civic heroes who solve the problems of society), are therefore pressured to follow the new focus on pragmatism. As a result fire's role in architecture continually grows weaker and the fire no longer feeds our inner fire. 


\section{Chapter 4: Fire and Primitivity}

"For primitive man thought is a centralized reverie; for the educated modern man reverie is a loose form of thought." ${ }^{34}$

Central to Bachelard's theory of fire is friction. Rubbing two sticks together is the most primitive method of creating fire. Continuing his ideas about reverie as inherent primitive thought, he coined the term Novalis Complex. Novalis is a pseudonym of a German romantic philosopher and writer, Friedrich von Hardenberg (1771-1801). Hardenberg's writings often use the primitive man as a subject and thus Bachelard refers to his work in explaining this theory. ${ }^{35}$ In fact the Novalis Complex explains the way fire is "an attempt to re-live primitivity." Complex and the Empedocles Complex are brought together. Bachelard believes that the act of rubbing two sticks resulted from our curiosity (Prometheus Complex) and the reverie fire ignites is that of love of a sexual nature (Empedocles Complex). The Novalis complex addresses primitivity on the basis of our animalistic nature such as our sexual tendencies through the way Bachelard refers to fire as a 'sexualized' element. The dancing flames of fire connect the reverie of passion and our need for excitement, our 'primitive mentality. ${ }^{37}$ Where the Prometheus Complex moves us forward and the Empedocles Complex reminds us of the 'past', the Novalis Complex explains the reason for both complexes, "man is a creation of desire not need." ${ }^{\text {"3 }}$ We move forward because we desire to, not necessarily because we need to.

Through interaction with fire, Bachelard suggest that we connect with our primitive selves subconsciously. During this stage we are reacquainted with feelings that complete us at a primordial level. For example we often build simple structures made of found materials, such as sand and wood, at the beach. This is seen as a way of returning to nature. In our return to nature, we often

\footnotetext{
${ }^{34}$ Bachelard, Gaston, 1964, pp. 22

${ }^{35}$ Gjesdal, Kristin, "Georg Friedrich Philipp von Hardenberg [Novalis]", The Stanford Encyclopaedia of Philosophy (Fall 2009 Edition), Edward http://plato.stanford.edu/archives/fall2009/entries/novalis/, visited 22 January 2011

${ }^{36}$ Bachelard, Gaston, 1964, pp 38

${ }^{37}$ Chimisso, Christina, pp. 205

${ }^{38}$ Bachelard, Gaston, 1964, pp. 16
} 
build these simple 'huts' out of drift wood and a bonfire at the centre of our 'settlement.' The fire acts as "chief agent" ${ }^{\prime 39}$ in creating a centre for the camp, and combined with the 'primitive' hut, we are able to re-live the 'natural' life. The romantic life of the primitive man.

This primitive need in creation is the main question asked by anthropologist Ellen Dissanayake. Her research is based upon a question of: "since all human societies, past and present, so far as we know, make and respond to art, it must contribute something essential to human life. But what?" ${ }^{\prime 40}$ According to Dissanayake art is not the product but rather the action of creation. She writes that in creating and appreciating art, we are given a sense of pleasure similar to that of togetherness and nutritional food - it simply feels good. ${ }^{41}$ Fire itself is not what provides us with pleasure in architecture but, rather, the activities it accommodates. In the presence of fire, or creating fire, we create a sense of primitive togetherness and acceptance. Hence we have a certain need for interaction with fire as an architectural element. The act of creating fire using two sticks is pleasurable as it reminds us of 'natural' life, one without modern technology. Naturalists who believe human's natural habitat are not our city, but rather the wilderness has a point to be considered. Architecture is often considered special due to the experiences it creates, fire in architecture is the vessel that catalyses some of these experiences.

Since fire is closely related to the human animalistic nature, as an element it becomes one of the symbols of primitivity in architecture. The primitive man views the fire as a life saving element, protecting them from the cold and other predators at night. Similarly, architecture functions the same way but for man and fire. Jung writes that this relation to survival is the reason fire is a symbol of life, and Bachelard agrees in saying "fire is life; life is fire." ${ }^{.2}$ Fire and life has a kind of interdependent relationship. When a fireplace is burning within the home, it can be seen as a way of suggesting occupation and existence of life within the home. Being the heart of the home, the fireplace is the main organ that provides a sign of life within the home.

\footnotetext{
39 Boerhaave, Herman, Elements of Chemistry, London: printed for J. Wilford, 1732, pp. 144

${ }^{40}$ Crain, Calib, 'The Artistic Animal', Lingua Franca Oct. 2009, pp. 1

${ }^{41}$ Crain, Calib, pp. 4

${ }^{42}$ Bachelard, Gaston, 1964, pp. 46
}
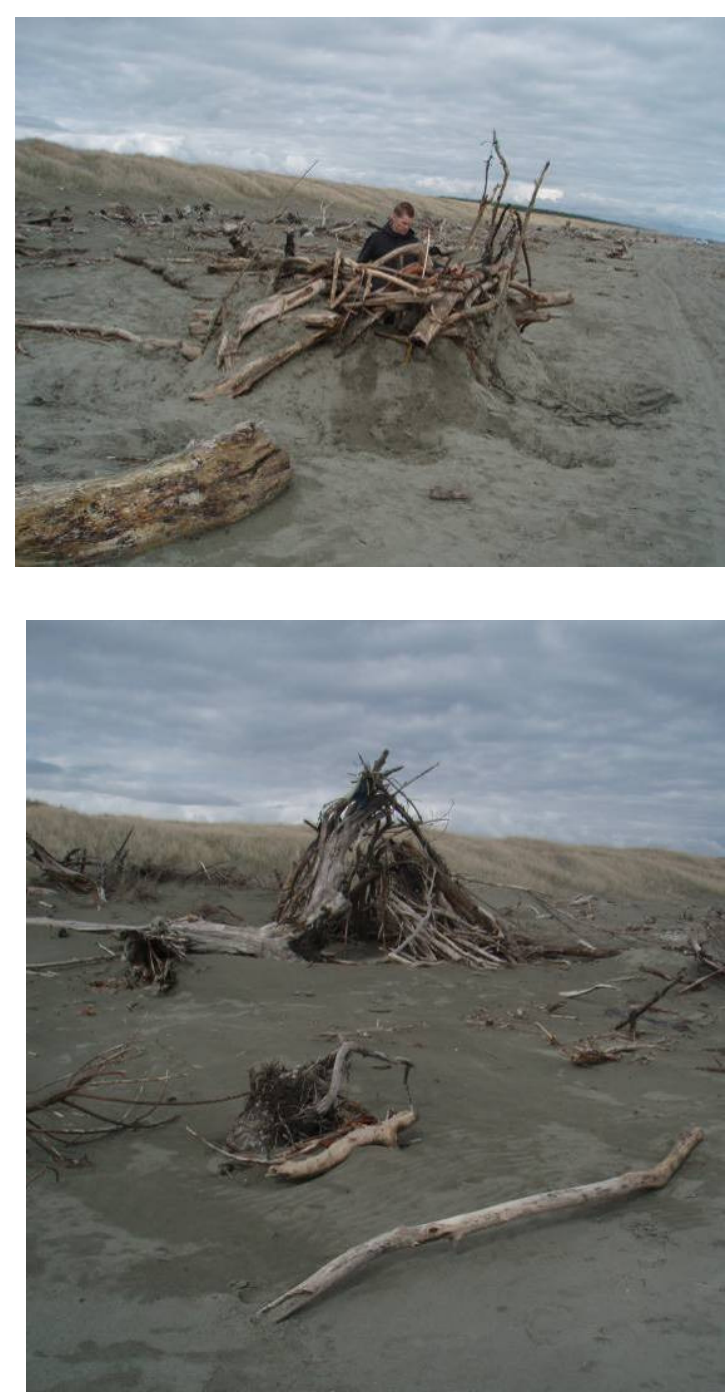

\section{Figures 13 \& 14:}

The beach at Waitaere on the Kapiti Coast has many 'shelters' made of drift wood built by people who visit. 
The rubbing of two sticks is considered a primitive action by many including Bachelard. He writes that the action is also a subconscious act of sexuality. It reflects our passions, and our need for "shared warmth." ${ }^{43}$ Not only does the rubbing create friction, it is a representation of life creation. Perhaps the spark that occurs before fire is equivalent to the 'spark' during love-making. This is represented through many tribal legends of fire that involve sexuality. ${ }^{44}$ Bachelard compares fire as being the son of man. Today the fireplace is equivalent to the primitive bonfire. The centre of the home is often compared to the womb. "A warm house [is] ike the maternal womb." 45 FernàndezGaliano writes that the fireplace is where our nostalgia of childhood, the nostalgia of the womb and the nostalgia of the home are combined and connected. ${ }^{46}$ Architecture often aims to recreate a sense of safety comparable to our mother's protection. ${ }^{47}$ Coincidentally this maternal protection is a primitive gesture. In feeling the safety through the warmth of fire, the fireplace becomes a focal point of inhabitation, central to the containment of life.

As an architectural element fire is frowned upon or legislated out due to sustainability and even electricity (which Bachelard considers a modern form of fire) is hidden inside walls. Bachelard compares electricity to "little balls of fire," Electricity is also the common cause of house fires. Its dangerous property meant that it cannot be openly celebrated nor used as a ritual vessel, (figure 15a). One of the only ways electricity is 'present' is through light - which means it is not commonly present during the day. The worth of electricity and fire is measured through its pragmatic values. It is seen as a machine element of architecture, not a visual element due to its invisibility to the naked eye. It is only visible when it is in a dangerous state and therefore for protection, electrical components are hidden. Due to Modernist influences, the poetic elements which fire provide is seen as an unnecessary indulgence that doesn't solve our global problems.

\footnotetext{
${ }^{43}$ Bachelard, Gaston, 1964, pp. 38

${ }^{44}$ For examples of these myths see: Frazer, Sir James G., Myths of the Origin of Fire, London, Macmillan, 1930

${ }^{45}$ Fernàndez-Galiano, Luis, pp. 15

${ }^{46}$ Fernàndez-Galiano, Luis, pp. 16

${ }^{47}$ Santamouris, Matheos, Environmental design of Urban Buildings: an Integrated Approach, USA: Earthscan, 2006, pp. 28

${ }^{48}$ Bachelard, Gaston, 1964, pp. 68
}

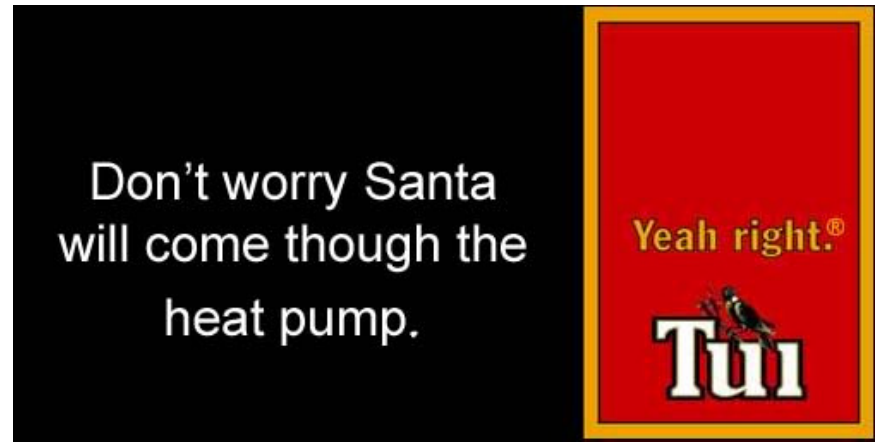

Figure 15:

A Tub Beer ad campaign over Christmas 2009 reflects the decreasing popularity of fire within the home.

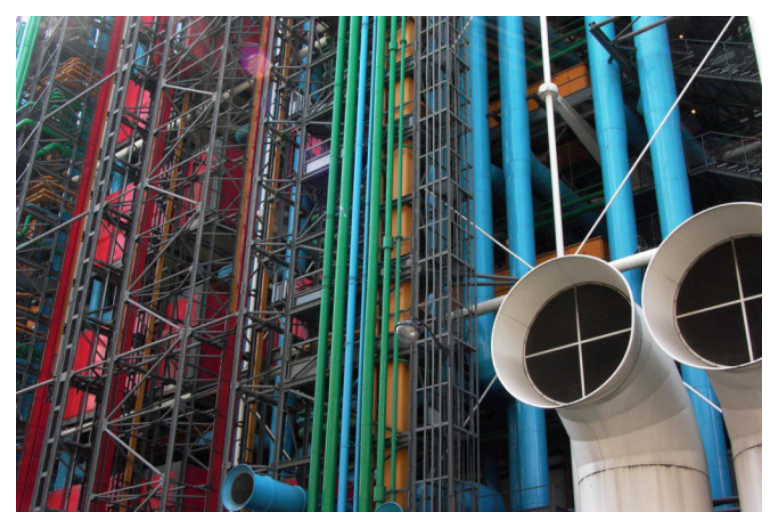

Figure 15a:

Even the Pompidou Centre by Renzo Piano, a building celebrated for showing the 'organs' of its architecture barely addresses the presence of electricity. 
I agree with Bachelard when he writes "man is a creation of desire not a creation of need." 49 Fulfilling needs is far from creating a pleasant experience. Similarly Dissanayake writes that it is not the purpose but rather the feeling we receive from architecture that is important. Fire in architecture should be celebrated, literally or symbolically. It enables us to reunite with our primitive nature, and reminds us of certain primitive needs such as the warmth of community. Architecture is most easily communicated visually, therefore its celebration must be visible to people and the poetics of architecture has equal focus with the pragmatics.

Another reason for fire's visual exclusion is the influence of today's media. What 'mental fulfilment' we receive today is from television and other electronics. This battle is strongest within the domestic home. The home has become a battle field of the family, sexuality, and ecology. ${ }^{50}$ Beatriz Colomina writes that "rituals that were once shared conspicuously in a group are now shared... in isolation." This means that due to the non-existence of fire, a type of gathering point where people socialize no longer exists. The community is under threat due to our ever increasing focus on technology. ${ }^{52}$ Face to face communication between families and friends are becoming rarer. We meet and communicate through these technologies such as cell phones and internet. The less personalized method of communication results in a decrease in our connection with our primitive needs such as safety in numbers. In other words, the priority has changed towards using these "counterdomesticity weapon[s]." ${ }^{53}$ These machines are described as counterdomesticity weapons due to the way they endanger the sanctity of the home. For example, the fireplace, which is the sacred element of the house, is now replaced by heat pumps, a machine that represents no reverie.

Reverie is one of the essential elements in architecture. It is makes architecture special by linking us to our deepest thoughts and memories. The experiencing of architecture relies on its ability to touch our reverie. Fire's ability to connect us to past experiences and primitive thoughts and needs make it

\footnotetext{
${ }^{49}$ Bachelard, Gaston, 1964, pp. 16

${ }^{50}$ Colomina, Beatriz, 'Domesticity At War', Assemblage vol. 16, 1991, pp. 15

${ }^{51}$ Colomina, Beatriz, pp. 22

${ }^{52}$ Spigel, Lynn, Make Room for TV: television and the family ideal in post-war America, Chicago: University of Chicago Press, 1992, pp. 38

${ }^{53}$ Colomina, Beatriz, pp. 20
}

Figure 15b:

Underground House by Jay Swayze designed as an option in case of a nuclear attack during the Cold War in the 60s. The design reflects the age of paranoia catalyzed by the media. "A few feet underground can give man an island unto himself; a place where he controls his own world - a world of total eases and comfort, of security, safety and above all, privacy." (Colomina, Beatriz, pp. 20) 
an important element in architecture. A house is not a home unless a sense of togetherness and safety exists. With the presence of the multimedia such as internet, our homes are open to the public and it is no longer a type of private sanctuary. We are constantly updated on news of violence, wars and other disasters. Having negative news bombarding us every day, no wonder our society has become somewhat paranoid. An example of this is America during the Cold War. Architects began finding ways to satisfy the demand for protection from nuclear attacks such as through Jay Swayze's underground house (figure 15b). While the chance of nuclear attack is unlikely, the constant reporting by the media caused citizens to believe the chance of a nuclear attack is as certain as the sun rising in the morning.

If fire as an architectural element connects us to our reverie in a positive way and provides for our primordial needs, it is essential we continue its presence. If fire makes a building more humane in its experience, we must be careful not to let it be defeated by the sometime insensitive media.

Fire, being such a long standing architectural element, means it has close relationship to our primitivity and architecture is inseparable from primitive ideals. ${ }^{54}$ Bachelard believes that through fire we are able to be in touch with our primitive needs, and subconsciously we have a need to relive primitivity. The Novalis Complex shows how important it is for architecture to address the issue of the primitive. With all the advance technology our society has, it is all the more important for architecture to continue the link to our primal needs. Our constant obsession with technology has meant that the environment is being damaged. Now in order to remedy our mistakes, fire is disappearing from architecture due to current 'green trends' and legislation. Fireplaces in the homes are replaced by other architectural machines that fulfil its heating properties more efficiently. ${ }^{55}$ Media entertainment such as television and the internet has become the social focus of our world. Though 'social', the television does not provide us with the primitive facets of our psyche. As a result a catalyst for primitive social interaction is missing because we have yet found a replacement for our primitive fire.

\footnotetext{
${ }^{54}$ Fernàndez-Galiano, Luis, pp. 17

${ }^{55}$ Spigel, Lynn, pp. 198
} 


\section{Chapter 5: Fire as Living Being}

"[Fire] is capricious; therefore it is a person." ${ }^{56}$

Although fire is not considered to be a living being scientifically, we still compare it to living things. There are many similarities between fire and living beings in regards of its survival. Fire requires fuel and grows. Scientifically, living things are defined by their ability for "growth, respiration, reproduction and metabolism. ${ }^{\prime 57}$ Bachelard agrees in saying "fire feeds itself like a living creature." In order to exist, both fire as well as living things requires fuel, respiration in the form of oxygen and the continuity of these fuels are essential for its survival. Where fire's fuel comes in many forms, living organisms rely on carbon based food sources. Another difference between fire and living beings lie within their ability to reproduce. Should there be sufficient oxygen, fuel and heat; fire can be recreated instantaneously - instant combustion. On the other hand, life cannot be created instantaneously. The life of fire is limited. Even though it is "fed, it grows old and dies like plants and animals. ${ }^{159}$ Fire therefore can be said to be mortal through these similarities.

Architecture too ages and requires 'fuel' similar to a living being. For architecture to exist, materials and energy are required. Therefore building materials can be considered as architecture's fuel. At the same time, fire in the form of electricity or coal can be a type of fuel to architecture. It is then apparent as to why fire is viewed as the being one of the elements which inject life to architecture, thus allowing it to 'live' and allowing life to live within it. Bachelard sees architecture as having "an entity and a dynamism of its own; it is referable to a direct ontology." ${ }^{160}$ Ontology is the study of life

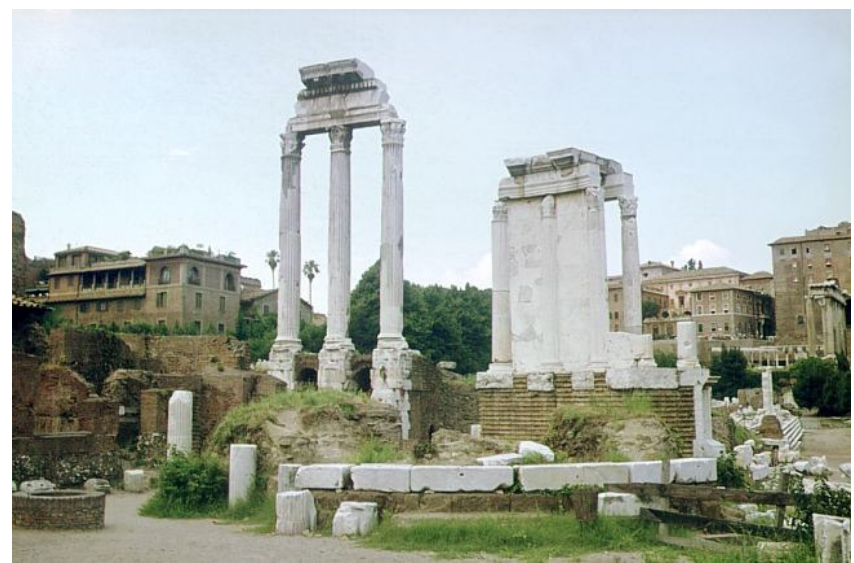

\section{Figure 16:}

The Vestal/Hestia Temple, which houses the civic hearth, in Rome is located within the centre of the city. Its central presence is highlighted by the high classical columns marking it as a 'heart' of the city.

\footnotetext{
${ }^{56}$ Bachelard, Gaston, 1964, pp. 64

${ }^{57}$ University of Hawaii, http://www.soest.hawaii.edu/GG/ASK/, visited 20 April 2011

58 Bachelard, Gaston, 1964, pp. 64

${ }^{59}$ Bachelard, Gaston, 1964, pp. 44

${ }^{60}$ Bachelard, Gaston, Poetics of Space, Boston: Beacon Press, 1958, pp. xvi
} 
forms in terms of its complexity. A building is just as complex as a body. We are able to see how architecture can be compared to a person due to its nature and complexity. ${ }^{61}$ Within both, there are numerous facets and levels that if arranged differently will result in a different experience. Centre to all of this is fire - the heart of architecture.

In the Greek and Roman era, Hestia or Vesta's civic fire is the heart of Greek and Roman cities (figure16). This fire becomes part of the city's architecture - one that is as ephemeral as life. Should the fire dies it is "dematerialized; it loses its reality; it becomes pure spirit." ${ }^{162}$ Though able to be maintained for long periods of time, sooner or later it will go out. Then another shall replace it. The replacement fire is not a form of reproduction but can be compared to it as it carries a 'lifeline' for the element. In other words, old or new fire carries the same effects and characteristics thus it continues to ignite the same primal reveries. If we exclude it out of architecture, a kind of disjunction will occur within architecture. Architectural machines may fulfil our ideals of efficiency and technology but it will not create a 'complete' architecture. For example the image of a family gathering around a television is not at all comparable to a family around the fire. Although both images bring together people, the image with fire is more fulfilling psychologically and emotionally. Television simply does not facilitate the same social interaction as fire.

Fire is often compared to living beings in literature and song. Many poems and song lyrics often speak of fire as if it is a living organism. At the same time, human emotions and characteristics are often described with characteristics of fire such as burning and flickering. Jimi Hendrix's Fire was recorded and released in 1967. The song is essentially a love song describing an attraction between a man and a woman. Fire is used as a metaphor to describe the urge and intensity of need to be next to each other. "I have only one burning desire/Let me stand next to you fire." ${ }^{63}$

Analogies of fire are also used in everyday speech. We often associate a living person as having fire inside them. For example George Bernard Shaw, a Nobel Prize winner and playwright, said "Life is a

\footnotetext{
${ }^{61}$ Nesbitt, Kate, Theorizing a New Agenda for Architecture: an anthology of architectural theory, Massachusetts: Princeton Architectural Press, 1996, pp. 63

62 Bachelard, Gaston, 1964, pp. 104

${ }^{63}$ http://www.metrolyrics.com/fire-lyrics-jimi-hendrix.html, visited 24 May 2011
} 
flame that always burns itself out." ${ }^{\prime 64}$ Here he compares the finite life of a human being to fire. Just as life ends when the body stops working, fire will die as soon as the fuel it runs on is finished. Fire became a symbol of life due to its similarities to a living being. Even though fire itself is not alive, there are characteristics that make it seem like it is. When a person loses the will to live, we often say that the fire in their eyes is gone. In observing everyday speech and literature, we see that living beings are seen as to have an 'inner fire.' This symbolic fire is what fuels life, it continues to burn as long as life exists within us. This inner fire is comparable to passion. Passion is equivalent to the will to live, and therefore when a passion for life is gone, our inner fire is said to be extinguished. This relationship between fire and living things is the reason why we often compare one to the other.

Fire's comparison to a living being is due to its complexity and capriciousness. Fire functions similarly to the complex body due to its need for fuel and its ability to grow and die. It is capricious as one can never fully control it. Even though it provides us with so many positive additions to life, it can unexpectedly change and destroy our lives instead. The unpredictability of fire is the reason for our lack of trust in the safety of the element. This is most shown through the many protective measures we have against fire within architecture. We create gates to ensure distance and fire proofing to prevent the loss of life. Just like a living being fire's personality is as complex as its living mechanisms and vice versa. It is a mortal 'being' that can unexpectedly be good as well as bad. The similarities between fire and living beings are the reason why fire is considered 'alive' by some.

\footnotetext{
${ }^{64}$ http://thinkexist.com/search/searchquotation.asp?search=flame\&page=4, visited 24 April 2011
} 


\section{Chapter 6: Case Studies}

\section{Case Study 1: Vanna Venturi House by Robert Venturi}

The Vanna Venturi House is an example of where the poetics of the fireplace have been incorporated into modern architecture. The house was Venturi's first design. Completed in 1964, this house broke the rules of Modernism and is believed to be the beginning of Post-Modernism. ${ }^{65}$ The house combines modernist characteristics with that of classicism, making it simple and yet complex. This play with duality later became the basis of Venturi's writing Complexity and Contradictions in Architecture ${ }^{66}$. The house's inclusion of the fireplace is one way it connects with fire. The fireplace is the sacred 'altar' in which fire resides within the home, and it symbolizes the heart of the home. The chimney is the external clue that fire exists within the home. At a deeper level, the house engages with the idea of fire through its duality. Fire is both caring and destructive; it is the symbol of life and the symbol of death. Fire as an architectural element is filled with complexity and contradiction. Through analysis of this house, we will find that architecture's dual personality is comparable to that of fire.

When talking about the house, Venturi openly admitted he was playing with the interrelationship of the architectural elements. Following the Modernist trend of the time, his mother wanted an unpretentious house. ${ }^{67}$ Venturi experimented with "blandness of architecture known as Modernism" ${ }^{18}$ by distorting its orders within the inside. From the outside, the house adopts the clean lines of Modernism. Its gable roof and chimney is reminiscent of a child's drawing of a house. ${ }^{69}$ However, through this simplicity

\footnotetext{
${ }^{65}$ Schwartz, Frederic (Ed.), Mother's House: The Evolution of Vanna Venturi's House in Chestnut Hill, 1992: New York, Rizzoli International Publications Inc., pp. 16

${ }^{66}$ Schwartz, Frederic (Ed.), pp. 12

${ }^{67}$ Schwartz, Frederic (Ed.), pp. 24

${ }^{68}$ Kahl, Douglas, 'Robert Venturi and His Contributions to Postmodern Architecture', Oshkosh Scholar vol. 3, 2008, pp. 56

${ }^{69}$ Schwartz, Frederic (Ed.), pp. 37
}

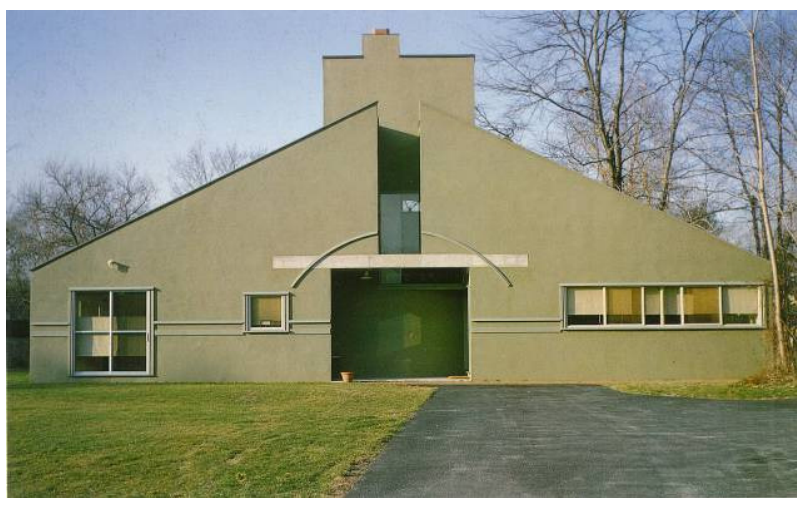

Figure 17:

Vanna Venturi House (1960) 
Venturi aimed to connect with our childhood reverie. Modernism as a movement did not often utilize symbolism, and Venturi broke the 'modern-ness' of this house by introducing symbolism that speaks to our memory. This connection to reverie fulfils the poetic need within architecture as it reminds us of our primitive needs. In remembering childhood memories, we are reminded of maternal love. Fernàndez-Galiano writes that fire is important to architecture as it connects to our memory of being in our mother's womb, cared for and protected. The memories from our childhood are often filled with our mothers' love and care. Here, through the inclusion of childhood iconography, Venturi addresses the importance of symbolism in architecture and connects with our reverie. ${ }^{70}$

Central to the elevation is the chimney. The chimney's location in the centre makes it a clear beacon for the centre of the home. It marks the point of gathering, the living room, to those outside. In interacting with the chimney, we no longer experience it simply as an object but a circulatory surface. The central core is a battlefield between the stairs and the flue - the pragmatic versus the poetic. However to address the idea of duality, the two elements inflects with each other. On one side the chimney 'moves' over for the stairs and on another the stairs move for the chimney. Therefore one element is both dominant as well as minor just as fire as an architectural element is dominant and yet minor. Furthermore, its location in the middle means the outside walls of the house acts as a physical threshold that separates the inside from the outside. Primitively, fire creates a kind of invisible threshold by marking an area with its warmth and light. By incorporating clean walls, Venturi has again connected with the poetics of fire and its threshold with Modernist ideals. In compromising the pragmatic with the poetics, Venturi was able to connect to our reverie as well as fulfil functions. Venturi who said "less is a bore" proved that in order to create a truly fulfilling architecture simply focusing on the essential is not enough. In order for a building to be considered architecture, it must harmonize both function and poetics so that it provides a variety of experiences.

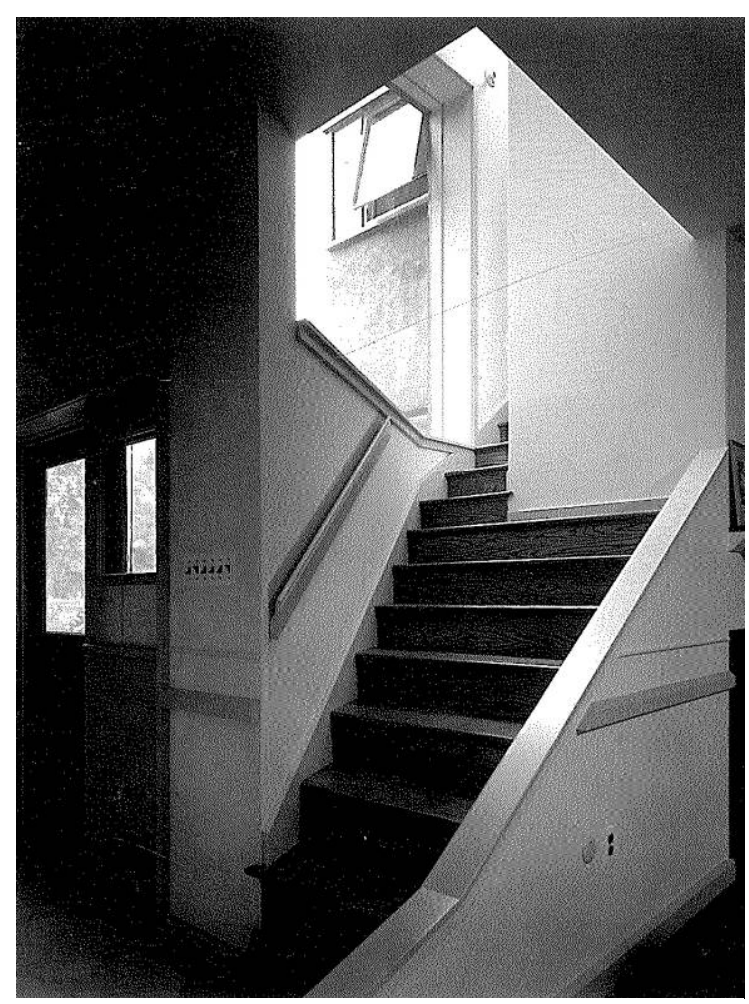

Figure 18:

The tension between the pragmatic and poetic is reflected in the way the stairs (pragmatic) is competing for space with the chimney (poetic).

\footnotetext{
${ }^{70}$ Kahl, Douglas, pp. 59
} 

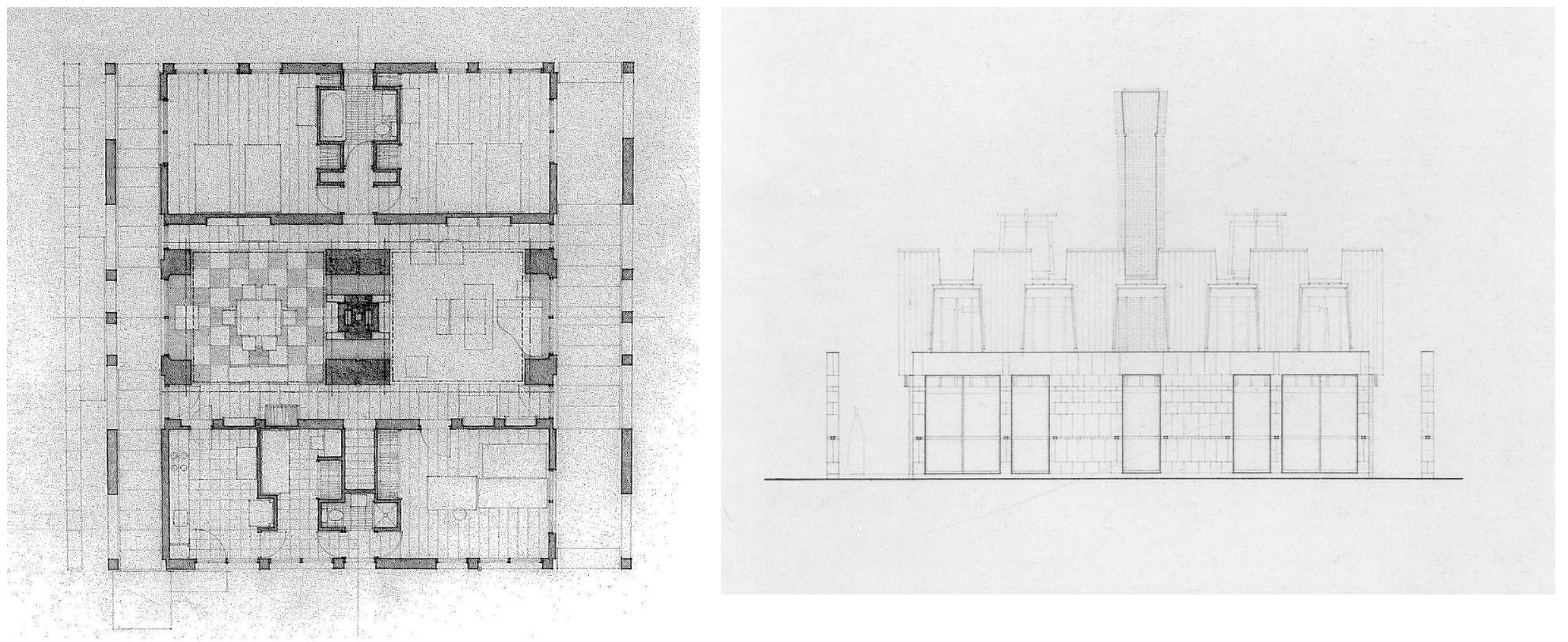

\section{Design Version I/2- July 1959}

This is one of the first versions of design Venturi drew for his mother's house in 1959. From this first version, the fireplace and chimney is given prominence within the composition of the building. 
Joey Goei - Playing with Fire: Analysing the role of Fire in Architecture
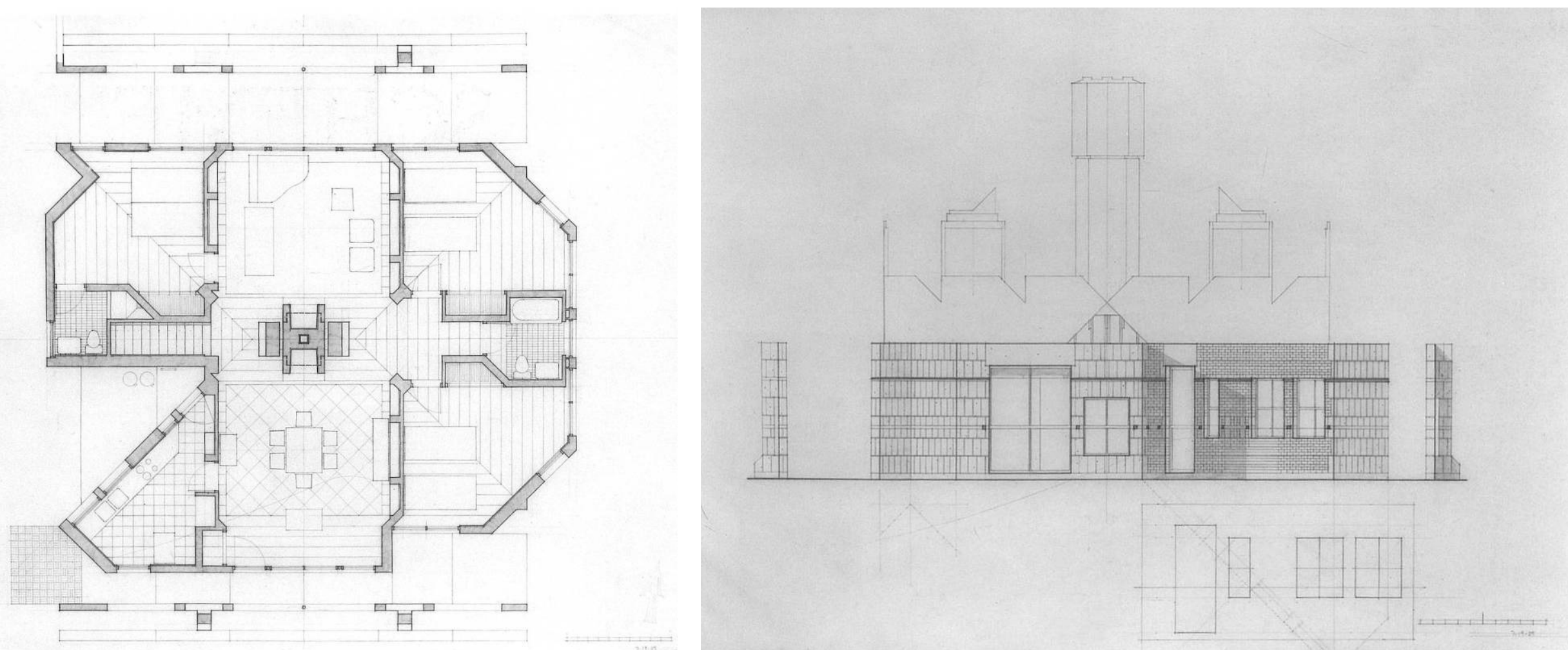

\section{Design Version IIA- 19 July 1959}

The fireplace here is still situated at the centre of the plan, and also elevation. 

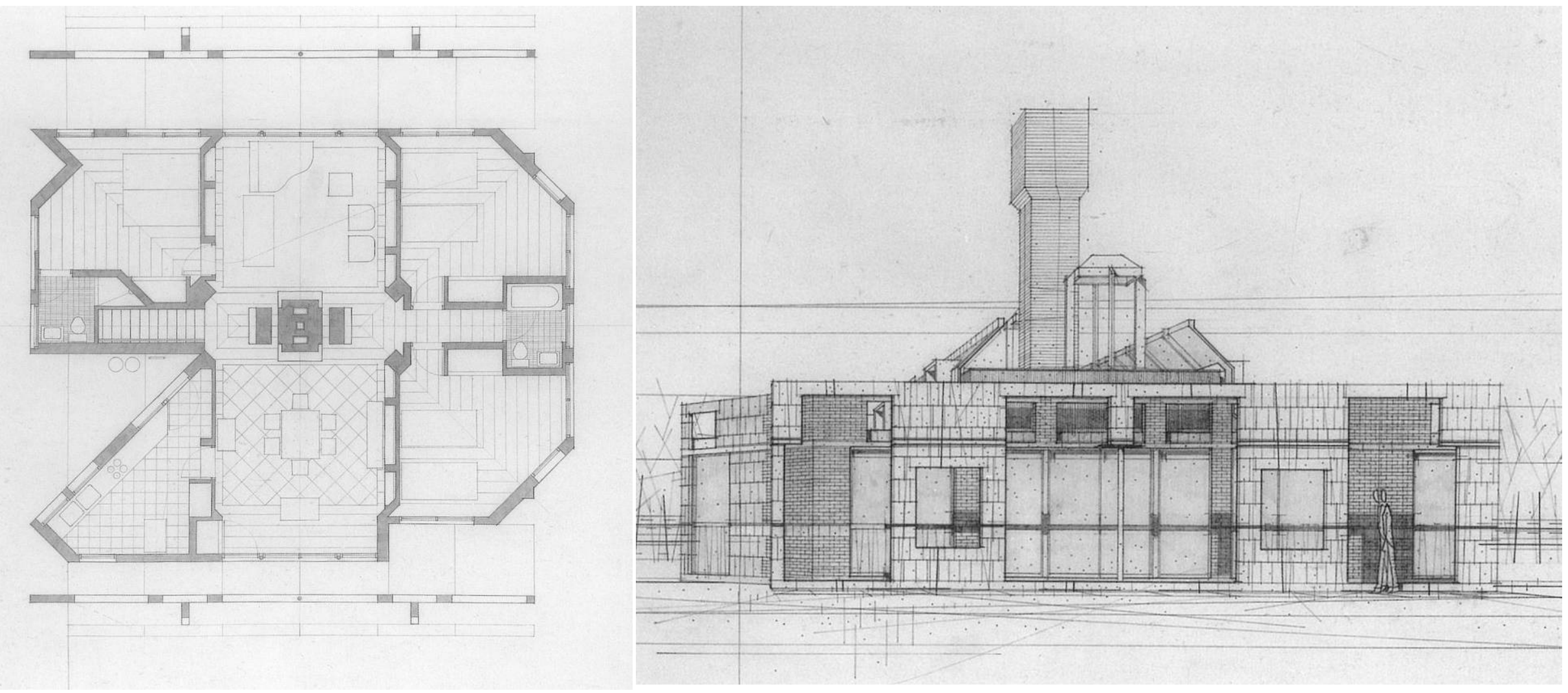

\section{Design Version IIB - 31 August 1959}

In this version, the chimney is given a stronger presence. This is due to the way the flat roof highlights the verticality of the chimney. 

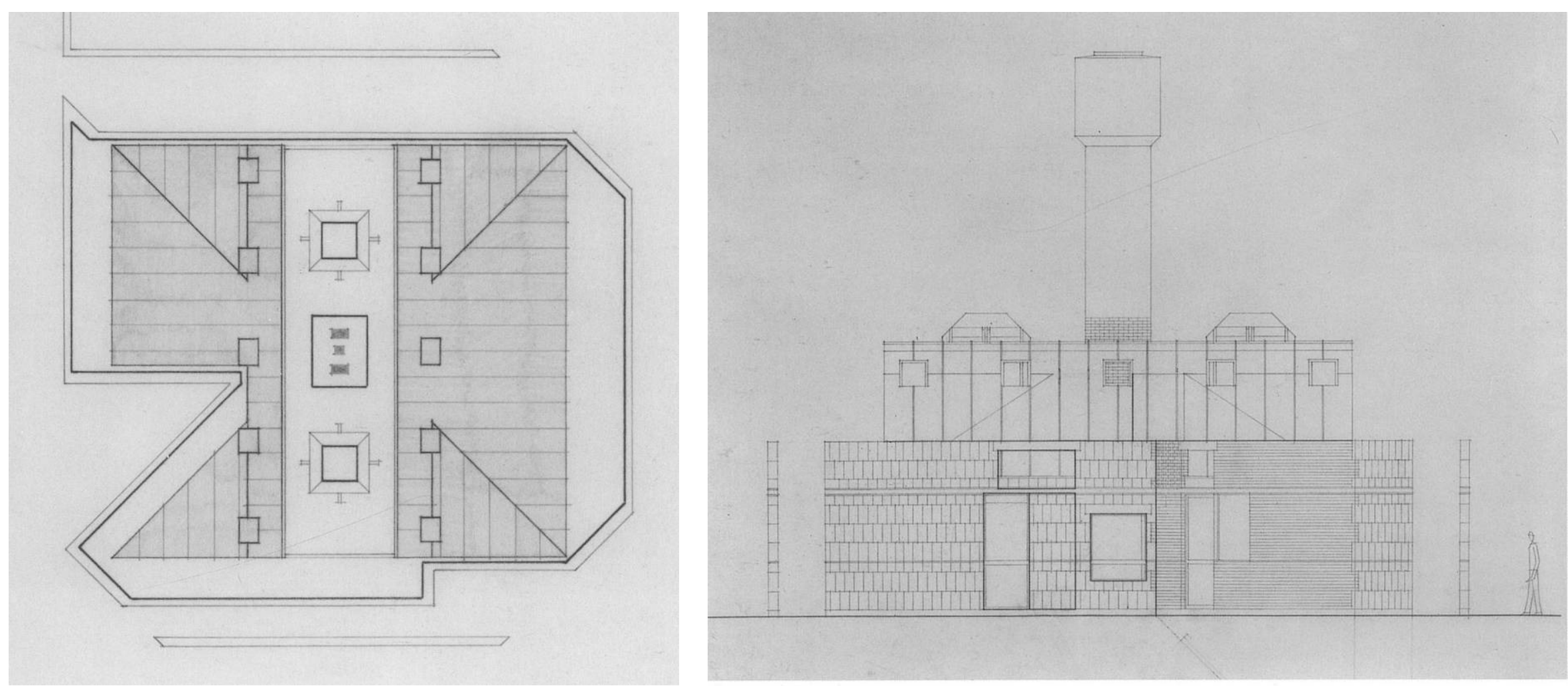

Design Version IIC - 1959

Here the chimney is highlighted through the gradual tapering of each level thus making the chimney a kind of climactic point. 

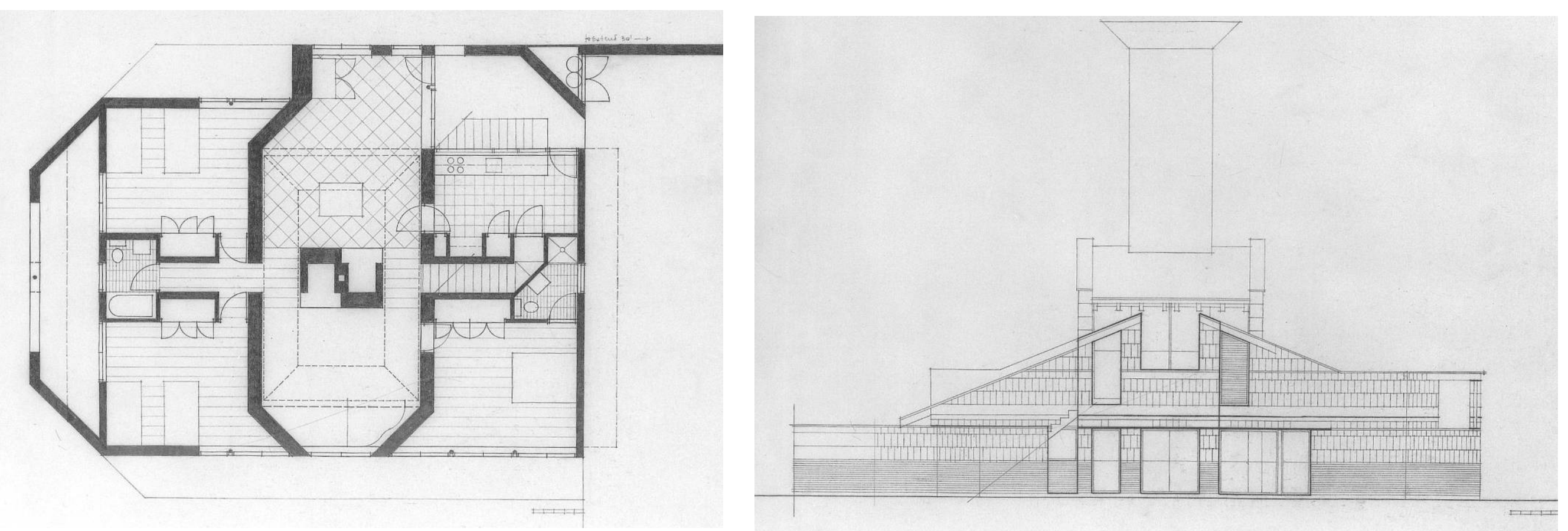

\section{Design Version IIIA}

In this version, the tapering of the composition is adopted again. However, the chimney is enlarged significantly, thus appearing somewhat out of scale with the rest of the building. 

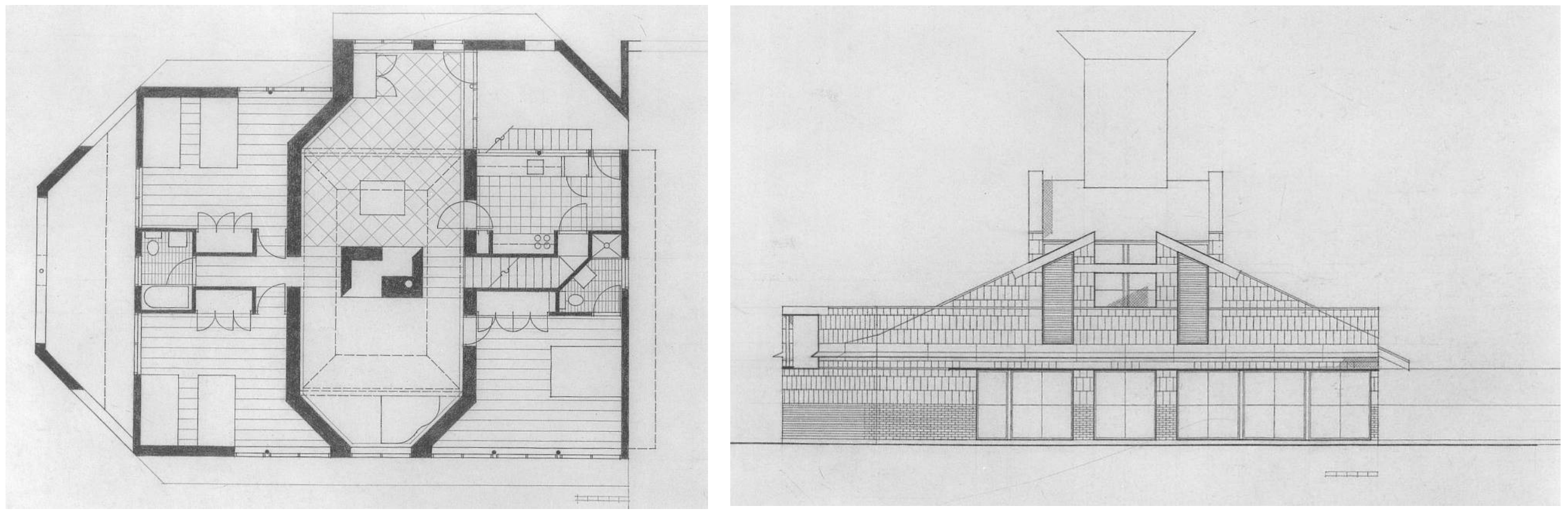

\section{Design Version IIIB}

Where the chimney seemed oversize in the previous design, Venturi made this chimney shorter to balance the volume of the chimney and the house. 
Joey Goei - Playing with Fire: Analysing the role of Fire in Architecture
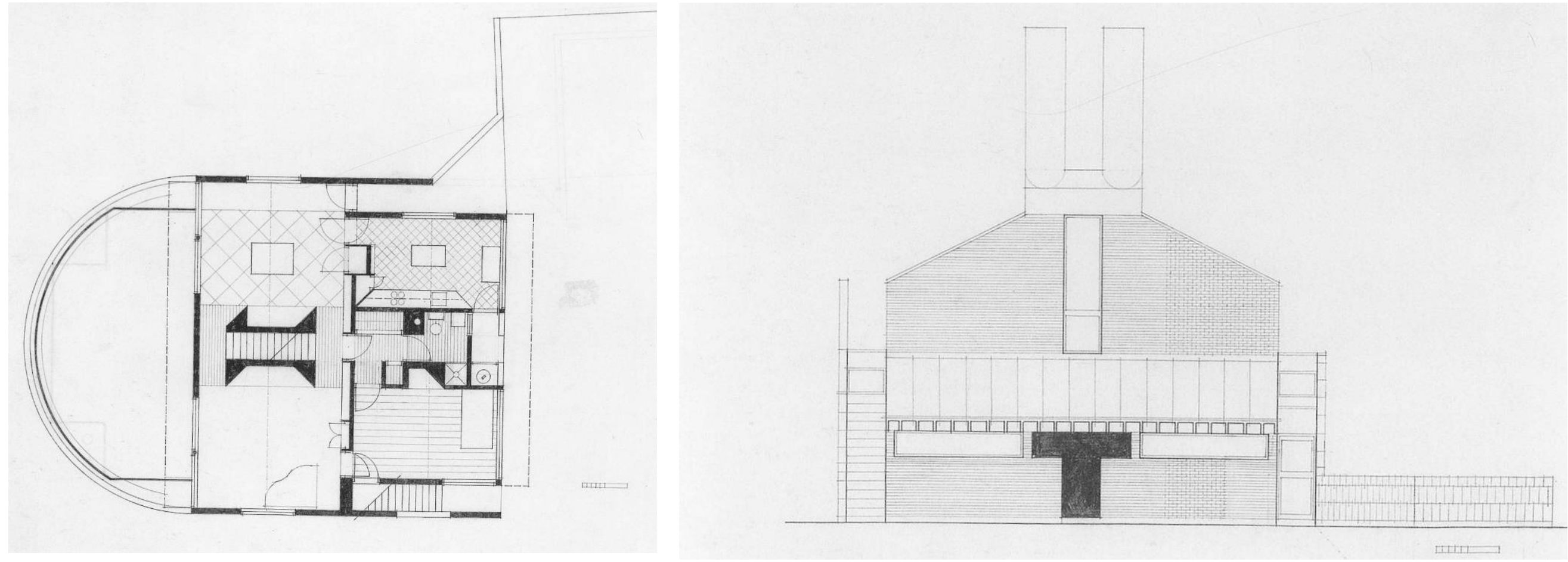

\section{Design Version IVA - 12 July 1961}

Here Venturi utilizes a larger fireplace and as a result reflects this on the elevation by having two chimneys instead of one. 

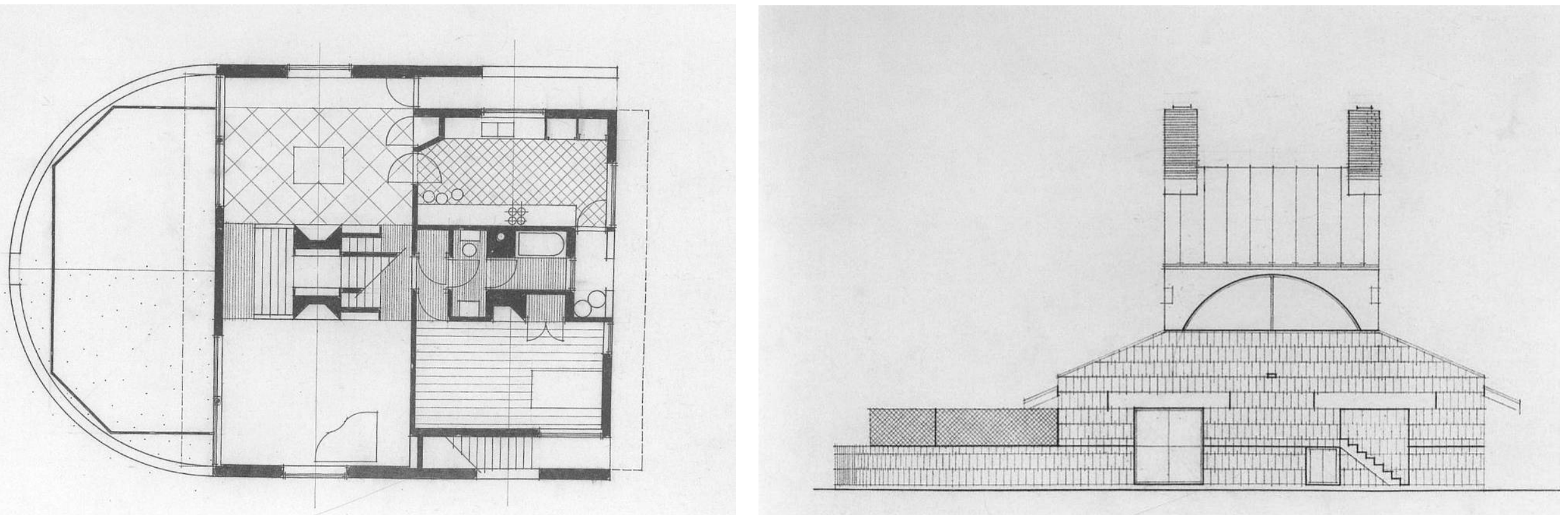

\section{Design Version IVB}

Here the previous version is developed so that the chimney becomes part of the roof composition. However in doing so, the chimney loses its prominent status. 

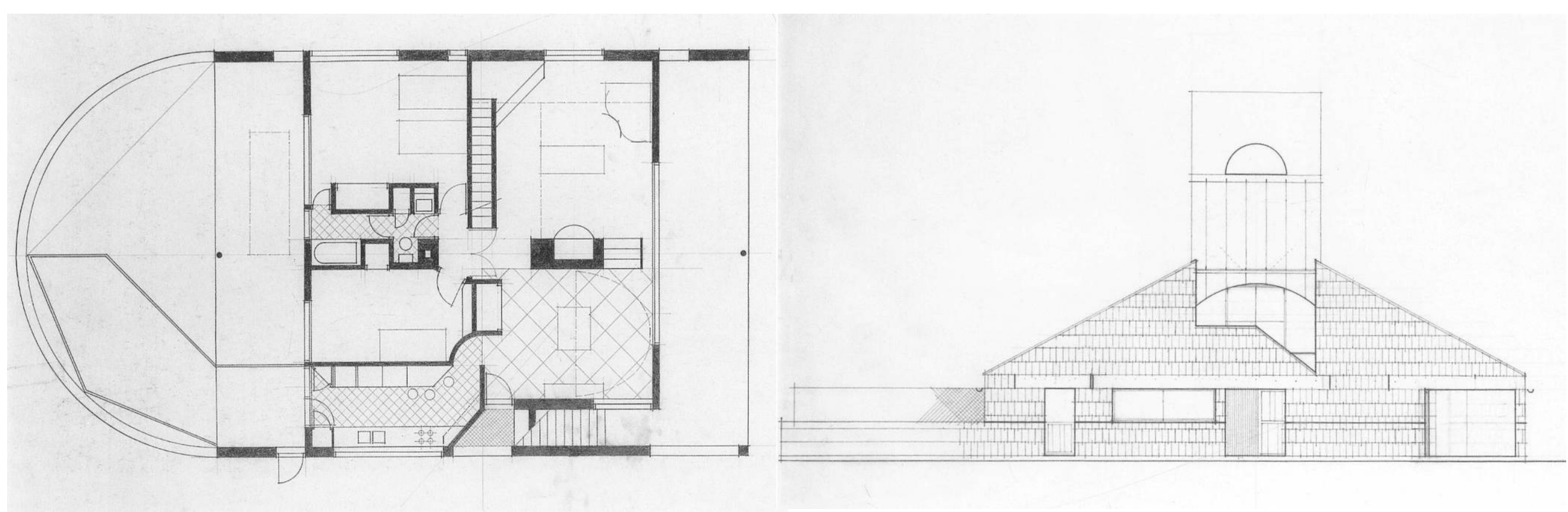

\section{Design Version V- 12 June 1962}

This version goes back to the tapering idea Venturi had before. However, he has changed the location of the fireplace in plan. It is now located on the right side of the house. This is his way of representing the shift in focus within the home but also showing how the fireplace can still be the centre of the home. 

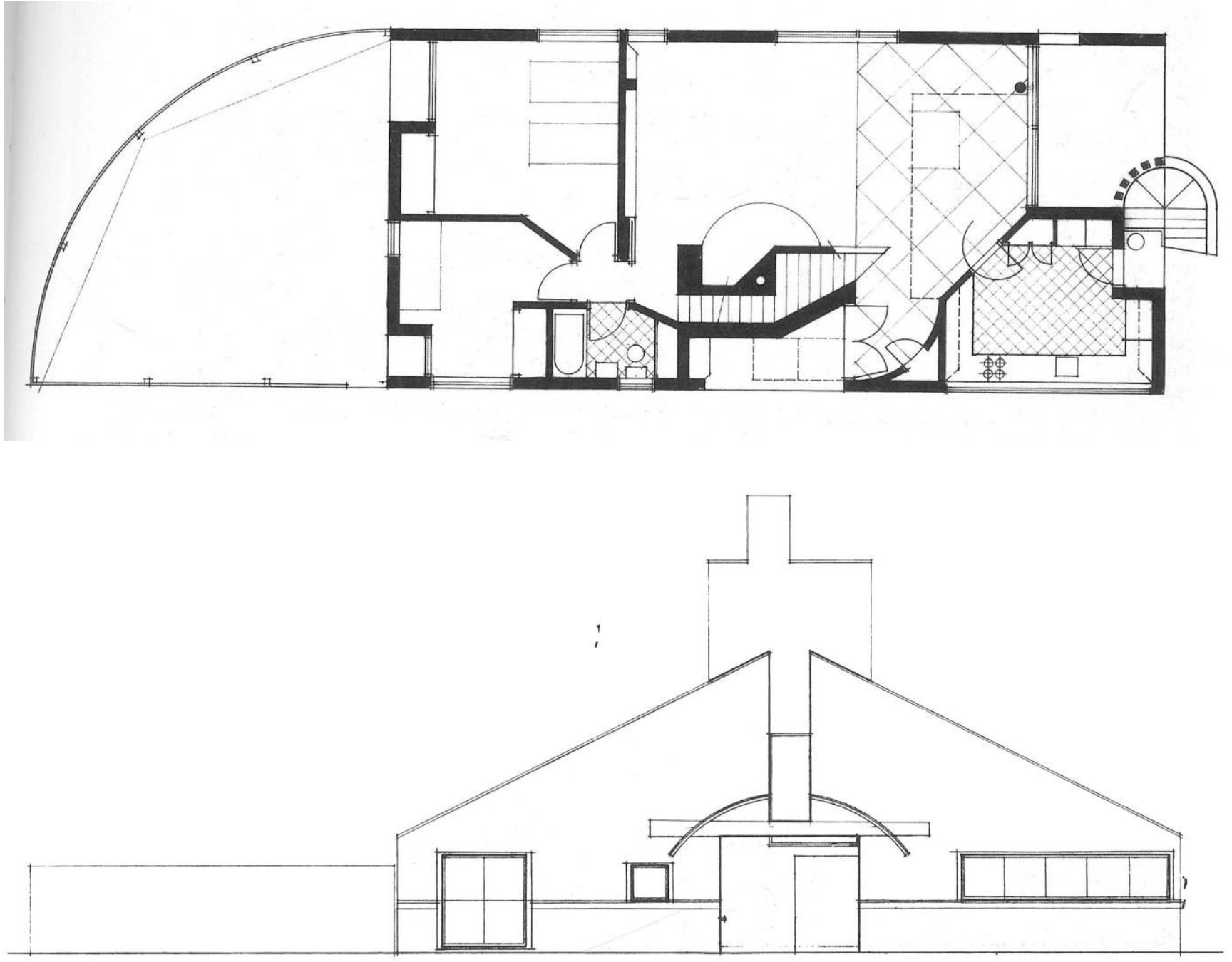

Final Design - 8 December 1962 
Venturi experimented with various designs before constructing the final one. Although the shapes and forms of the house vary, the centrality of the chimney and fireplace remains the same. Being central to the plan is a symbol of community. Fire as an architectural element gathers people and creates a sense of safety. As fire is central to this idea, in placing it in the centre of the house, Venturi expressed that the fireplace, the symbol of community, is principal within the home.

The Vanna Venturi house is an opposition of Modernism and the beginning of Post-Modernism. Although it incorporates certain elements of Modern architecture such as simple lines, it aims for complexity. Through this house, Venturi showed that less is truly a bore. Venturi felt architecture should be full of complexity and contradictions. Using fire is one way of adding complexity and contradiction because of its dialectical nature. Fire as an element is complex and contradictory in meaning. It is both the symbol of life and death; it is caring as well as destructive. However at the same time, Venturi's inclusion of the fireplace represents fire's connection with our primal needs. It illustrates fire's ability to gather people, thus fulfilling our primitive need for safety in numbers. Being literally centre to the house, the chimney/fireplace is symbolic of the idea of community in many levels. Community is central to the idea of home, and the chimney's apparent presence in elevation shows that within the walls, is a space of warmth and safety.

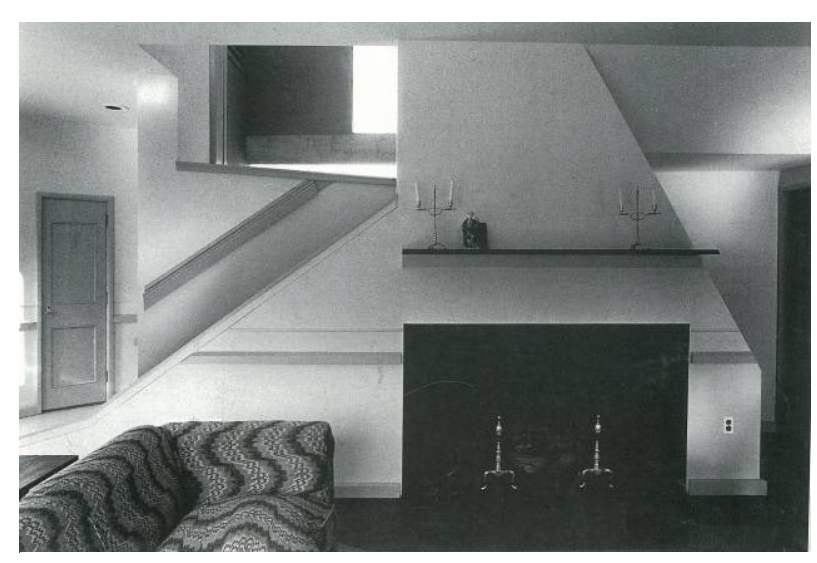

Figure 19:

View of the fireplace located at the centre of the home. The staircase intrudes into the chimney space, and vice versa 


\section{Case Study 2: Element House by MOS}

The stereotypical image of a house ${ }^{71}$ is also utilized in the Element House by MOS. Created for an exhibition in April 2010, the architecture of Element House focuses on the idea of growth and community. ${ }^{72}$ Fire as an architectural element brings people together and allows a sense of community to grow. Here MOS employs these ideas of fire while they also look to renew the use of the hearth and chimney within the home appropriate to today's eco-focused society. Though fire is not present literally in the design, MOS addresses the fire symbolically through its association with the chimney. The architecture of the house employs many modern techniques and ideals while still continuing the poetics essential for a meaningful architecture.

MOS recognizes that due to technological advancements and sustainability, fire as an architectural element is losing its place in society. ${ }^{73}$ At the same time they realize the importance of fire within architecture. Therefore the house acts as an experiment on how the ideas of fire as an architectural element can be continued within today's architecture. ${ }^{74}$ Similar to Venturi's approach they began by manipulating the simple icon of a house. Within the image, the chimney is the only indication of the hearth inside. Rather than focusing on the reverie of the image, the design focuses in using the 'chimney' as a form of lighting and natural ventilation. This way the vertical space that is normally occupied by fire still exists and marks the focal point of space. ${ }^{75}$ The atmospheric inlet satisfies modern expectations of sustainability and efficiency without sacrificing the memory of the fire. MOS feels that by keeping the footprint of fire, its absence will provide more presence. ${ }^{76}$ This means when people

${ }^{71}$ The stereotype referred to is the image of a rectangular house with a gable roof and chimney.

${ }^{72}$ Smith, Lisa, 'Element House by MOS', Core 77 ,

http://www.core77.com/blog/object culture/element house by mos, visited 22 April 2010

${ }^{73}$ Smith, Lisa

${ }^{74}$ Meinhold, Bridget, 'Element Prefab Housing by MOS Utilizes Fibonacci Growth Patterns', Inhabitat,

http://inhabitat.com/element-prefab-housing-by-mos-utilizes-fibonacci-growth-patterns/mos-element-house-15/, visited 22 April 2010

${ }^{75}$ Meinhold, Lisa

${ }^{76}$ Smith, Lisa

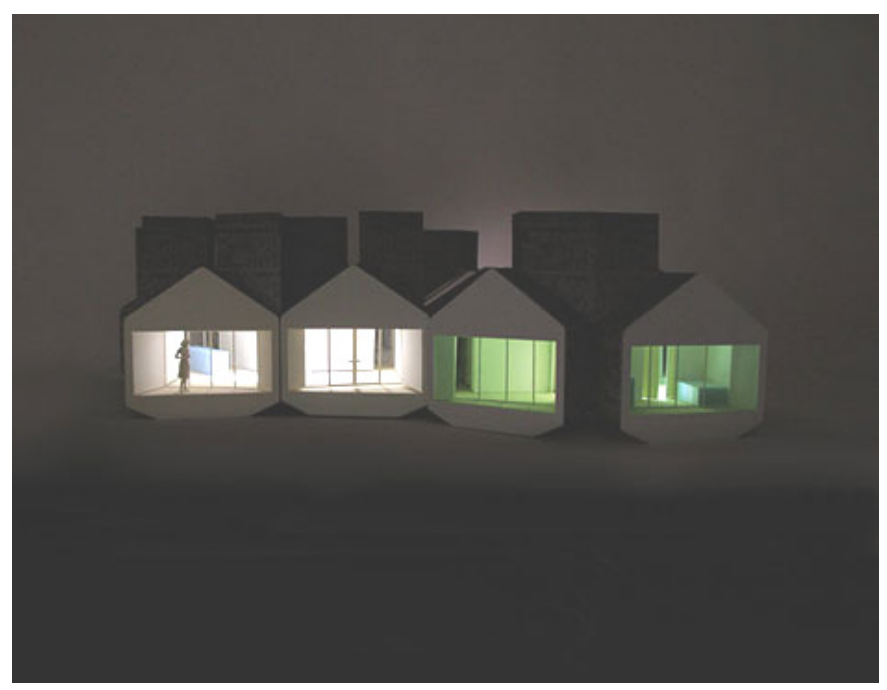

Figure20:

From the front, you can see how the typical image of a house is used as the base imagery of the modules 
gather around the light well, they will be reminded of similar experiences around the fire. The sense of togetherness, warmth and community exists even without physically having a fire. The light acts as a symbolic fire that replaces the physical fire.

The Element House provides opportunities for growth. Important to today's architecture is efficiency in construction. To achieve this, architects often opt for prefabricated elements. MOS' design is based upon one single module that is the image of the house. This module can be multiplied, joined and separated as the occupants need to. Through the idea of growth, the house addresses another characteristic of fire - its association with the living being. As discussed, fire is often compared to a living being due to its mortality and its growth pattern. The Element House represented this living pattern through the use of Fibonacci sequence in the growth of the modules. The Fibonacci sequence is the development pattern of living organism. By arranging the modules to the sequence, MOS is able to move away from the mechanic grid. This way although the modules are prefab and therefore mechanic, its arrangement provides the sense of the organic. Therefore just as fire, though not a living organism, is comparable to living organism, the architecture is considered organic although its elements are mechanic.

The use of modules also continues the idea of community. One of the most important functions of fire is to gather people. Fire has an ability to create a sense of safety in numbers and acceptance into a community. Fire's ability comes from connecting us with our primal reverie of fire creating a protective threshold that marks the safe inside from the unknown outside. The Element house addresses the idea of community through its module by allowing it to multiply. Although this means there will be several cores, a cluster of modules can still be seen as a community. Perhaps this is a representation of the decentralisation of community in today's society. On top of having one central core, several cores are present. In other words although our society is now decentralized due to our communications technology, it is important for architecture to become a central core for all the minor cores. At a deeper level, fire is one of the main 'central cores' for architecture. Therefore perhaps a civic fire, where a number of communities gather at is an application to be looked at for today. This design by MOS shows at a smaller scale, how fire's focalising characteristics can be used at many levels and methods even without the presence of physical fire.

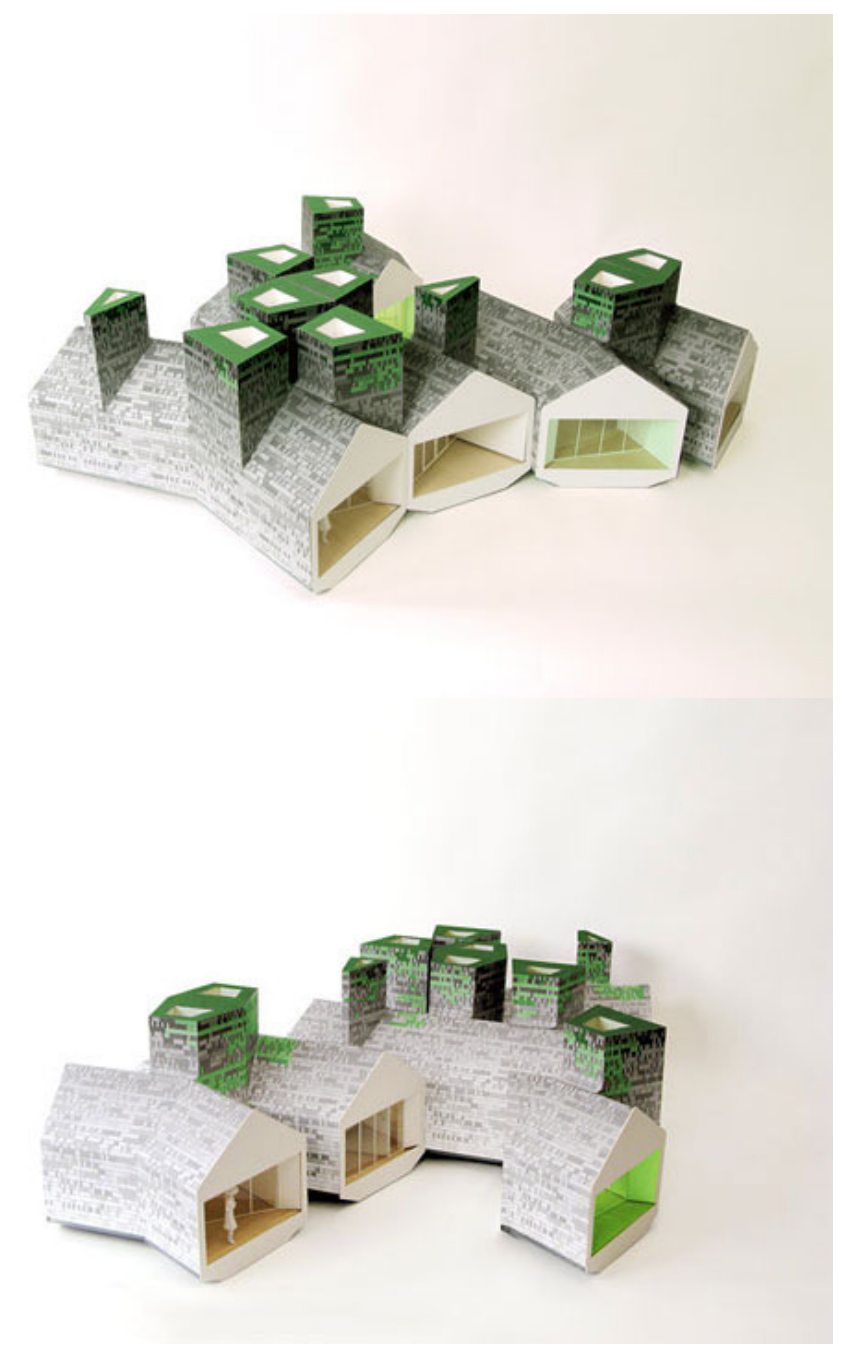

Figure 21:

The modules are able to be arranged and extended in a variety of ways depending on the requirement 
The Element House by MOS utilizes Venturi's approach in a different way. Beginning with the same image of a house, MOS entirely replaced the hearth and chimney. However in replacing the hearth and chimney, the skeleton of the elements remain. The functions of the chimney are changed into that of an eco-friendly atmospheric inlet to satisfy today's desire for efficiency and sustainability. Regardless, the gathering effect of fire exists even when it is absent due to our associations of the chimney with the fireplace. These light wells create a decentralised community of modules, with the central module's chimney being the main gather point. Furthermore, the architecture of the house speaks of the duality of fire. Fire is often seen as a living being, even though it is not. In the design, the house being a module is clearly mechanic and lifeless. However the input of the Fibonacci sequence is an attempt to give the lifeless module organic qualities. The concept taken by MOS in this experimental design is a step towards including fire in architecture today. Though fire is not present physically, elements such as the chimney create a link to fire by association. The design also proposes the adaptation of chimneys from an emitter of pollution to an eco friendly architectural element.
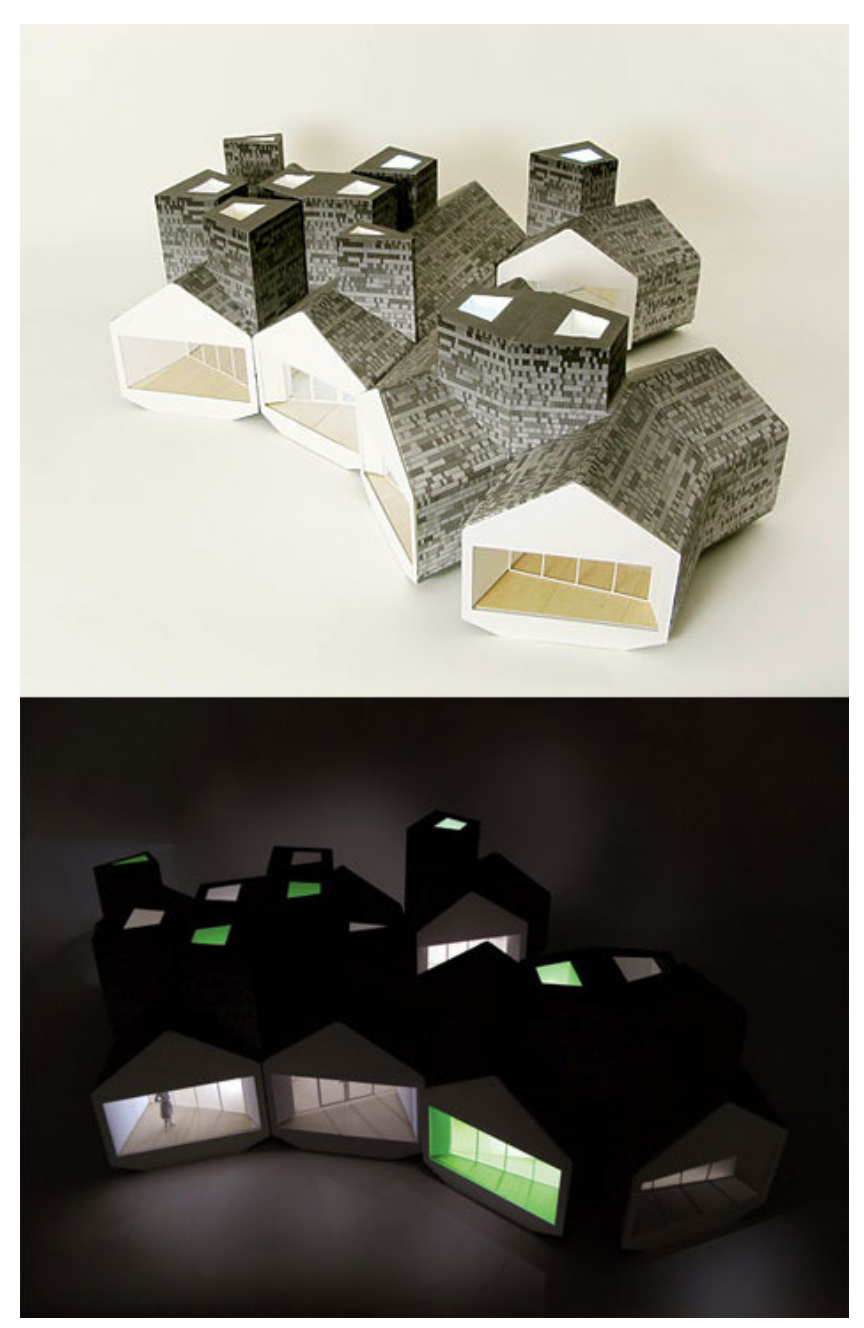

Figure 22:

The images above show how the 'chimneys' are the focal point of the various spaces, even though there are several of them 


\section{Case Study 3: Treptow Crematorium by Schultes Frank Architekten}

Crematoriums are one of many examples where fire as an architectural element is used outside the home. Regardless of the scale, the fire still acts as a focal point which people gather around except this time for the rite of passing. As discussed, fire is the symbol of life and death. Bachelard states that the ritual of cremation the least lonely type of death. This is due to the gathering of people that occurs when a person passes away. The presence of fire in the crematorium makes the building a kind of gathering point for people to celebrate their loved one's life. Historically, fire's association with life and death is due to the idea of reincarnation. Death is not seen as the end but rather a rebirth. The Treptow Crematorium (1999) seeks to create a space of contemplation where people can truly embrace this transition between this world to the next. ${ }^{77}$ Schultes stated that in winning the competition to design a crematorium he was apprehensive. ${ }^{78}$ The western world is new to the process of cremation; Catholicism for example only began to allow cremation in 1966 . Schultes' apprehension is understandable when we see the disjunction between fire and ritual within his design. Although it is a great attempt at bringing fire into today, the complexity of fire was not successfully addressed in its entirety.

From the outside, the solid concrete crematorium stands monumentally on the landscape. Although the appearance of the crematorium is very modern, Schultes stated that he wanted the architecture to speak of our primordial characteristic. This is done through the way the concrete has an appearance of "weathered purity of the past." ${ }^{\text {79 }}$ In other words, Schultes has intentionally left the surfaces unpolished and rough around the edges. In addressing the primordial, the architecture relates to the characteristics of fire, the central element in cremation. Bachelard writes that fire connects us with our primitive side. When we are in contact with it, we are able to enter a reflective state that enables us to engage with our subconscious memory of the primordial. The problem with the Treptow Crematorium is that visitors are not in contact with the fire visually or physically. The architecture focuses on the materiality of the

\footnotetext{
${ }^{77}$ Russell, James S., 'Evoking the Infinite', Architectural Record vol. 188 no. 5, May 2000, pp. 224

${ }_{78}^{78}$ Davey, Peter, 'Ritual of Death', Architectural Review 205/1223, January 1999, pp. 52

${ }^{79}$ Russell, James S., pp. 225
}

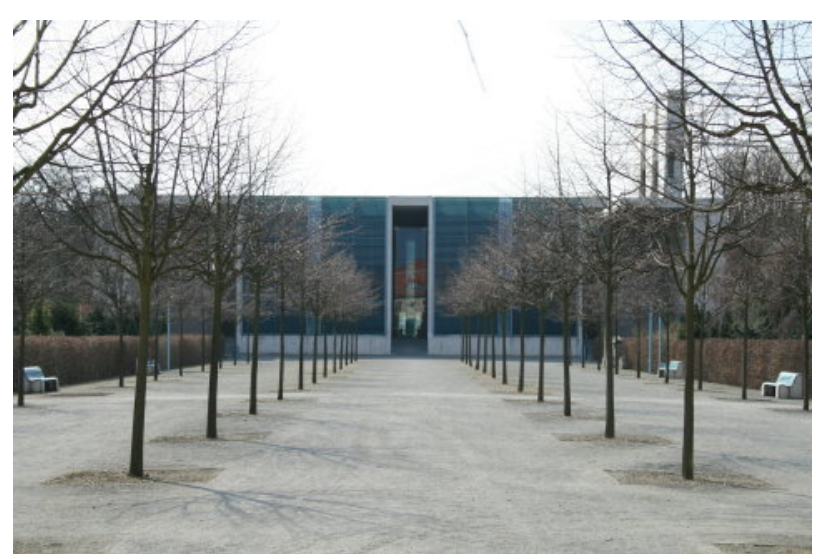

\section{Figure 23:}

View of the entrance of Treptow Crematorium clearly indicates the modern design of the building

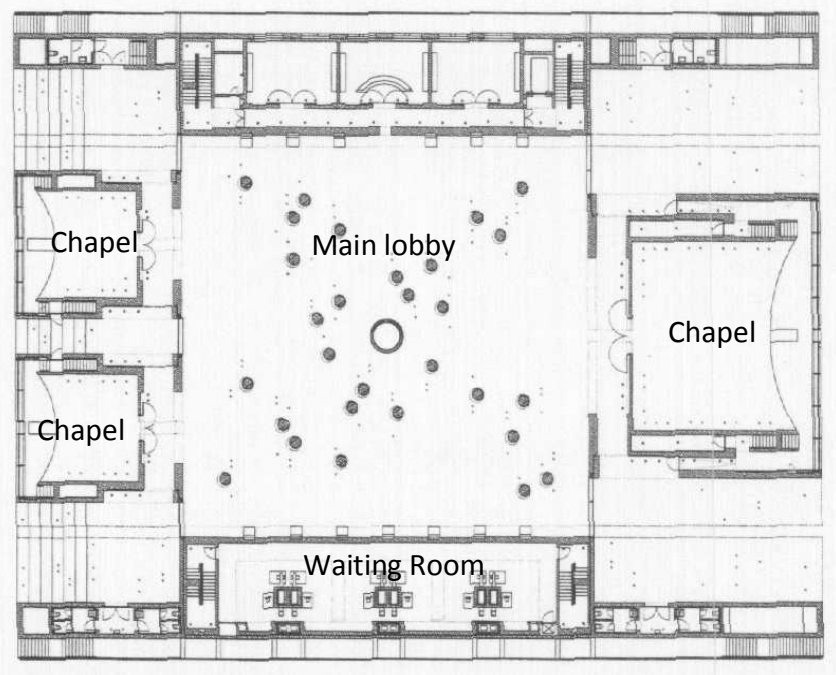

\section{Figure 24:}

Plan of the upper chapel level shows how the series of columns act as room dividers creating a number of gathering spaces and private spaces 
concrete - the material of modernity. Even the furnace room is not addressed in any way. The only indication of their existence is three chimneys located above it. ${ }^{80}$ Although the architecture attempts to address the connection between fire, people and primitive, the stoic form lacks naturalness. As a result the architecture does not speak of the primordial. The building appears too modern and does not speak of humanity.

On the other hand, the architecture successfully addresses fire's ability to gather people. Within the lobby of the crematorium there are several concrete columns. These columns are arranged in a series of clusters allowing a kind of private space to form. The different sizes of the cluster accommodates for both small groups as well as large by creating a threshold that binds people together. ${ }^{81}$ The columns allow a group of people to celebrate the deceased's life in one space while the next discreetly allows a person to quietly bereave. Rather than fire, water is used as the central focal point within this lobby. Fire as an element has many dialectics. Water is one dialectic of fire. Perhaps this is Schultes' compromise for not physically addressing fire within the architecture. Furthermore floating above the pond is an egg, a symbol of new life. Here we can see Schultes' attempt to address the cleansing nature of fire when it comes to death, allowing the rebirth of the soul. Fire is used firstly as a point where a community gathers, without using fire literally, the architecture of this crematorium is successful in creating a sense of community at a difficult time for people.

Hinduism is one of many religions that require the family of the deceased to watch the fire cleanse the body of their beloved. By excluding fire entirely within the architecture, Schultes has not fulfilled the needs of the majority of people who will use the crematorium.

The architecture of the Treptow Crematorium appears very modern. Even so, Axel Schultes aims to address the primordial through it. Fire is central to the ritual of cremation, and yet it is completely unaddressed within the architecture. The viewer is unable to even see the furnace room or even realise its presence. Water, the dialectic of fire, is used as a focal point within a vast lobby. However, it is not

${ }^{80}$ Matthews, Emma-Kate, 'Treptow Crematorium, Baumschulenberg, Berlin', University of Nottingham Journal, 2007, pp. 32

${ }^{81}$ Russell, James S., pp. 224

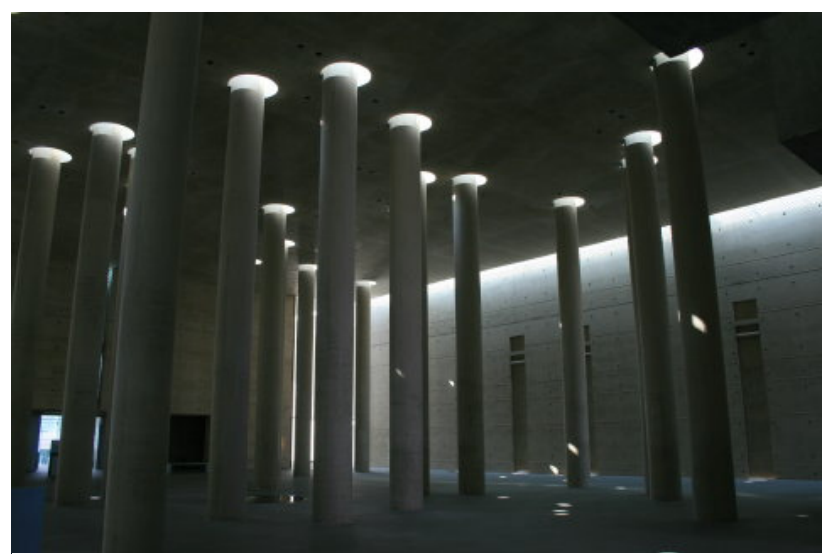

Figure 25:

View of the columns within the central lobby

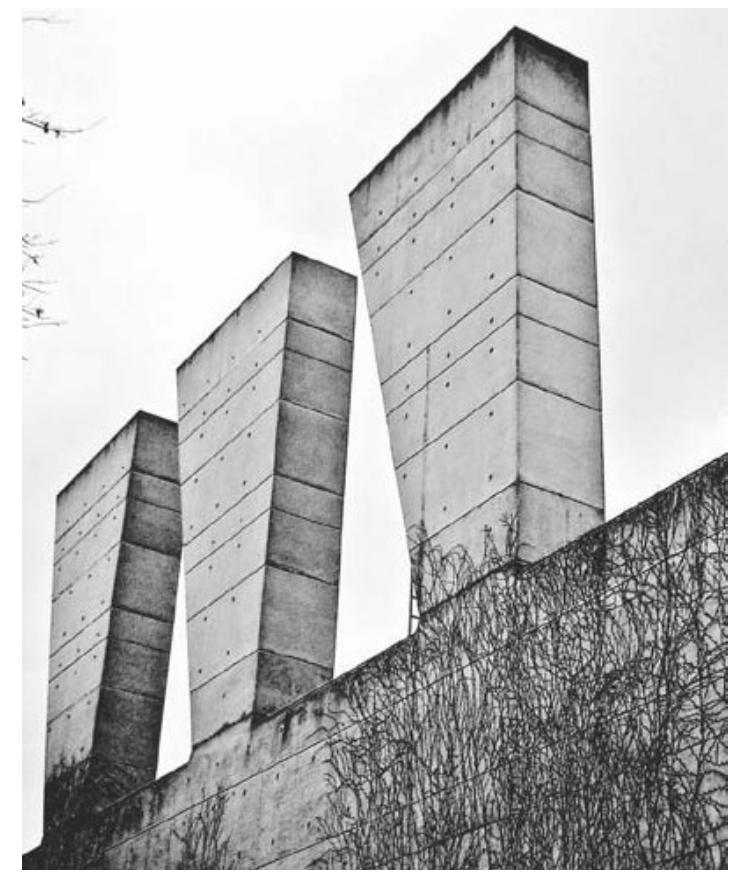

Figure 26:

The only indication of the furnace room is through these chimneys that are visible from the outside 
the device that gathers people like fire is. Instead clusters of concrete columns are present for gathering people in remembrance of the deceased. Therefore although the architecture aims to represent characteristics of fire as an architectural element, it has not been entirely successful. Aspects of fire such as a sense of community and contemplation are present throughout the lobby, but due to the formation of columns rather than connection with fire. The idea of the primitive is addressed only through unpolished concrete surfaces, and I feel this does not speak of the natural state of primordial. As a whole the crematorium is a step towards a more civic use of fire, however, it has not truly represented the ideas related to fire. 
Joey Goei - Playing with Fire: Analysing the role of Fire in Architecture

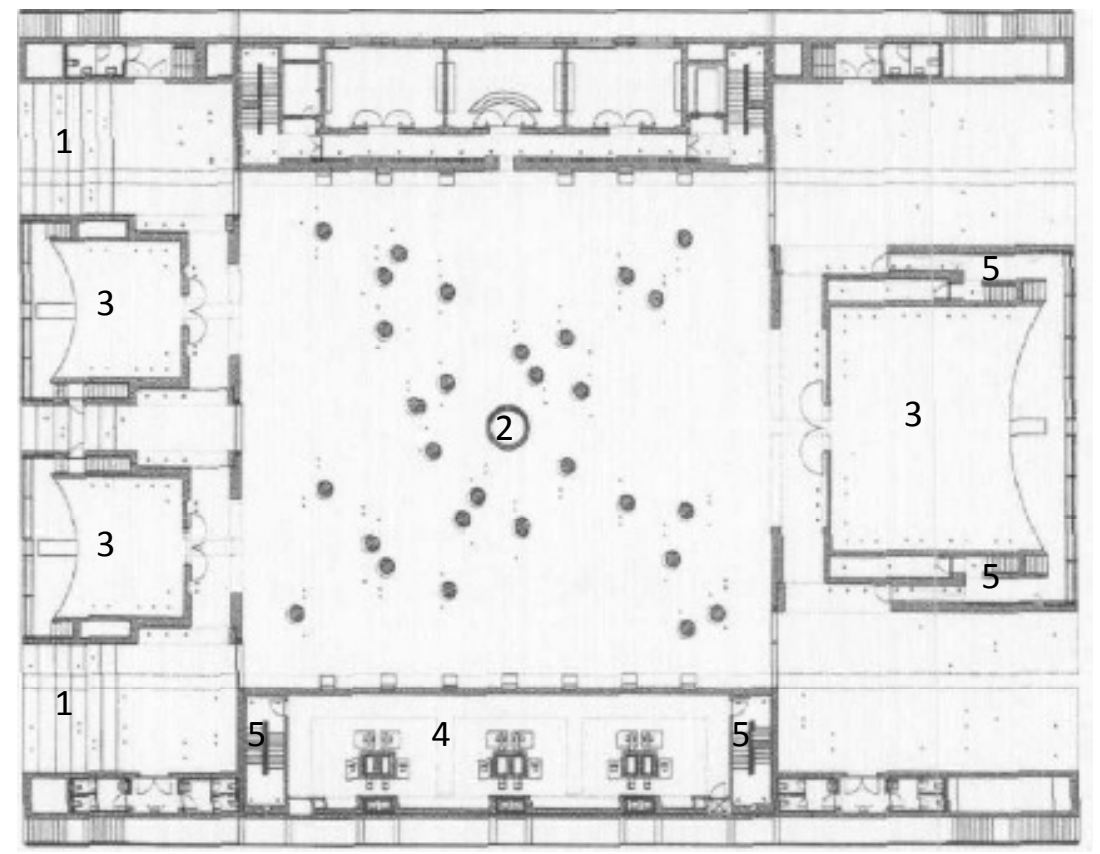

Main level (left):

1. Entrance

2. Main Hall

3. Chapel

4. Waiting room

5. Stairs to furnace level (basement)

Furnace level (below):

1. Furnace

2. Storage

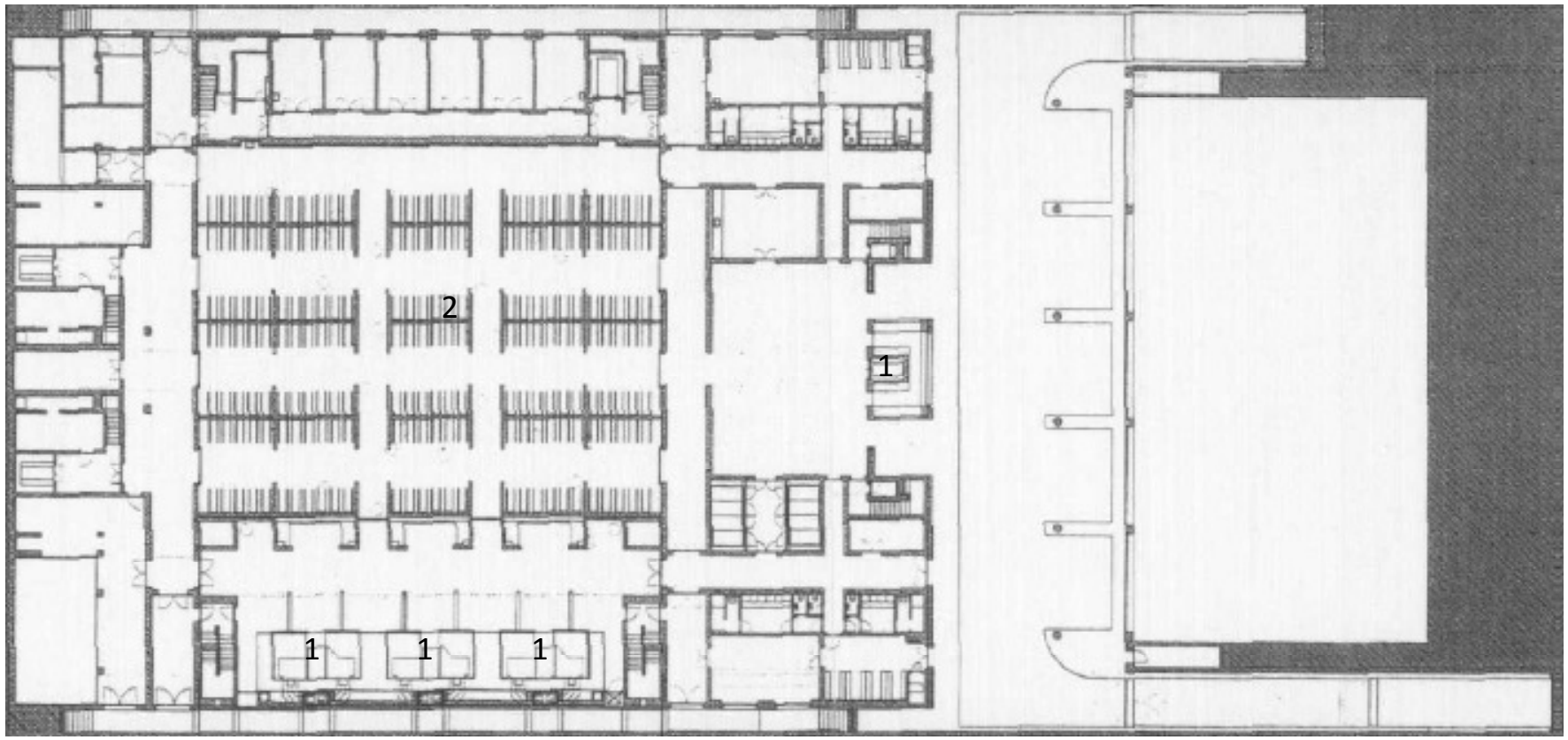




\section{Case Study 4: Takasugi-an Teahouse by Terunobu Fujimori}

On the wooded area of Mt. Moriya, Japan, sits a tall teahouse $6 \mathrm{~m}$ above ground. Completed in 2004, this teahouse is less than 10 metres squared. ${ }^{82}$ Terunobu Fujimori, an architect-historian, recently has begun to express his ideas architecturally. In a short time he has created several teahouses amongst other buildings. Central to his design is the Japanese traditional way of life. Japanese culture is known to be ultra modern, and yet the Japanese are still very traditional. ${ }^{83}$ Rituals are still centre to their lives. Fujimori's teahouse is one architectural example where a ritual that involves fire still lives even in the modern world.

The small teahouse follows the tradition of the Rikyu era. ${ }^{84}$ This means that the 'tea master,' is the one in charge of the design and build of the teahouse, hence Fujimori built this teahouse for his own use. The construction of the teahouse is somewhat simple and yet complex. The house sits on two tokonama poles and sways in the wind. ${ }^{85}$ Although Fujimori is interested in modern techniques, he feels that there should be a respect for tradition. The Japanese tea ceremony is very precise in ritual, and therefore Fujimori has ensured the central element, fire, is included within the architecture. The ceremonial hearth is built into the floor, sunken in. This way it provides the 'clean' lines modern styles have while still allowing for ritual to be accommodated. During tea ceremony, the host is required to prepare the tea in front of the guest beginning with lighting the fire that heats the water. All preparation of tea is made while the teapot is on the fiery hearth. Hence the central hearth is very important. The manner in which the host makes the tea is essential as it shows the stability and honour

\footnotetext{
${ }^{82}$ Fujimori, Terunobu, Fujimori Terunobu Architecture, Tokyo: TOTO Ltd., 2007, pp. 86-87

${ }^{83}$ Buntrock, Dana (Ed.), Materials and Meaning in Contemporary Japanese Architecture Today, New York:

Routledge, 2010, pp.1

${ }^{84}$ Fujimori, Terunobu, pp. 86

${ }^{85}$ Meinhold, Bridget, 'Japanese Treetop Teahouse is "Built Too High"', Inhabitat, http://inhabitat.com/fujimori-teahouse/, visited 3 May 2010
}

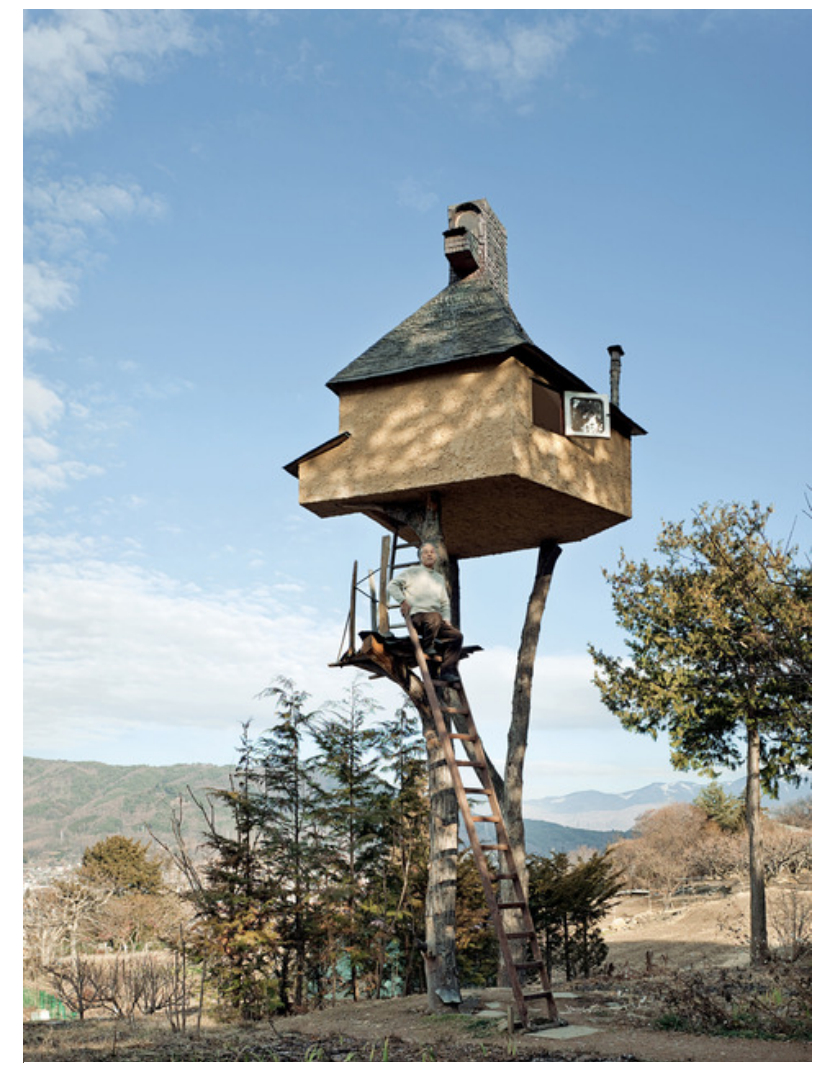

Figure 27:

Fujimori standing on the ladder that leads to the entrance of the tea house. 
of the host. ${ }^{86}$ The guests gather around this hearth in respect of the ritual and waits in contemplation. As a result the ceremonial hearth is seen as a symbol of repose. This is especially true due to the way the samurai used the tea ceremony as their only break during duties. ${ }^{87}$ Fire as an architectural element is a sign of repose to many outside the Japanese. Bachelard feels that it is due to the fire's ability to entrance us and thus clear our minds of the worries of our surrounding. Similarly the presence of the teahouse's central hearth provides a visual centre point which guests focus on, thus cleansing and refreshing the mind. The architecture of the teahouse is quiet so that the focus is on the hearth and nature. The materials used are natural materials found around the area. Therefore it is not distracting to the occupant, and they are able to truly have a moment of contemplation and repose.

Although the teahouse is private, it still provides the feeling of community due to the use of the central hearth. Strangers become part of the group when they are invited to sit around the hearth and be part of the tea ceremony. Therefore the hearth addresses the moment where fire became a threshold between private and public. Once invited to the fire's space, you are accepted into the private space and are able to leave public outside. The structure itself appears to be a primitive structure, a tree house. Through these connections Fujimori aims to continue the enduring "human values within architecture. ${ }^{\prime 88}$ Some of these values are solely represented through the presence of the small central hearth: community, repose and ritual. The combination of tradition and primitivity is therefore able to be clear due to the presence of fire as an architectural element. Although the element is in such a small place, it still enhances the experience within it. The idea of community is further extended through the simple construction of the teahouse. Fujimori relied mostly on his childhood friends and other members of the community in constructing the structure. Even children from the nearby Nemunoki School helped in creating the roof. ${ }^{89}$ As a result, the architecture of the teahouse is truly a symbol of community, brought together around the ritualistic fire.

\footnotetext{
${ }^{86}$ Fujimori, Terunobu, pp. 50

${ }^{87}$ Fujimori, Terunobu, pp. 51

${ }_{88}^{88}$ Pilling, Simon, 'Tea for Three', Architecture Review 223/1335, May 2008, pp. 94

${ }^{89}$ Buntrock, Dana, pp. 38
}

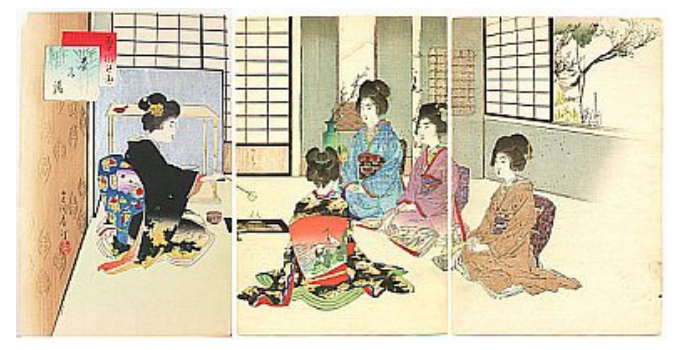

\section{Figure 28:}

Japanese painting showing a typical tea ceremony. The guests sit patiently around the hearth, watching the host make the tea

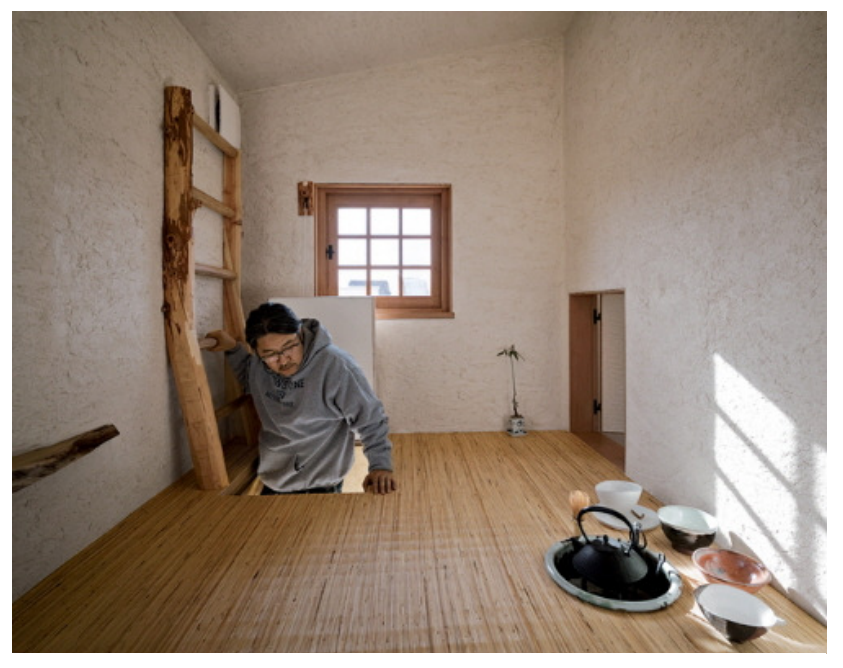

Figure 29:

View of the intimate interior of the tea house. The hearth is an inset into the floor, and is kept to a minimum. This shows that even very small gestures can still be a strong gesture in representing fire in architecture. Even though small, the hearth is still the focus of the space. 
Modernity is represented through the minimal ornamentation and simple forms of the small tea house. On the other hand, the form still accommodates every need of the ancient ritual. Traditional Japanese tea houses have a central hearth which is essential to the tea ceremony. It is the focal point in which this particular tradition revolves around. Fujimori addresses many psychological aspects of fire within the architecture of his teahouse. The ritual of tea making symbolises repose just as the fire often reminds us of relaxation. The fire is used as the central vessel which provides a moment of contemplation and quietness. At the same time, it is the focus of the ceremony as the tea is made using the hearth, thus enabling a kind of entrancing moment. The idea of community is also represented in the way the hearth gathers people. Once invited for the ceremony, you are accepted into the private space the fire marks. Furthermore the method of construction also supports the idea of community. Due to the simplicity, Fujimori was able to involve untrained members of the area to become part of the whole architectural ritual. I feel that this teahouse is proof that the historical elements and values that are essential to architecture can be continued even within a modern society. Even though we are reliant on our advance technology, there will always be a need for escape to the simplicity of tradition.

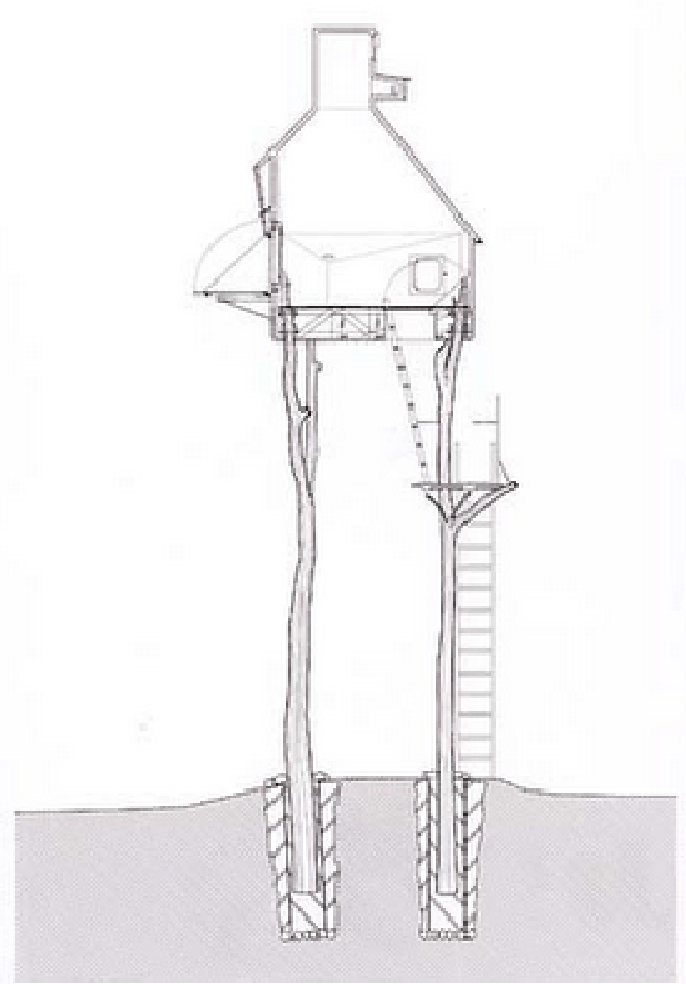

Figure 30:

Section of the tea house shows the deeply rooted high poles 


\section{Case Study 5: Bruder Klaus Feldkappelle by Peter Zumthor}

One architectural example created by fire is Bruder Klaus Feldkappelle by Peter Zumthor. The monolithic concrete structure appears like a standalone chimney in the quiet field of Wachendorf, South Germany. ${ }^{90}$ The chapel is dedicated to St. Niklaus, the $15^{\text {th }}$ century hermit saint. Zumthor, who originally rejected the proposal, agreed due to his connection to the hermit-like life. As an architect, Zumthor is known to use building materials to speak the message of his architecture. He feels that creating an emotive architecture is essential, as it "reveals the core of things." ${ }^{11}$ In this chapel, the characteristics of fire as an architectural symbol are addressed. Through the construction and finish of the building, Zumthor has represented fire's associations with life, death and community.

The interior of the chapel is moulded by 112 tree trunks from the surrounding forest. ${ }^{92}$ Zumthor's approach to the construction of the project reflects the communal association with fire. He has kept the construction method simple so that the people around the area can help construct the chapel. The 112 trunks act as form work on which 24 layers of concrete were poured. After the concrete was set, the wood inside was set on fire creating a kind of communal bonfire. This means the fire that created the architecture has brought the community together, similar to the primitive fire. ${ }^{93}$ As the fire burns, those who built the structure were able to watch in contemplation, thus linking the architecture to Bachelard ideas about reverie. By setting the logs inside on fire, there was nothing left except traces of soot in the interior of the concrete space. ${ }^{94}$ The logs left a footprint on the concrete and when inside, one feels as if they were transported to the woods. These traces are proof of fire's destructive power. The great logs

${ }^{90}$ Casciani, Stefano, 'Il Santo e l'Architetto = A Saint and an Architect [Bruder-Klaus-Feldkappelle]', Domus 906 (2007), pp. 52-59

${ }^{91}$ Saieh, Nicoh, 'Multiplicity and Memory: Talking about Architecture with Peter Zumthor', ArchDaily November 2010, http://www.archdaily.com/85656/multiplicity-and-memory-talking-about-architecture-with-peterzumthor/, visited 16 November 2010

${ }_{92}$ Casciani, Stefano, 'Il Santo e I'Architetto = A Saint and an Architect [Bruder-Klaus-Feldkappelle]', Domus 906 (2007), pp. 52-59

${ }^{93}$ Fernàndez-Galiano, pp. 13

${ }^{94}$ Casciani, Stefano

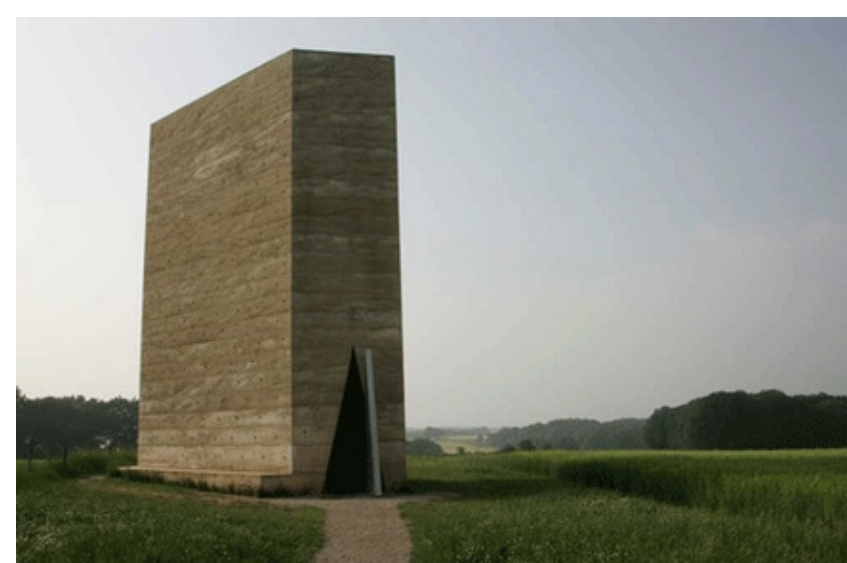

Figure 31:

The chapel stands tall within the vast green field

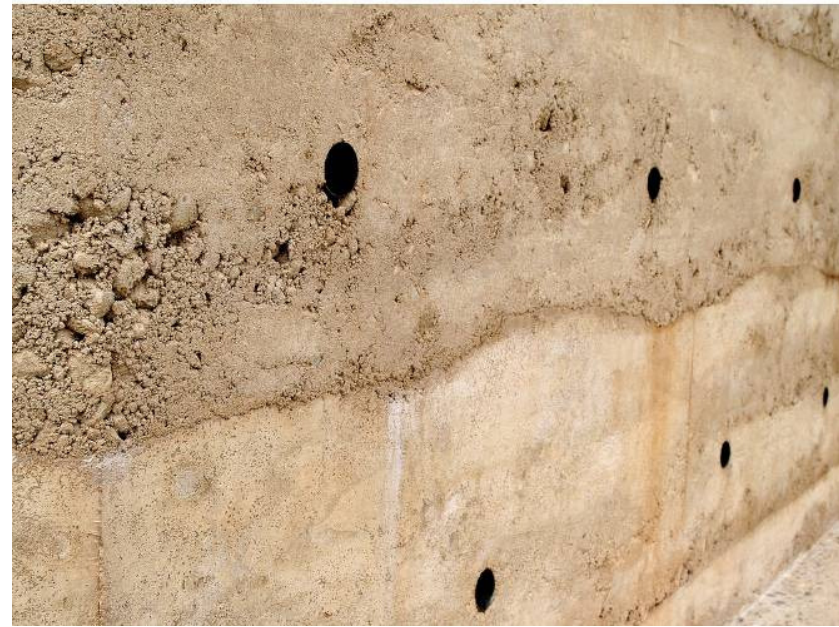

Figure 32:

The layering of concrete is visible on the finish of the exterior 
that used to stand in the forest were reduced to nothingness. Although fire is associated with fertility and life, it has a dialectic that is destructive. ${ }^{95}$ This may be one of the reasons why it has an association with sacred power and therefore distance. Even though it is a life preserving element, we must give it respect, as it can just as easily destroy everything in its path.

The duality of life and death is also represented through the construction and materials of the chapel. The act of burning the formwork means the death of the structure. However, through the death of the structure comes the birth of the chapel itself. This is an architectonic representation of Bachelard comments when he said in fire love, death and life unites. Zumthor's aim of creating a space for remembrance and contemplation is thus achieved through the idea of rebirth. The transformation of the logs from positive to negative space creates a sense of remembrance. ${ }^{96}$ The absence of the logs provides it with a haunting. Although it is not physically present, traces suggest the existence lost. This is similar to the technique used by MOS in creating a memory of the hearth. I believe that Zumthor is successful in his attempt to create a message through the materiality of the architecture. ${ }^{97}$ Although the concrete is all that is left for its final structure, the journey of the architecture is clearly represented. In observing the surfaces of the concrete, we see that it began with a formwork made of local logs. Concrete is poured layer by layer manually, and then once set; the log is set on fire. The open air, dark space inside is created through the absence of the logs. Through the death of the 'architecture' of the logs, a new one is born. The more primitive log structure is gone, and reborn as the 'modern' concrete structure.

Zumthor's chimney-like Bruder Klaus Feldkappelle is a great example where fire is the creative tool used in the making the architecture. The architecture firstly shows the destructive power of fire. The big logs that used to be part of the surrounding woods were reduced to nothingness, with only traces of soot and their 'footprint' left. In the act of burning the wood, an event similar to the primitive bonfire

\footnotetext{
${ }^{95}$ Frazer, James, The Golden Bough: A Study in Magic and Religion vol. 3, London: Macmillan, 1933-36, pp. 127

${ }^{96}$ Casciani, Stefano, 'Il Santo e I'Architetto = A Saint and an Architect [Bruder-Klaus-Feldkappelle]', Domus 906 (2007), pp. 52-59

${ }^{97}$ Saieh, Nicoh, 'Multiplicity and Memory: Talking about Architecture with Peter Zumthor', ArchDaily November 2010, http://www.archdaily.com/85656/multiplicity-and-memory-talking-about-architecture-with-peterzumthor/, visited 16 November 2010
}

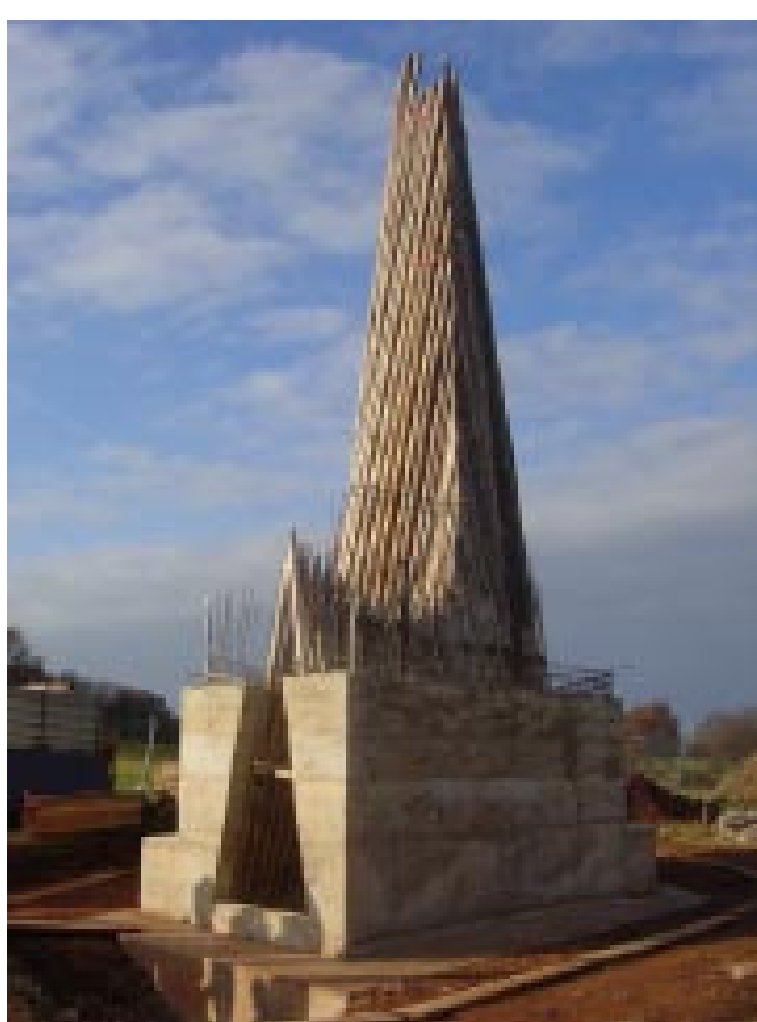

Figure 33:

This image during construction shows the logs used as formwork prior to being burnt 
occurs. The community, who helped build the chapel, were able to stand back and reflect together. The burning structure has brought them together in remembrance of the patron Saint Niklaus. From this we are able to understand the ritualistic nature of fire, providing a transcendental experience. More importantly, the architecture of the chapel represents how life and death are connected within fire. Bachelard's work states that fire has a connection with both life and death due to its dialectical characteristic. Through the construction and materiality of the chapel, Zumthor is able to show this architectonically. The tree trunks that were arranged in a cone-like shape can be considered a type of primitive structure. With the literal death of this structure, it is reborn as a new one. Even though fire is not physically present within the architecture of the chapel, Zumthor is able to let the architecture speak of the ideas of fire through the construction and materials of his Bruder Klaus Feldkappelle.

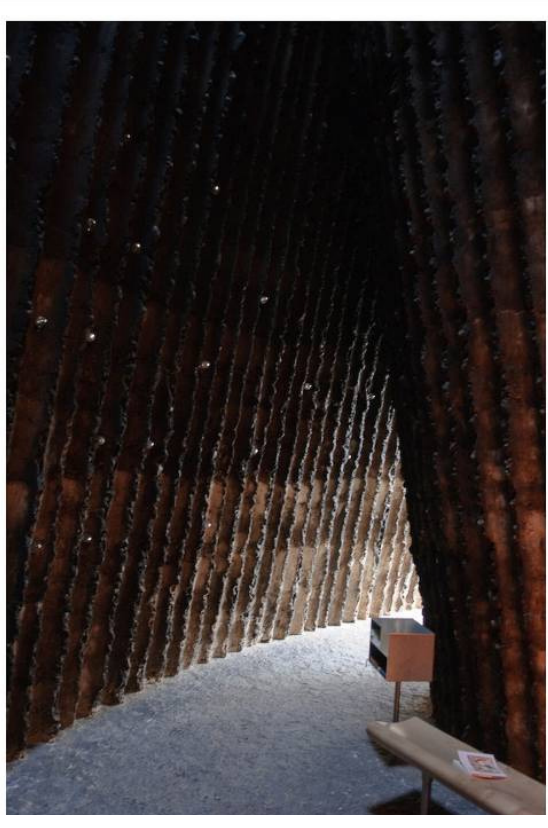

\section{Figure 35:}

The interior has an organic appearance, the opposite of the monumental exterior

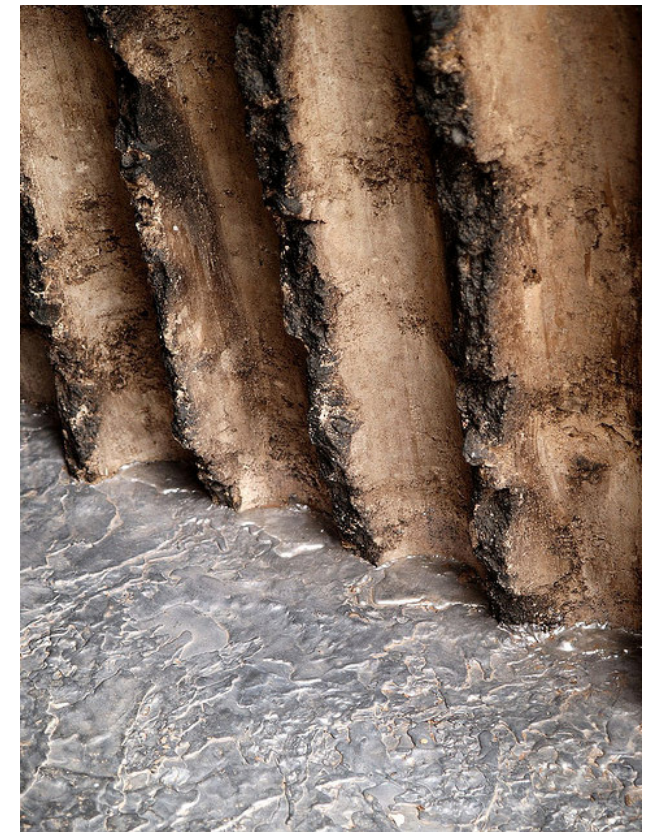

\section{Figure 36:}

Close up of the soot mark and texture left by the burnt logs

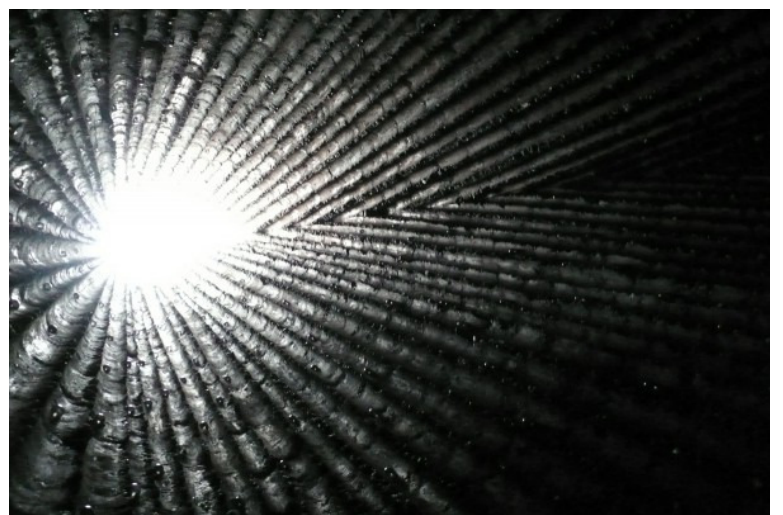

Figure 34:

View of the cone-like light well from inside 


\section{Chapter 7: Semiotics}

"Every human society communicates architectonically." 98

\section{Fire as communicative tool:}

Beyond the functions of shelter and protection, architecture is a form of cultural communication. It is the setting for our lives and in turn it influences how we live. Fire is one architectural element that has served as both. Mari Hvatum states that fire is a "symbolic representation of the sacred centre of community." ${ }^{\prime 99}$ However its application in today's society seems to be reducing due to environment concerns. This focus on the environment has shifted our attentions away from the communicative aspect of architecture. Historically, architectural ornament speaks of the current beliefs and stories of the time. Today ever since modernism, less is believed to be more by many. Buildings simply serve their function and some no longer provide the story that comes with the events inside or the people that use the space. Fire as an architectural element has a high value in semiotics and in this section we will learn in depth the various ideas that fire symbolize.

Semiotics is a study of symbols and signs. In architecture, we often use symbols and signs to communicate our concept and the meaning of our spaces. It is a way one "seeks to construct permanence out of the ephemeral." ${ }^{100}$ The meaning intended may not necessarily be the same meaning received by occupants, but it is a meaning nevertheless. The use of symbols may be geometric, representational or phenomenal. The importance is to acknowledge architecture as "a system of signs." 101 Therefore not only the use of the symbols is important, but also how it is arranged and its relationship with one another. The symbols may work together coherently, or they may create "disjunctions, contrasts and [or] discontinuities." ${ }^{102}$ The combination of the same symbols arranged in one way will differ in meaning to one arranged in a different way. Figure 37

\footnotetext{
${ }^{98}$ Preziosi, Donald, The Semiotics of Built Environment, Bloomington: Indiana University Press, 1979, pp. 1

${ }^{99}$ Hvatum, Mari, Gottfried Semper and the Problem of Historicism, Cambridge: Cambridge University Press, 2004, pp. 13

${ }^{100}$ Castle, Helen Ed., 'Poetics in Architecture', $A D$ vol. 72 no. 2, Mar 2002, pp. 6

${ }^{101}$ Preziosi, Donald, pp. 2

102 Preziosi, Donald pp. 12
}
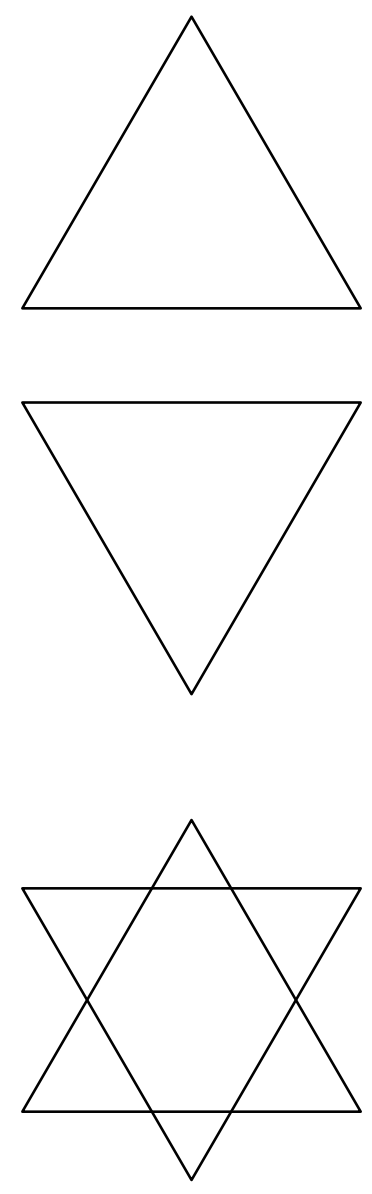

Figure 37:

In alchemy, an upside triangle means fire-a male element. Upside down means water - a female element. Together, they are combined to become the Star of David. 
is an example where a form can mean several things only through a different arrangement. A triangle can mean fire, water or a symbol of a religion.

According to Paul Walker there are two types of symbols: conventional symbols and natural symbols. Conventional symbols have their meaning due to common conventions set up, whereas natural symbols are "inherent in the order of things." ${ }^{103}$ When we look at fire as a symbol, it fits with both conventional and natural symbols. The natural meaning comes due to the connection with our psyche and the conventional meaning comes from its association with other ideas over time. For the purposes of this project, life and death will be the natural symbols of fire, and power and violence will be the conventional symbols of fire.

\section{Fire of Life and Death:}

In Greco-roman times, fire was one of the main architectural symbols of the city (figure 38). Its existence symbolises the city's live. As mentioned this is to do with Hestia, the Goddess of the Hearth. It is believed that the fire will sustain the wellbeing of the city and protect it from bad omens. However, extending from the myth, fire is the central architectural element because we live our lives around it. Historically, the hearth is the place where people warm themselves, cook and where the sense of community/family centres. Semper, too, agrees that fire is "the centre of family life." ${ }^{\prime 104}$ He writes that being included to share a meal around the fire is the ultimate act of acceptance into a community. Hence sitting around the fireplace is associated with togetherness and brings us a sense of safety in numbers (figure 39).

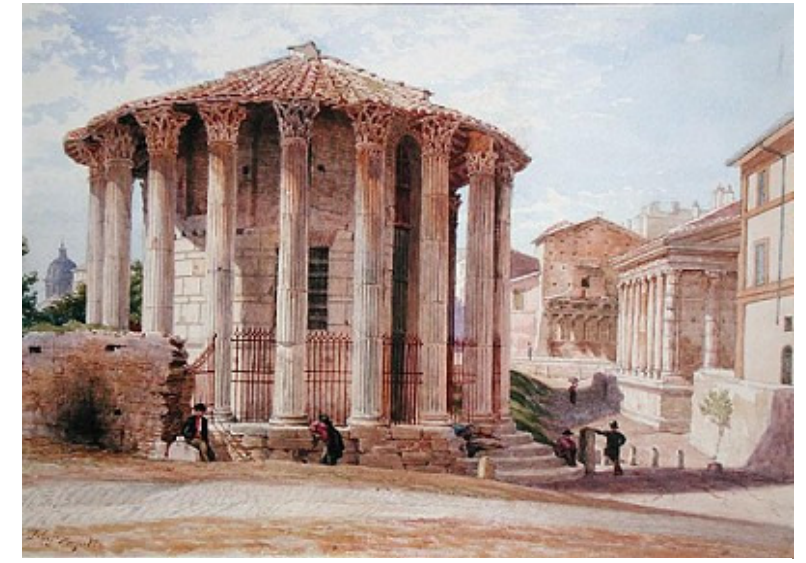

Figure 38:

The Vesta Temple in Rome houses the city's fire. From this painting by T.G. Jackson (1880) we can see that it is a highly protected element, this was destroyed during the sack of Rome to symbolize the fall of Rome

\footnotetext{
${ }^{103}$ Walker, Paul, Semiotics and the Discourse of Architecture, Auckland: University of Auckland, 1987, pp. 5

${ }^{104}$ Hermann, Wolfgang, pp. 198
} 
On the other hand fire inevitably represents death due to its potential for destruction. Despite this, the association with death is not always negative. Due to its associations with purification, fire's destructive power can also be seen as a form of renewal. Therefore we can say that in our reverie of fire, the changing in state into 'nothingness' is also that of rebirth. For example we often burn objects that symbolise a negative event to be rid of it, to be cleansed from it. By bringing death to the object associated with the event, we are renewed ready to move on. Just as people gather around punch in Bachelard's writing, people will gather around his cleansing fire. Also often this act of cleansing becomes a kind of ritual. Rome's architecture was set on fire when the city was sacked. The barbarians wanted to 'cleanse' Rome of its previous ruler and value thus declaring its end. The remnants of the 'old Rome' were destroyed by fire's fury making way for a 'new Rome'. In setting the city on fire, a new pure city is able to be built on the purified grounds.

Acknowledging fire as a natural architectural symbol is to do with our primal instinct. As Bachelard, Jung and others have written, it is inherently coded in our subconscious and therefore easily recognized by us. However, as a conventional symbol, humans have played a major part in its creation. Just as described by Bachelard in Prometheus Complex, the first thing we learn about fire is its danger and prohibited nature.

"By this should be understood a study of the phenomenon of the poetic image when it emerges into the consciousness as a direct product of the heart, soul and being of man, apprehended in his actuality." ${ }^{105}$

Fire's relationship with life and death is due to its dialectical nature. It has the ability to both care for us and destroy us. This dual connection can also be seen as a type of cycle. In caring and nourishing living beings, it brings the end to them so that it is renewed. As a result its destructive nature is the same nature that recreates life. Hinduism for example believes that when fire destroys our physical being during cremation, it is recreating a new 'life' at a different realm. In other words, fire is the gateway between this life and the next.

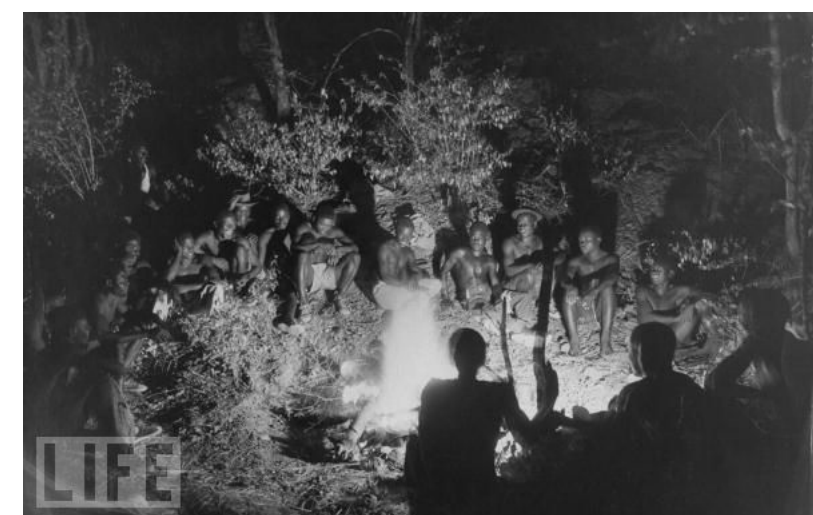

Figure 39:

Image of native scouts sitting around the campfire. Those accepted around the campfire are protected by the community

\footnotetext{
${ }^{105}$ Gaston, Bachelard, 1958, xviii
} 


\section{Chapter 8: Design Proposal:}

From the case studies, I have gathered that we should use fire for civic purposes as it is becoming more inapplicable physically in the home. Being one of the four classical elements, fire has often been related to the balance of our world. It has become the symbol of a variety of things and in particular life and death. As an architectural element, fire is able to transport our consciousness to a deep level of reverie, thus providing us with a kind of spiritual fulfilment. Bachelard states that in fire, love and respect, the instinct for living and the instinct for dying are united. ${ }^{106}$ This means that our association of fire with life and death is not only semiological but also primal. Preziosi writes "there is no human society which does not communicate, express and represent itself architectonically." 107 This means that architecture is one of the main ways in which we communicate to future generations. It represents our way of life, our culture and our beliefs.

The historical information and analysis of fire's role as an architectural element and symbol lead to the proposed application of a crematorium. From the research conducted, I believe that within crematoriums, "love, death and fire are united at the same moment." 108 This comment by Bachelard sums up the dialectical nature of fire - life and death. Many religions such as Hinduism, Buddhism and even Christianity, view death as a beginning not an end. ${ }^{109}$ It is our transition between one state of life to another. Bachelard mentions that "in the heart of the fire, death is no longer death." ${ }^{110}$ When we die, 'death' only occurs to our physical being, not our spiritual. Our physical being is

\footnotetext{
${ }^{106}$ Bachelard, Gaston, 1964, pp. 16

107 Preziosi, Donald, Architecture Language and Meaning, Netherlands: Mouton Publishers, 1979, pp. 6

108 Bachelard, Gaston, 1964, pp. 17

109 Encyclopaedia of Britannica, 'Concepts of Life after Death',

http://www.britannica.com/EBchecked/topic/115240/Christianity/67527/Concepts-of-life-after-death, visited

29 January 2011

${ }^{110}$ Bachelard, Gaston, 1964, pp. 18
} 
reduced to dust, "to nothingness." ${ }^{\text {"111 }}$ From this we can understand Bachelard's statement when he says in being cremated, we are being transformed from "the life of men... into the life of phantoms. ${ }^{\prime 112}$ Fire as an element is the magnet that brings people together and as a result creating a transcendental experience of space. It is used to bring a certain importance to an event or activity.

Cremation has been very common in the East; in the West it has been less common. Catholicism lifted their ban of cremation only in 1966. Today, it has been gaining popularity due to the decreasing number of burial site. Furthermore, it is seen as more environmentally friendly due to the advances in technology. Previously, the chemicals used in preparing the body for cremation is known to release mercury into the atmosphere when burnt. Today, the smoke control and sterilization mechanism are so advance, only steam is released. ${ }^{113}$ At a poetic level, some cremate their beloved so that they are able to take the ash home and have the deceased 'amongst' the family. When cremated, nothing is left of the body, thus the reflection and ritual performed prior to cremation is important. Crematoriums are where these rituals performed. Architecturally, it creates a "meeting point for the complex human and cultural issues whose resolution into a successful building is potentially very difficult."114 Crematoriums as we know them today are based upon rituals which are adopted during the late twentieth century. Therefore the methods differ to that of ancient cremations. Today, the burning of the body is concealed as a way to respect the mourners. They simply part with their beloved and are reunited once the process is done. Architecture here is used as a vessel for reflection and solemnity. It is where the lives of those dear are celebrated and thus enabling us to let them move on to the 'after-life.'

It seems that the focus has shifted from doing rituals for the dead to doing the rituals for those who are left behind by the dead. The process of cremation and other rituals are there to accommodate the stages of grief experienced by those left behind. Even referring to those still alive as being left

\footnotetext{
${ }^{111}$ Bachelard, Gaston, 1964, pp.19

112 Bachelard, Gaston, 1964, pp. 18

${ }^{113}$ Ciroldi S.p.A, 'Fumes purification', Ciroldi - Technology for People and the Environment, http://www.ciroldi.it/en/spa/fumes_purification/, visited 8 September 2010

${ }^{114}$ Grainger, Hilary J, Death Redesigned: British Crematoria History, Architecture and Landscape, Oxford: Spire Books Ltd., 2005, pp. 15
} 
behind implies that death is most sufferable by the living and the attention is on them. Unfortunately crematorium architecture caters mainly for the living. It focuses on the togetherness of the living so that they can cope, while solving the pragmatics of processing the body. I feel that we should celebrate the departure through an architectural gesture. This way, the transition to the next world is able to be celebrated more than just during the service. For example, though it can be scary, a smoking chimney will remind people of the cremation process and the floating smoke can symbolise the soul rising to heaven. 


\section{Drawing Experiments:}

In terms of design process, several drawing experiments were done to create a complex abstract image. This image is then later used as the base of final design.

\section{Fire as Life}

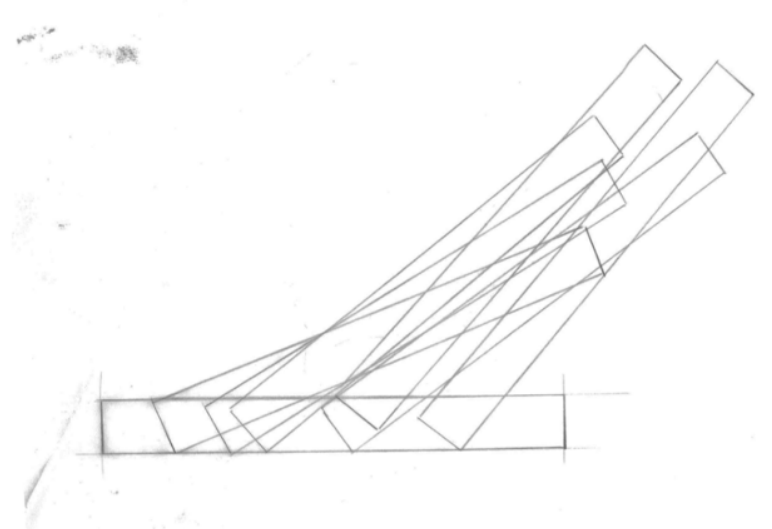

Image 1

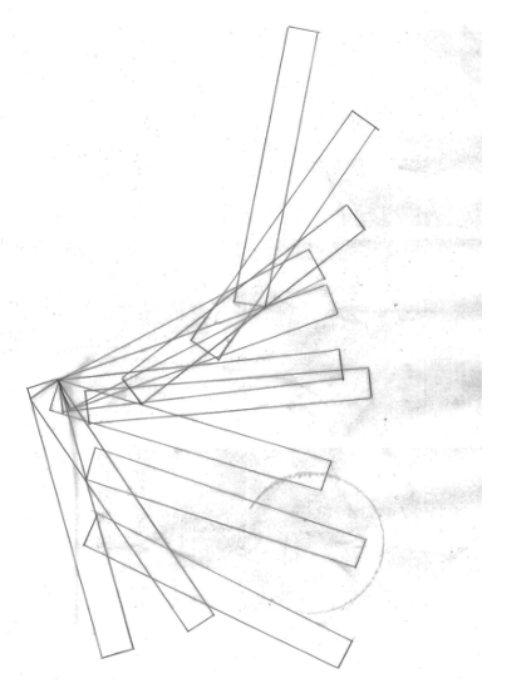

Image 2

1. Bachelard writes that the rubbing of two sticks is the primitive way of creating fire. A simple diagram showing the motion of rubbing one stick against another is taken as a starting point.

2. This image is then tessellated along its edge, and imposed on top of the original image.

3. Image 2 is then flipped along its centre axis and the flipped image is imposed on top of the original image 2

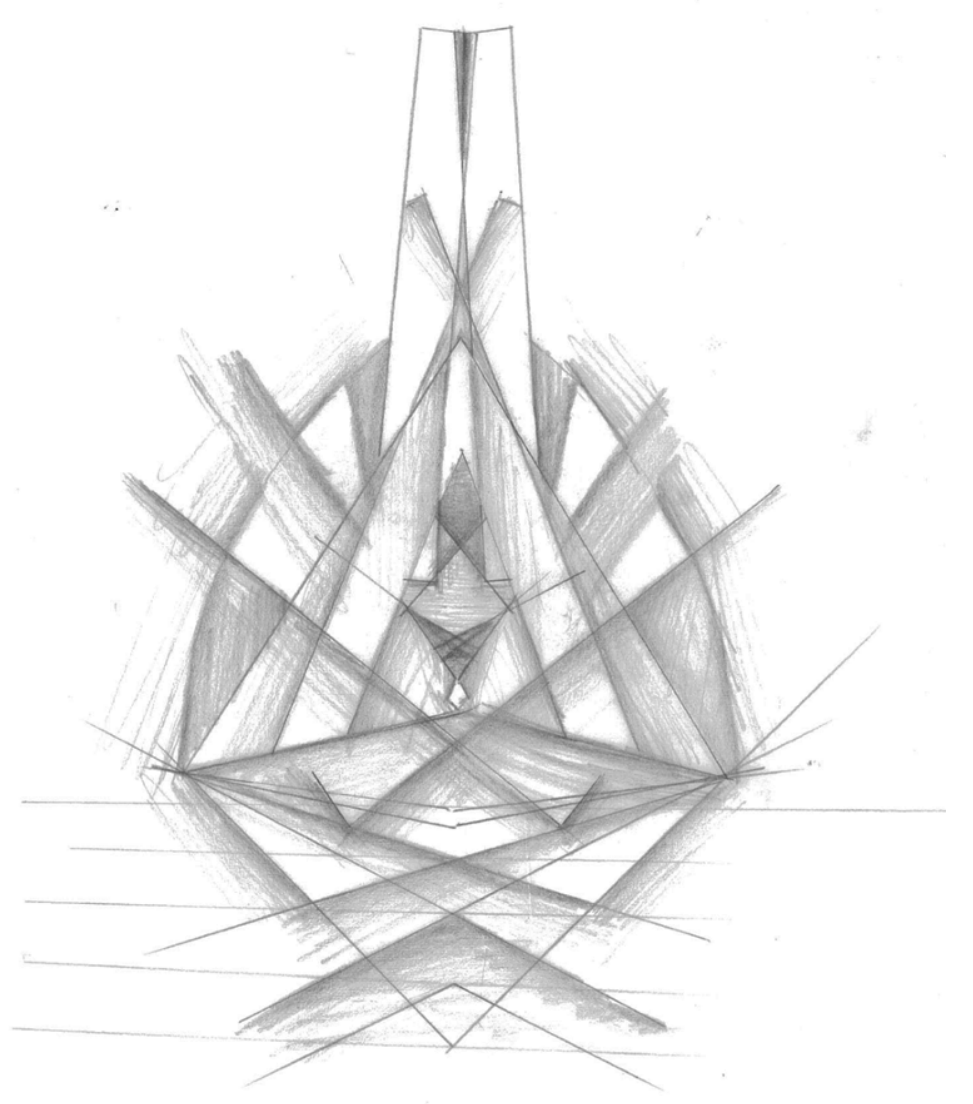

Image 3 



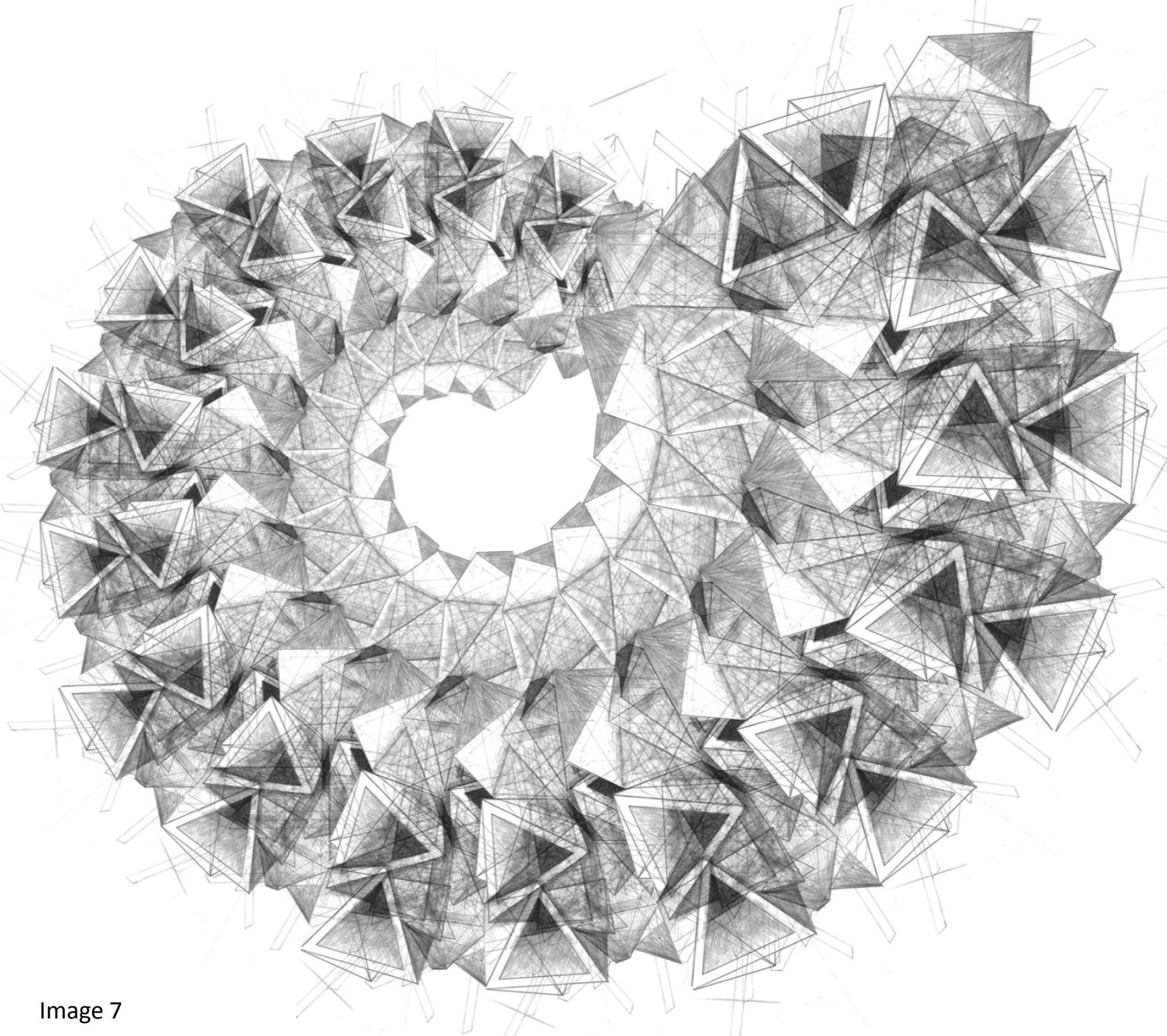

4. In image 3, a triangle formed. Due to the upside triangle being the symbol of fire, I rotated Image 2 at 60 degrees three times to form Image 4.

5. Image 4 is then tessellated and rotated 30 degrees four times. Then the vertexes are connected to create a solid form.

6. Image 5 is then layered several times on top of itself in order to form Image 6.

7. The complexity of Image 6 means that a secondary order of geometry is needed. As a result I rotated the image into a spiral, decreasing in size by $5 \%$ each time. 


\section{Fire of death}

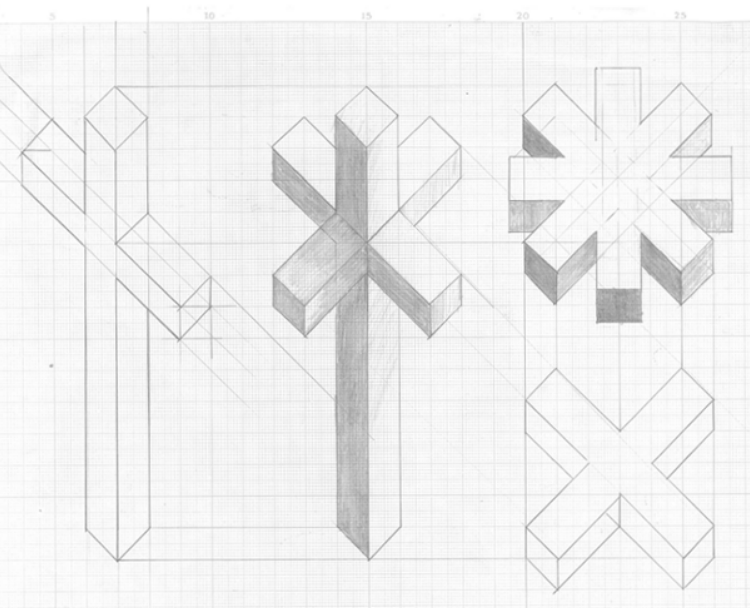

Image 1

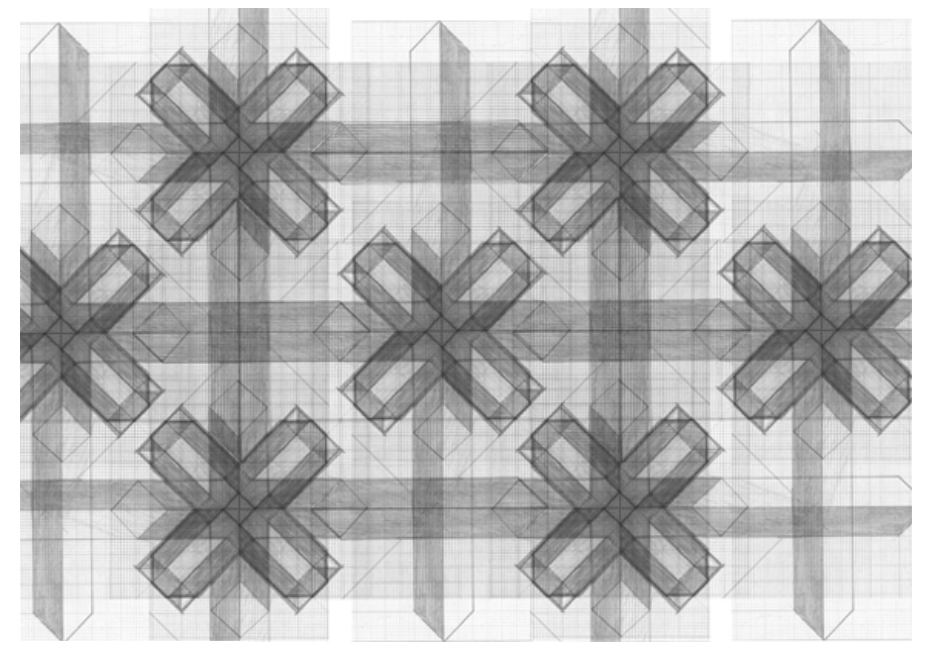

Image 2

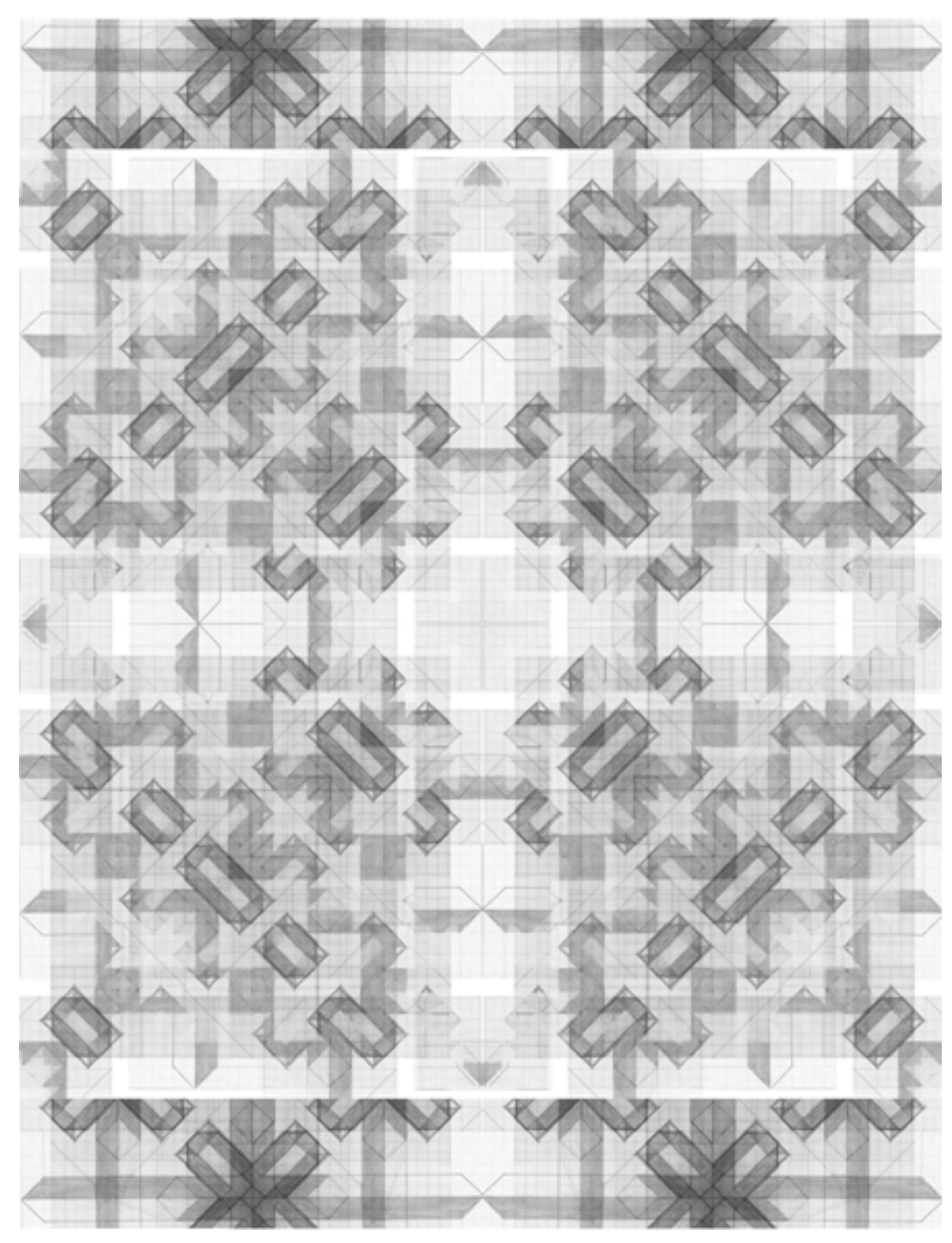

Image 3 


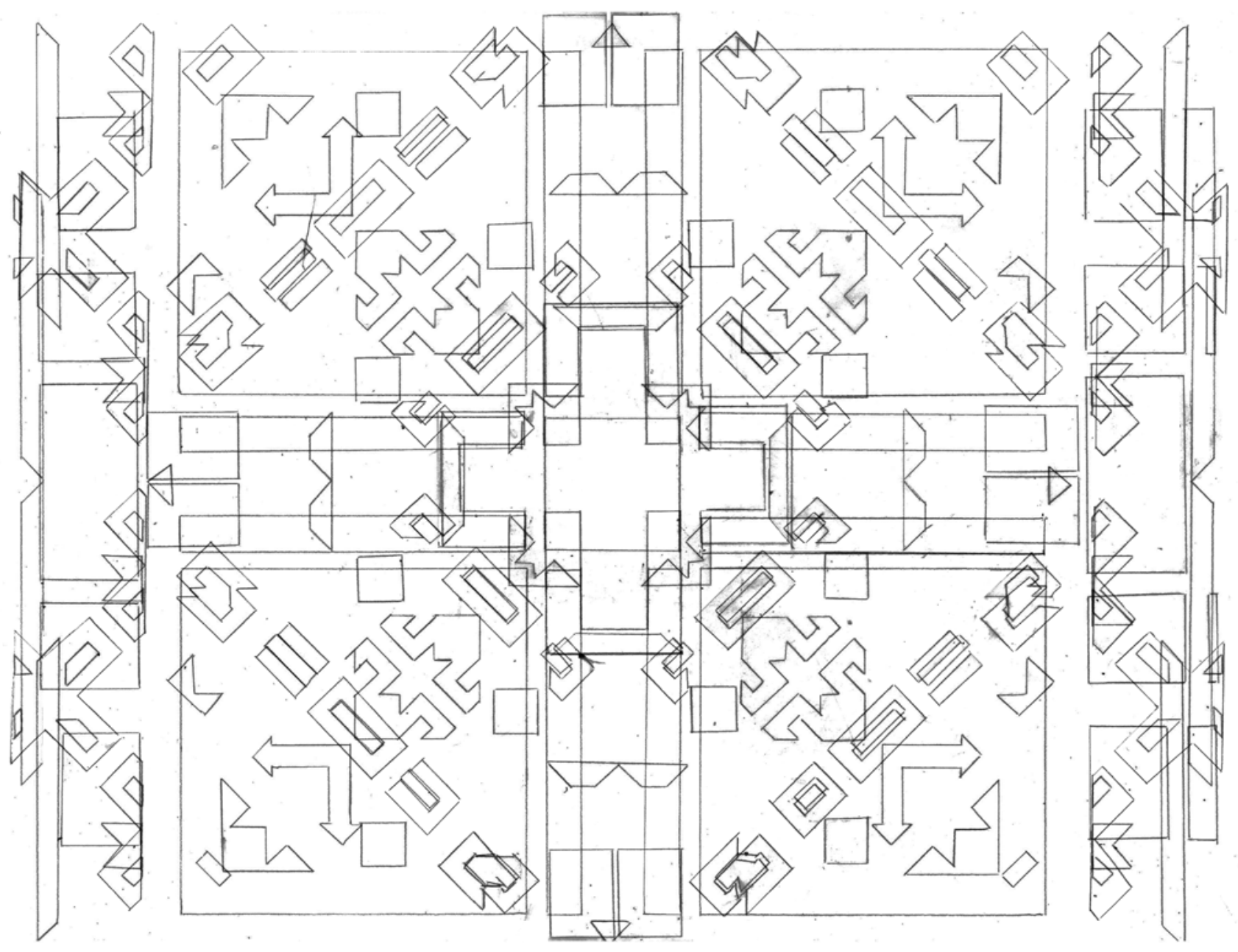

Image 4
The cross was the symbol chosen for death. This is due to the common act of placing a cross at a place where someone has died and due to the cross being a religious symbol in the western world. Furthermore Adolf Loos has associated the cross as being a dialectic symbol of male and female, similar to the way alchemy represented the triangle.

1. The first cross is drawn as a 3 dimensional object, and then rotated along its axis by 90 degrees. The same process is applied to a cross with equal length.

2. The image of the long cross and the short cross is combined together and tessellated in order to create a pattern.

3. Image 2 is then rotated at 90 degrees and superimposed on top of the original Image 2. This created a pattern with a sense of depth within it.

4. Image 3 is divided into several sheets of drawing where similar shapes were recorded on each page. These drawings are then combined together to create a line drawing. 


\section{Fire of Violence}

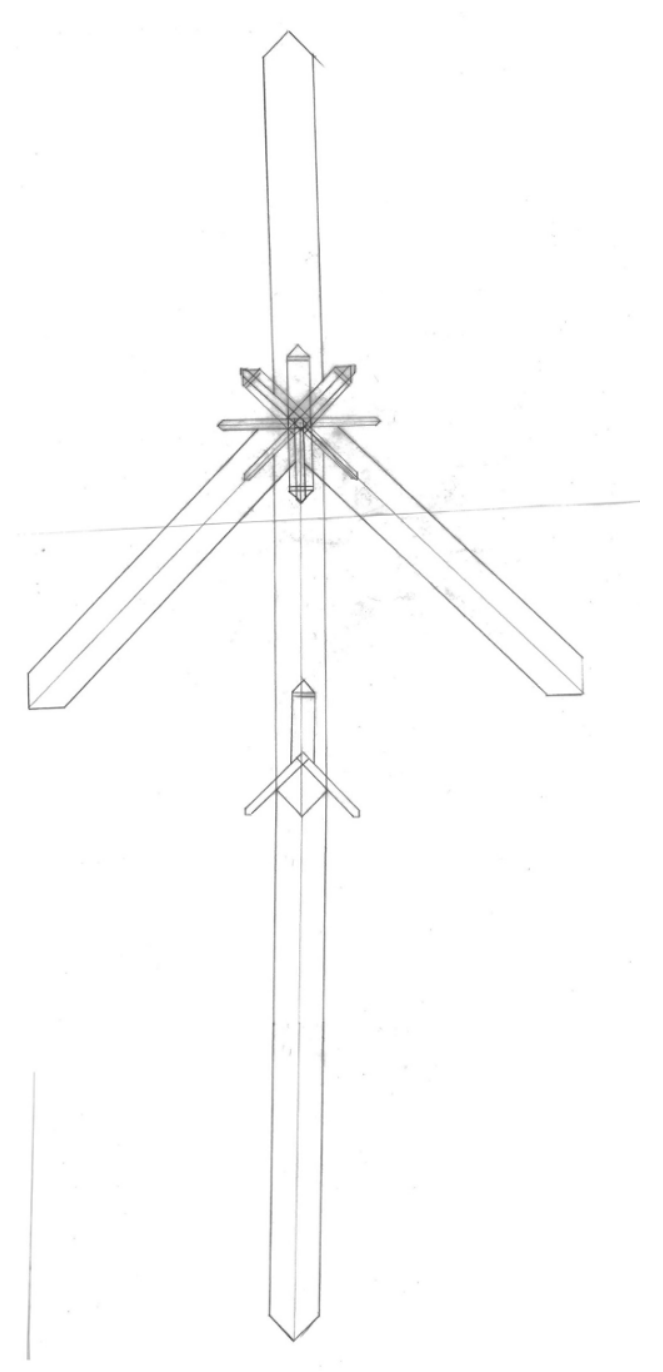

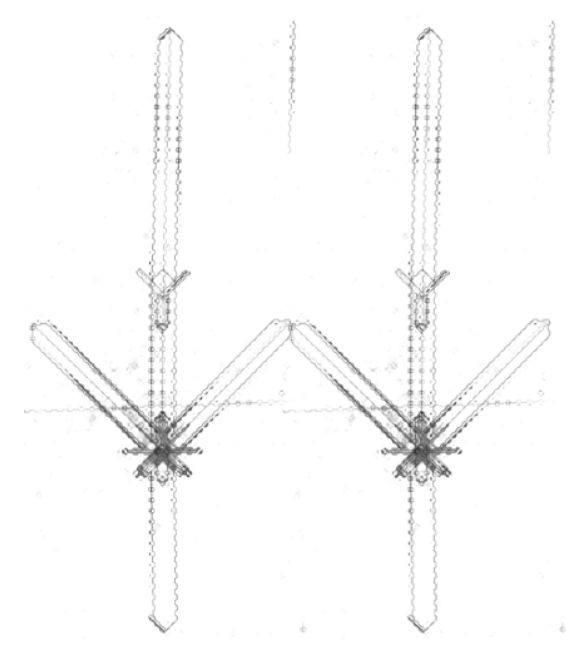

Image 2

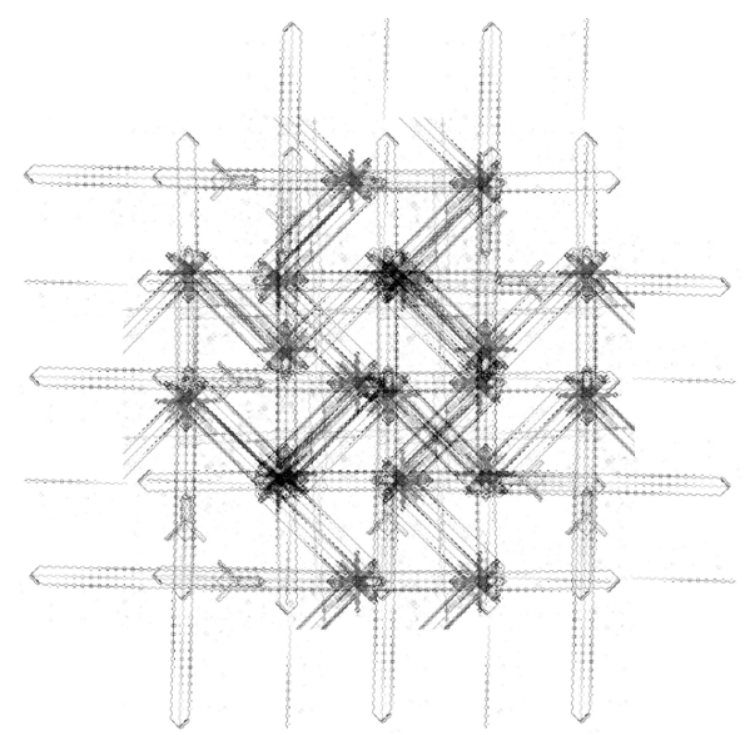

Image 3

In Greek Mythology, Hephaestus is the God of fire and blacksmith. I believe that the invention of blacksmith is the first evolution of fire in terms of its use as a weapon. The image of a sword is taken as the starting point for this drawing experiment as swords are often used in crests as a symbol of power through war.

Similar to the previous processes, the image of the sword (Image 1) is tessellated and rotated in order to create a complex pattern via a simple image. Image 3 is where the tessellated image of 1 is rotated about 45 degrees and superimposed upon the previous image. 

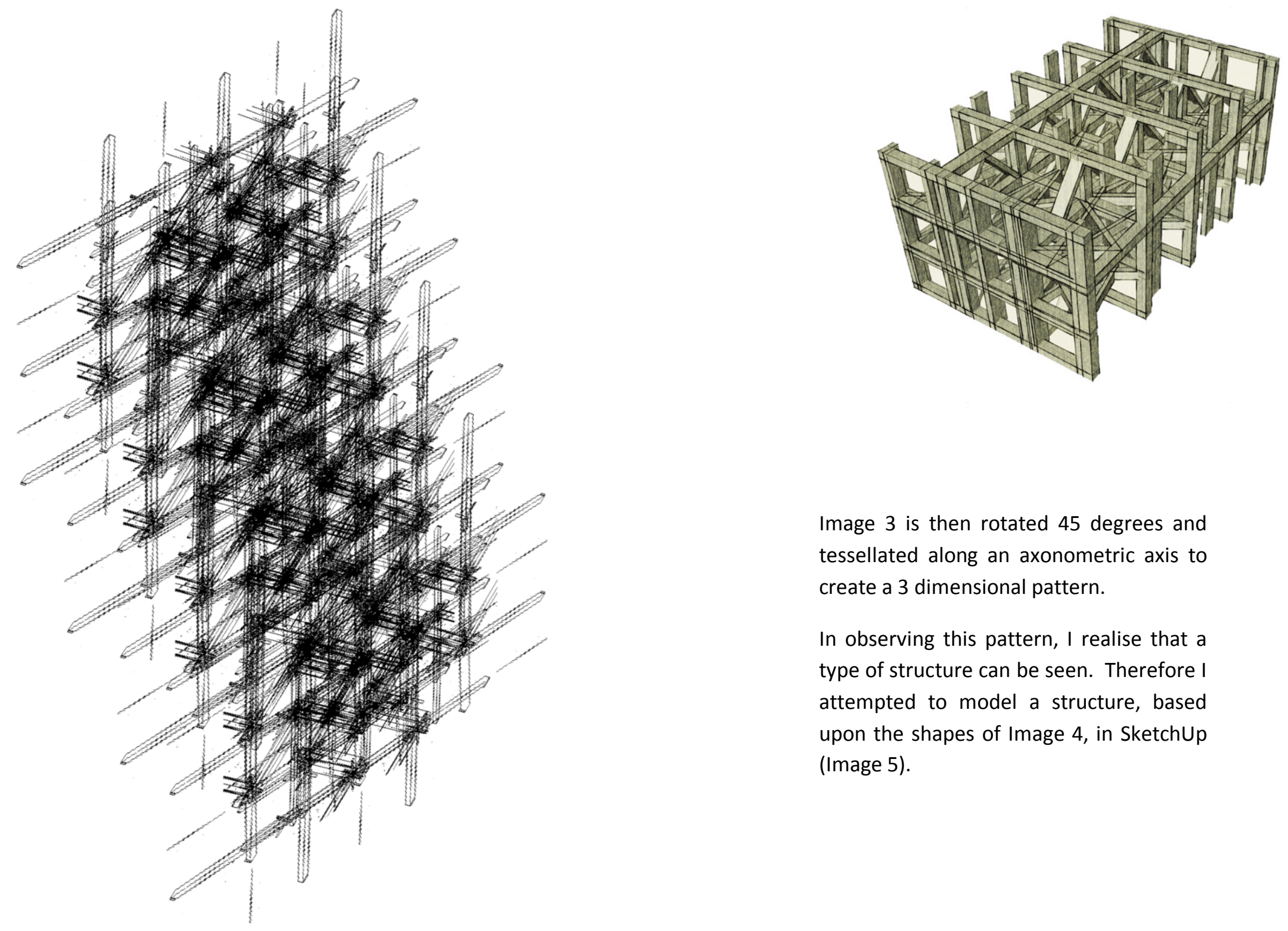

Image 3 is then rotated 45 degrees and tessellated along an axonometric axis to create a 3 dimensional pattern.

In observing this pattern, I realise that a type of structure can be seen. Therefore I attempted to model a structure, based upon the shapes of Image 4, in SketchUp (Image 5). 


\section{Fire of Power}

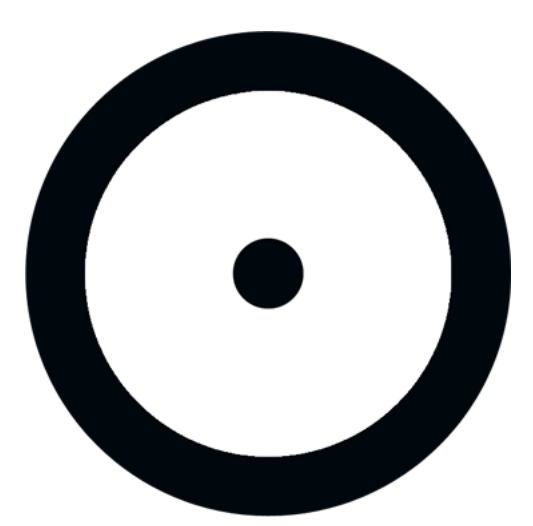

Image 1

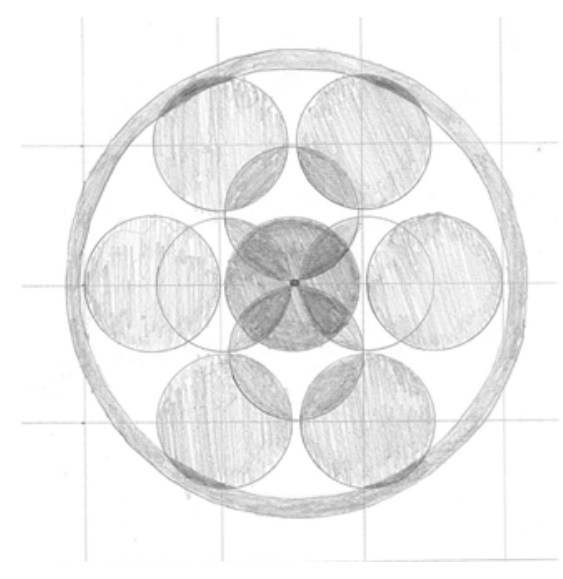

Image 2

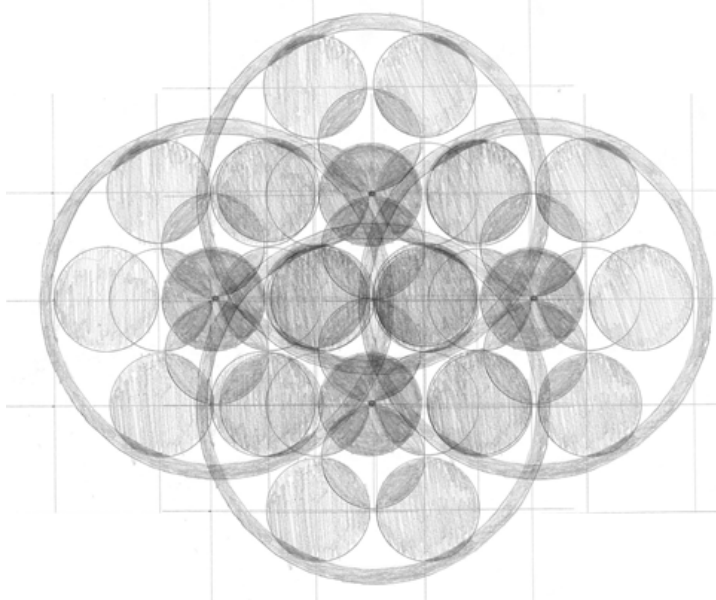

Image 3

Again, the influence of Alchemy is used for this set of experiments. The Alchemy symbol of power is a circle with a dot within its centre.

In a similar method of tessellating, rotating and super imposing, the symbol is layered into a more complex form that implies the existence of 3 dimensional spaces. 


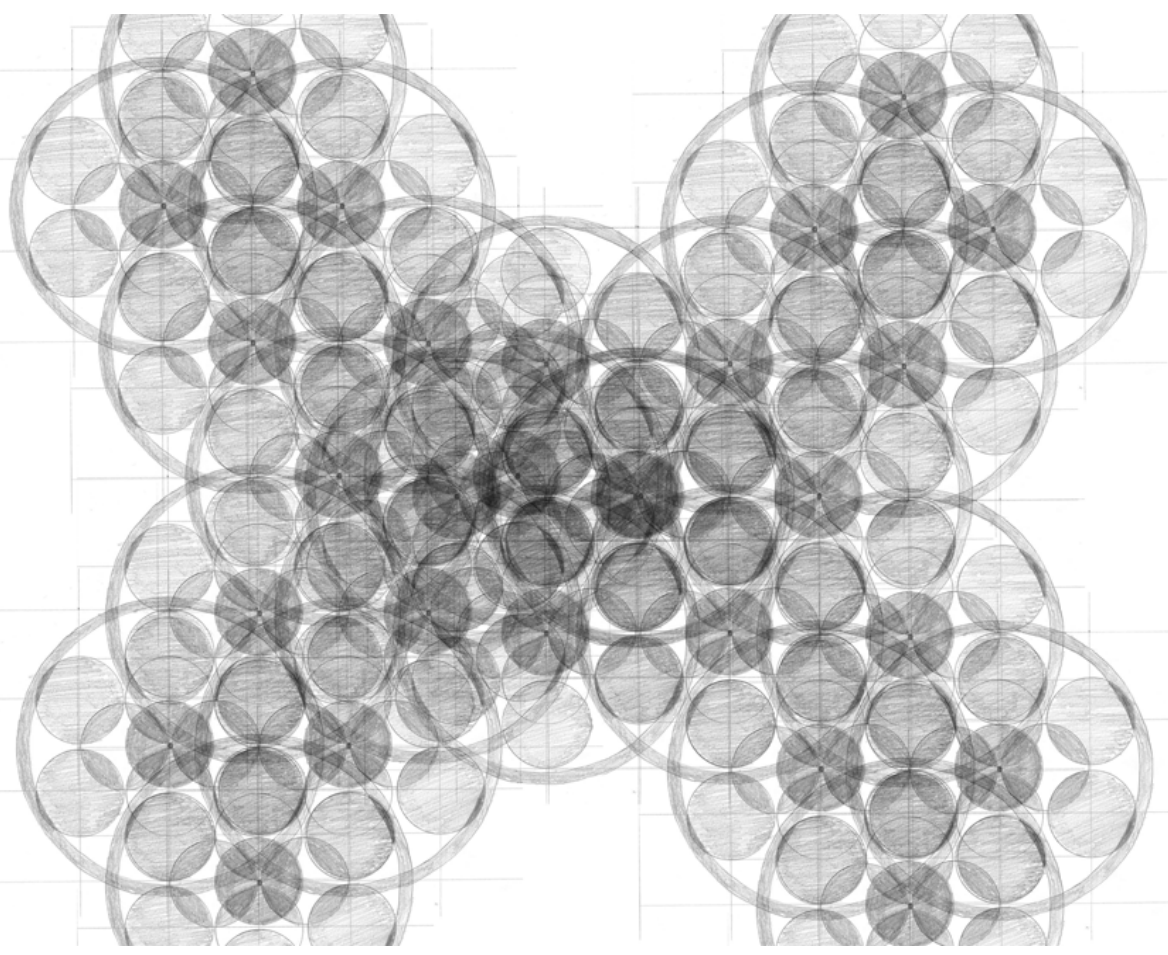

Image 4

Image 5 is created by rotating Image 4 by 90 degrees and layering the two images. Using Photoshop, the image is then inverted thus making the dark strokes light, and the light strokes dark. From this a new type of image with strong compositional lines appeared.

The central Image of Image 5 is taken and divided into half. Then the 'half triangle' form is rotated around the perimeter of the original image. This is a way to represent the way fire creates a circular threshold around the perimeter of its centre.
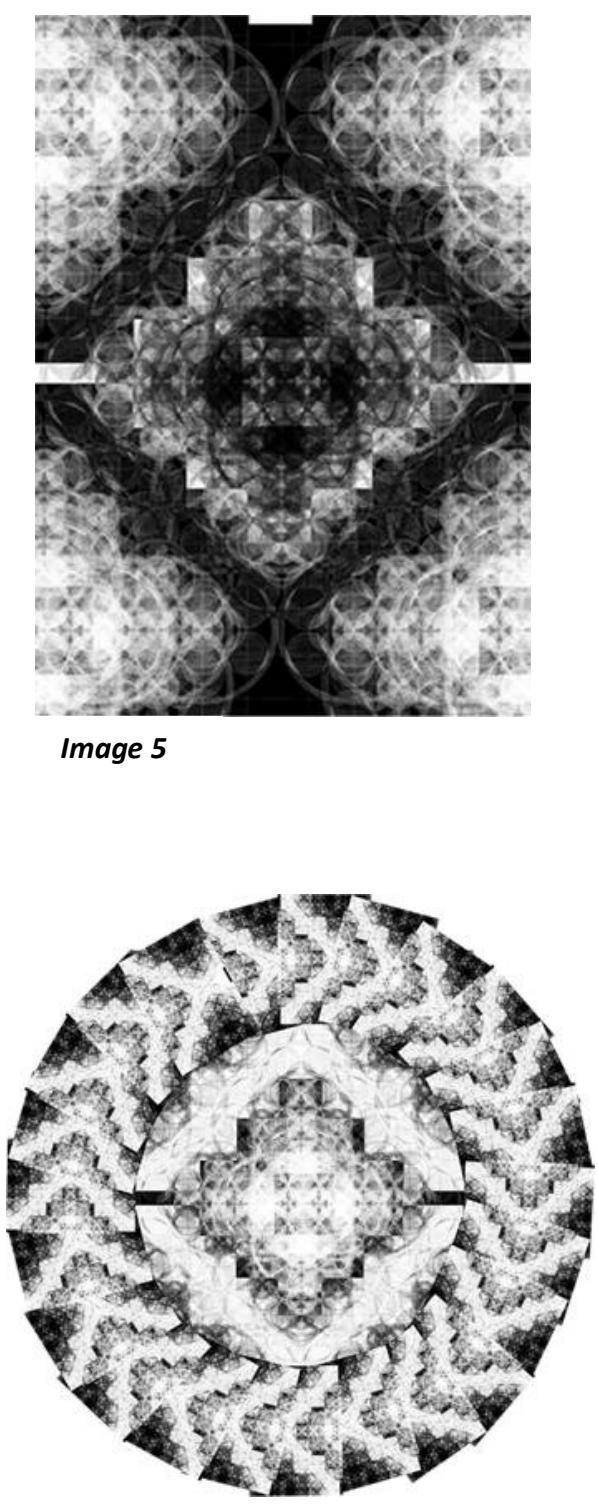

Image 6 


\section{Design: Mt Victoria Crematorium, Wellington}

Within the design influences from semiotics as well as the five case studies have been taken and applied. Fujimori and Venturi's use of fire as a symbol of a gathering point where contemplation and reflection is present in the way people remember the life of the loved one during the service prior and during cremation. Crematoriums simply provide the setting for a ritual, like that of a tea house, and gather a community thus tapping into the primal need of security in numbers.

Fire's dialectical symbol of life and death is the main reason the programme of crematorium is chosen. Death is believed to be a type of rebirth, a renewal of life itself. Therefore as it ends, a continued line begins. The circular plan is done so to reflect the idea of cycle. Juxtaposing the horizontal nature of the circular building with the vertical chimney, is a way of furthering the idea of dialectics just as Zumthor's chapel dies in order to be born. This duality is also addressed in the way the triangles are placed against a circular plan orbiting the central pond.

Image on the right: Site plan of proposed crematorium on the town belt of Wellington

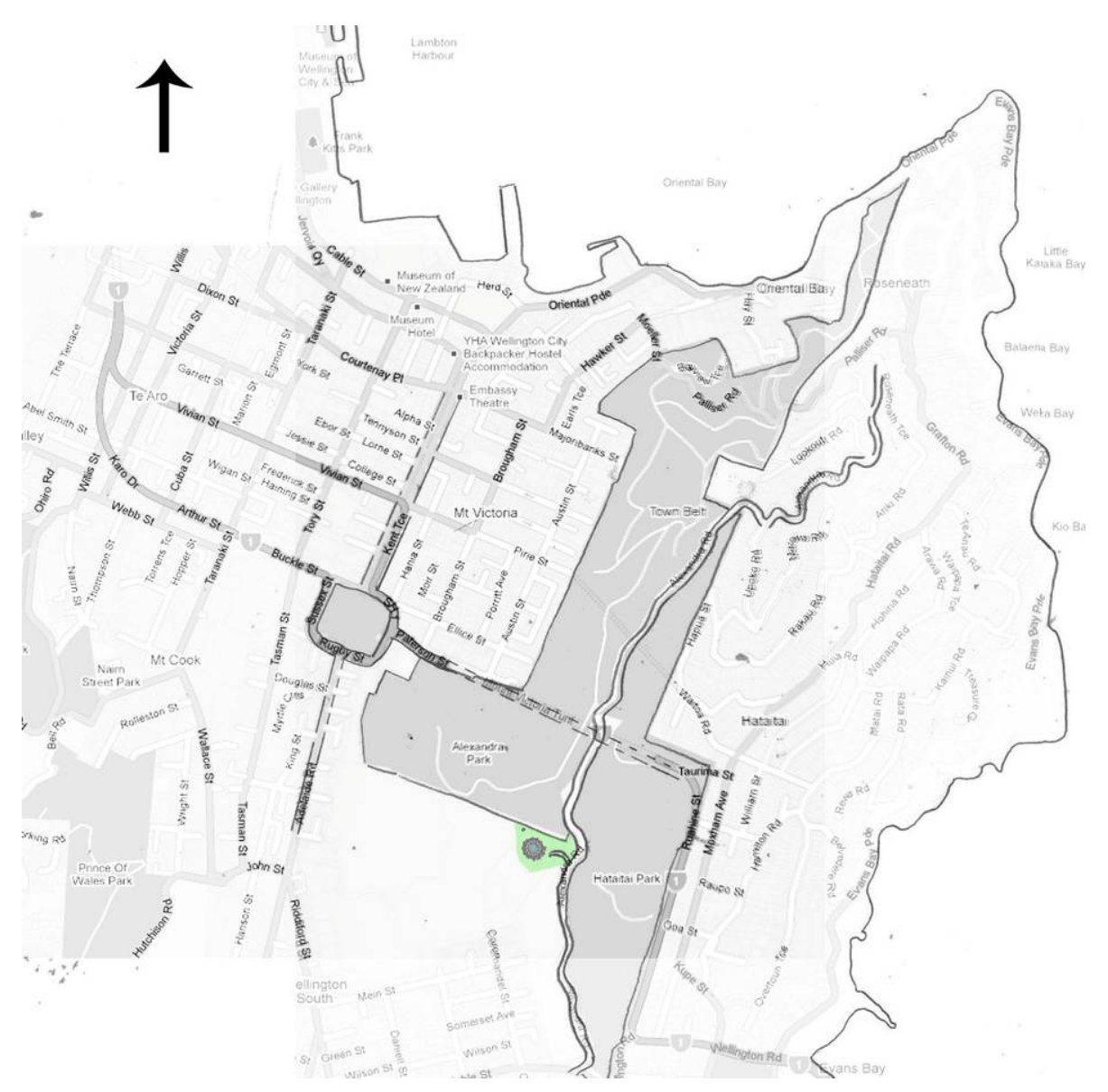


During the drawing experiments, the simple geometric forms are multiplied and imposed upon each other. The abstract images became the basis of the module which the crematorium is based upon. The walls are a series of pyramids, based on the drawings from 'death.' The roof modules are an extrusion of the final image from 'life' repeated around the circular plan. In using the repetition of single images, not only a pattern is formed but a dimension of depth is created with the form of the building.

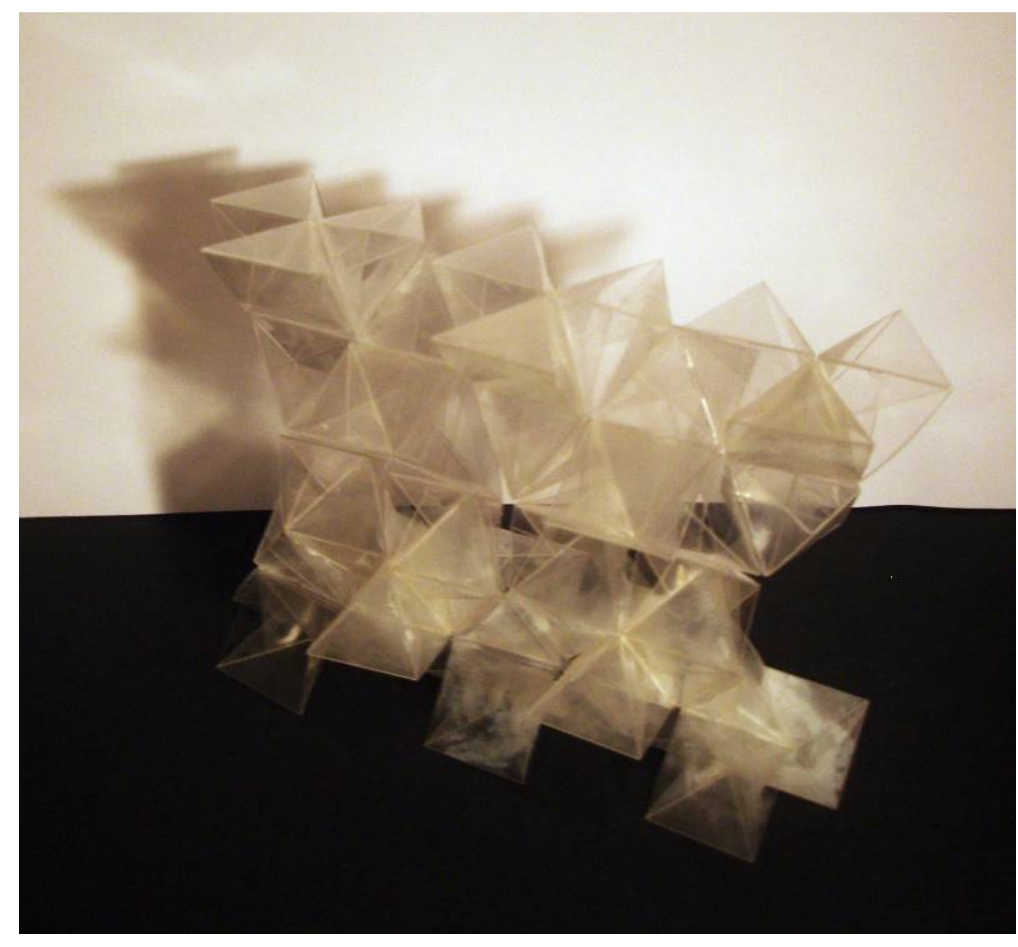

A three dimensional model was made in order to understand the way the modules fit together as a wall unit.

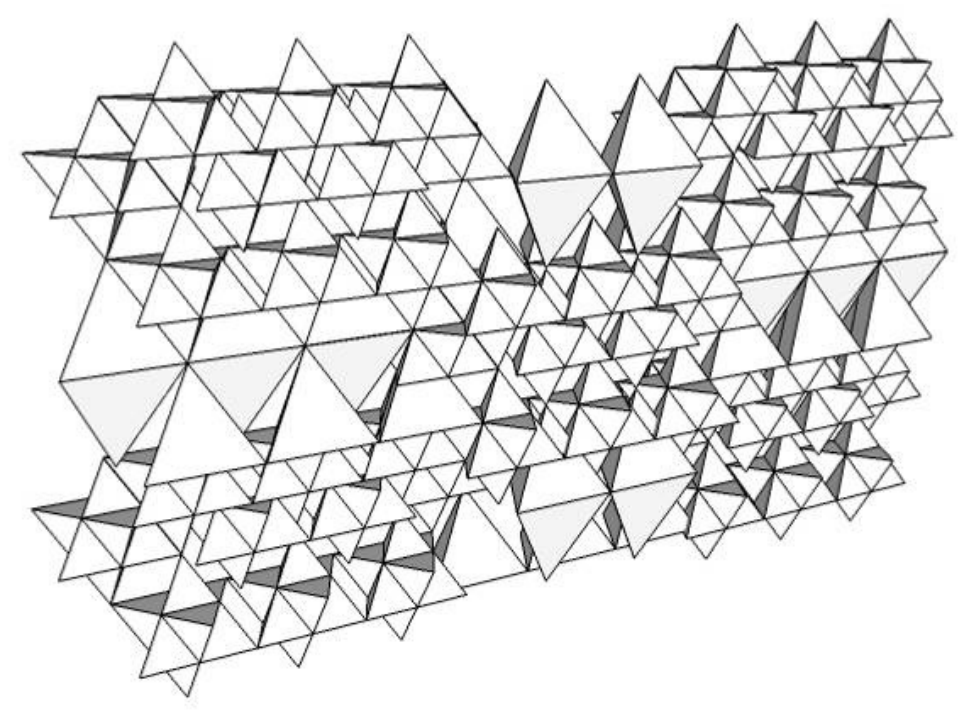

This model is then drawn in SketchUp as a component to be used in the final computer model. 


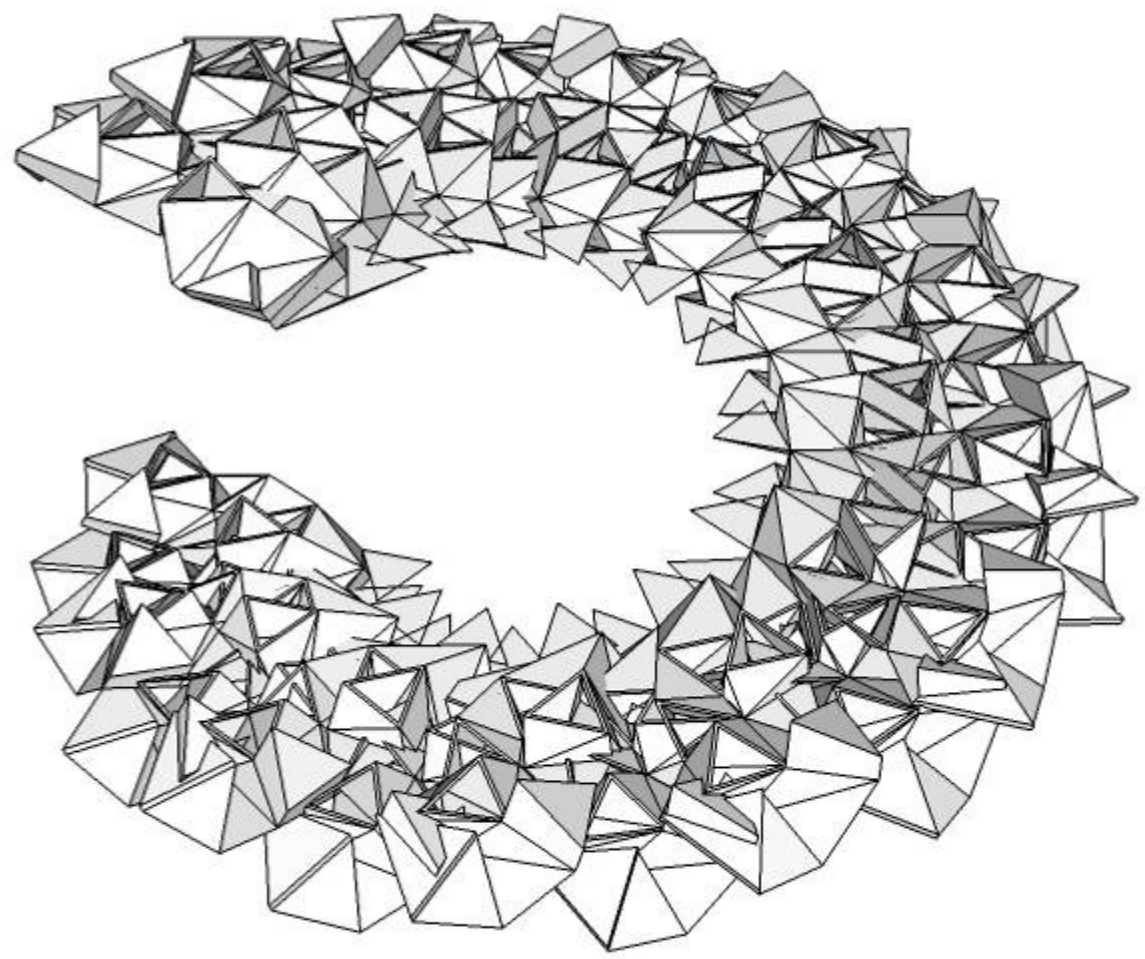

The opposite approach was taken for the roof. The abstract image from 'Fire of Life' is three dimensionalized in SketchUp

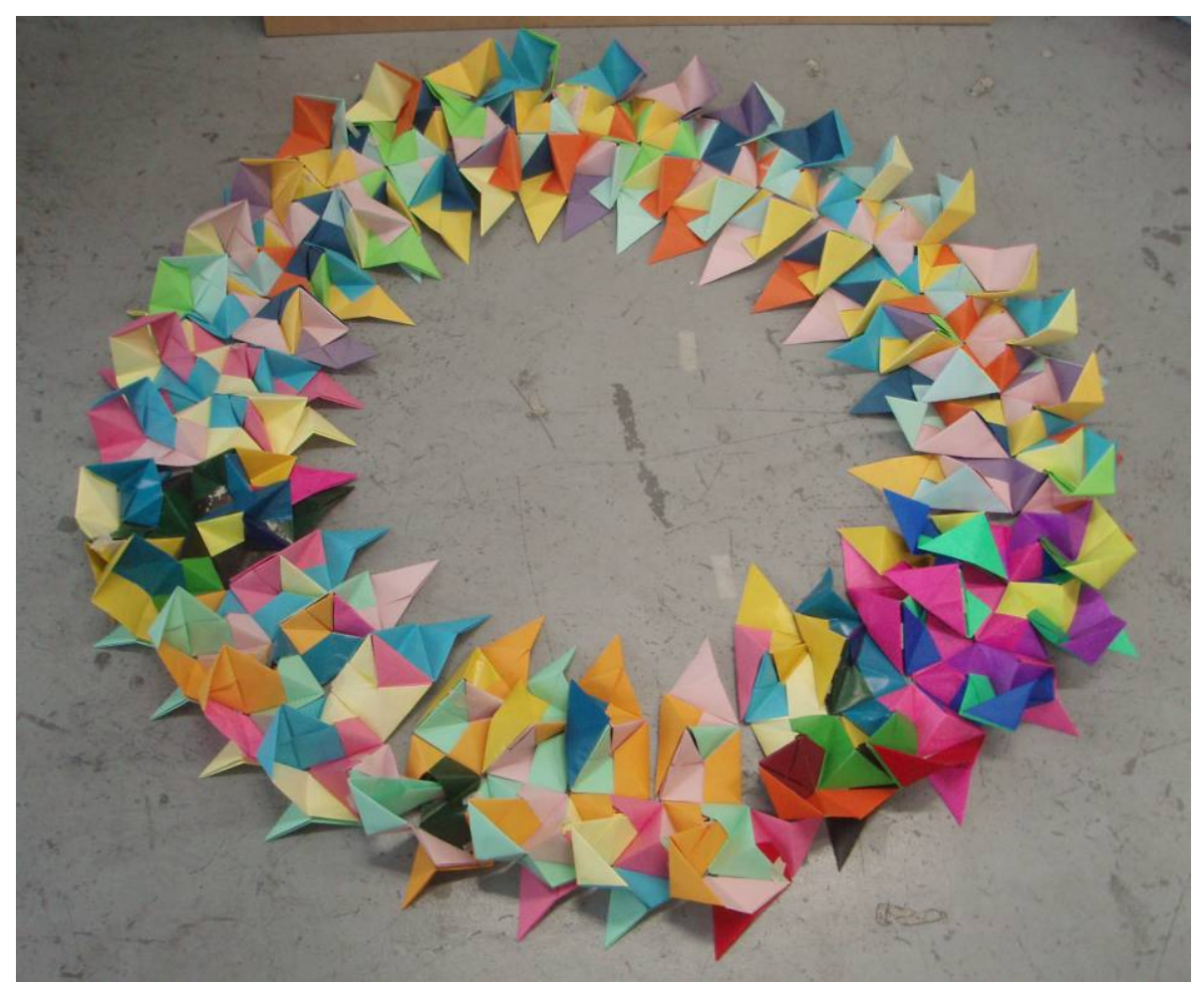

In order to simplify the geometry of the repeated module, a development into origami models using the 'Sonobe Module' is made. 


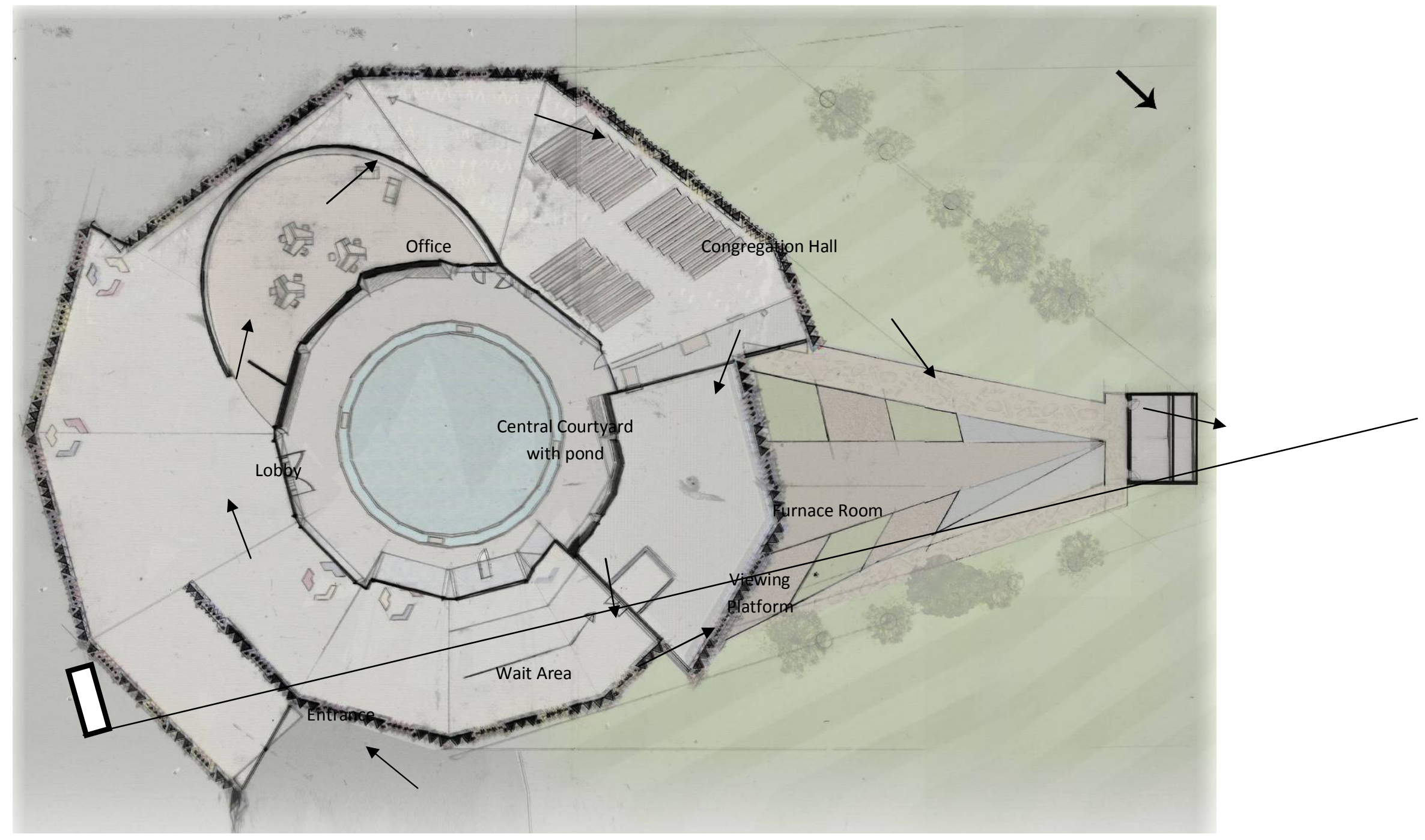

\section{Plan of Crematorium:}

The circular circulation of the building is one way of addressing the cyclical nature of life and death. On arrival, visitors are greeted by a vast lofty lobby. Prior to entering the main ceremony hall, they pass through a small hallway. From the ceremony hall you can exit to the pond in order to go on the viewing platform to view the cremation or step outside and light a fire in the chimney to symbolise the end of the ceremony 


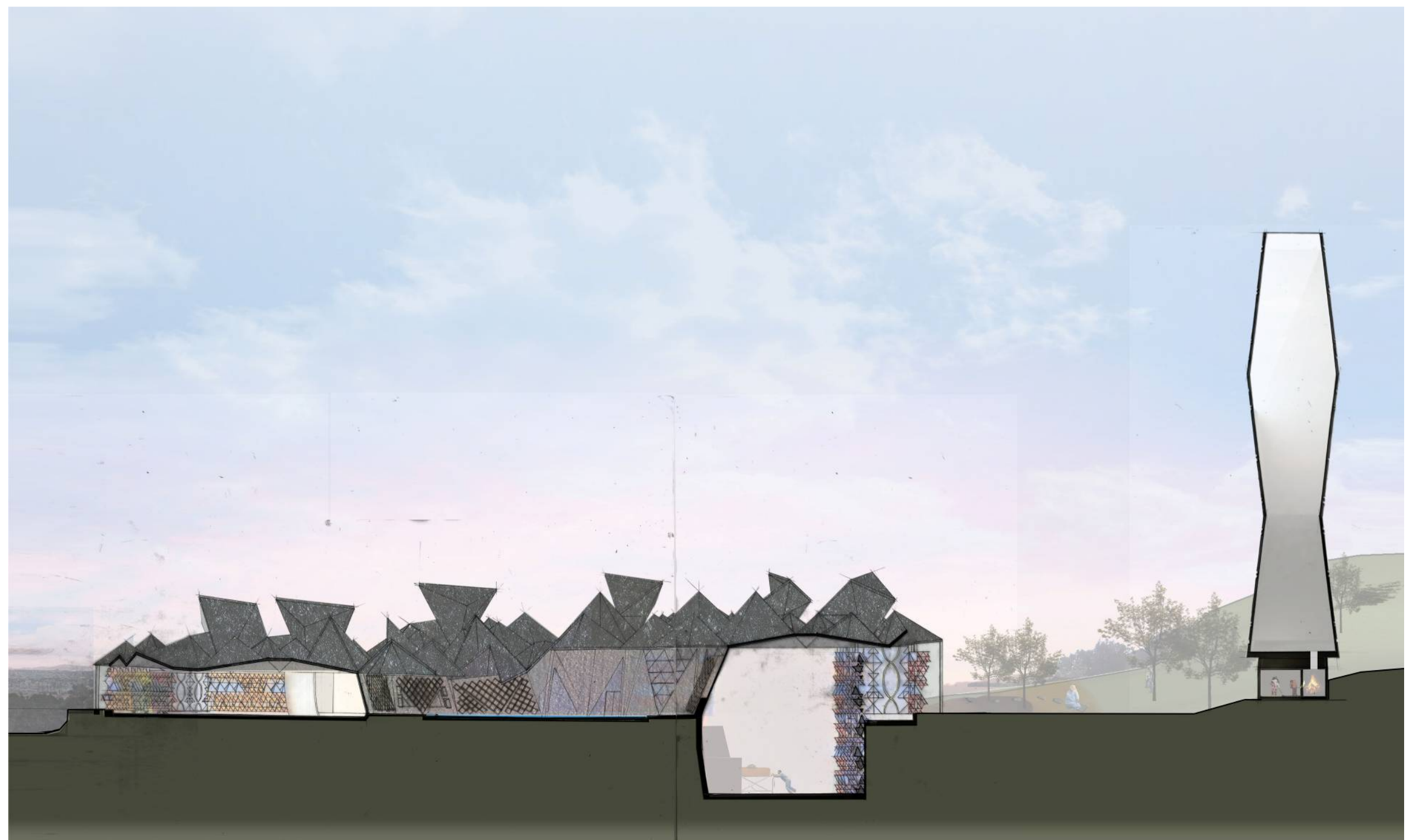

Longitudinal Section of Crematorium:

The dialectical nature of fire is represented in the way the crematorium consists of two dialectical structures, one horizontal the other vertical. The section shows how the furnace room is set into the ground so that those observing can be a part of the process from above the viewing platform without being so close that they find it gruesome. The large chimney adjacent to the crematorium acts a ritual spot where families can light a fire and say goodbye. 


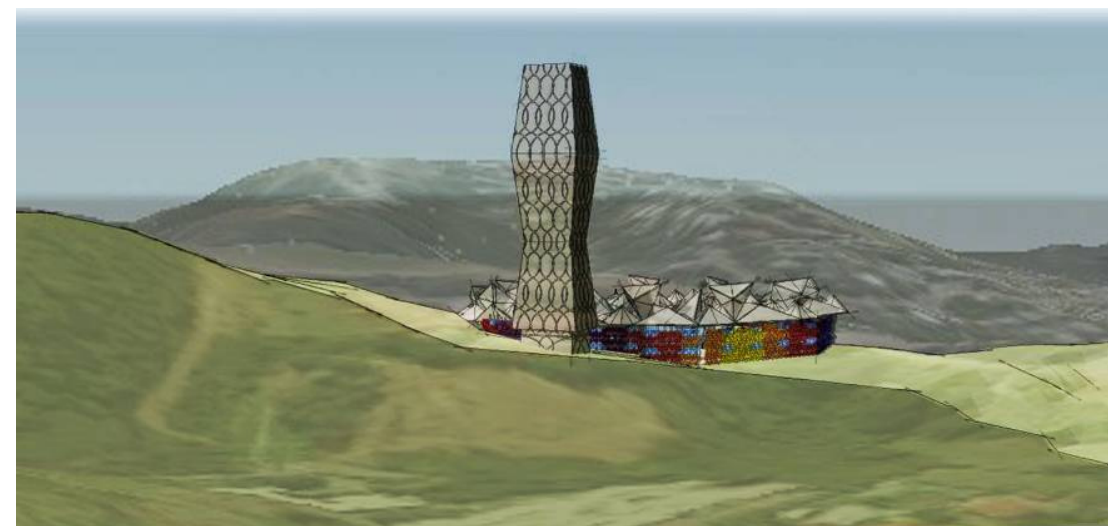

View of the crematorium from the city centre

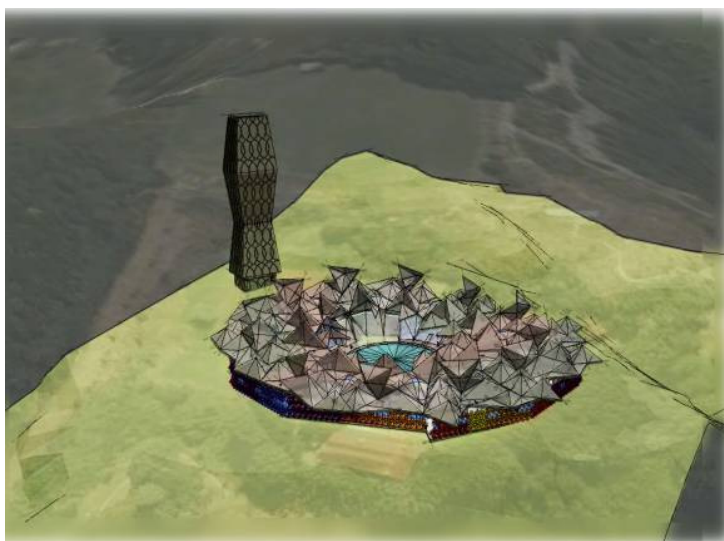

Aerial view of the crematorium

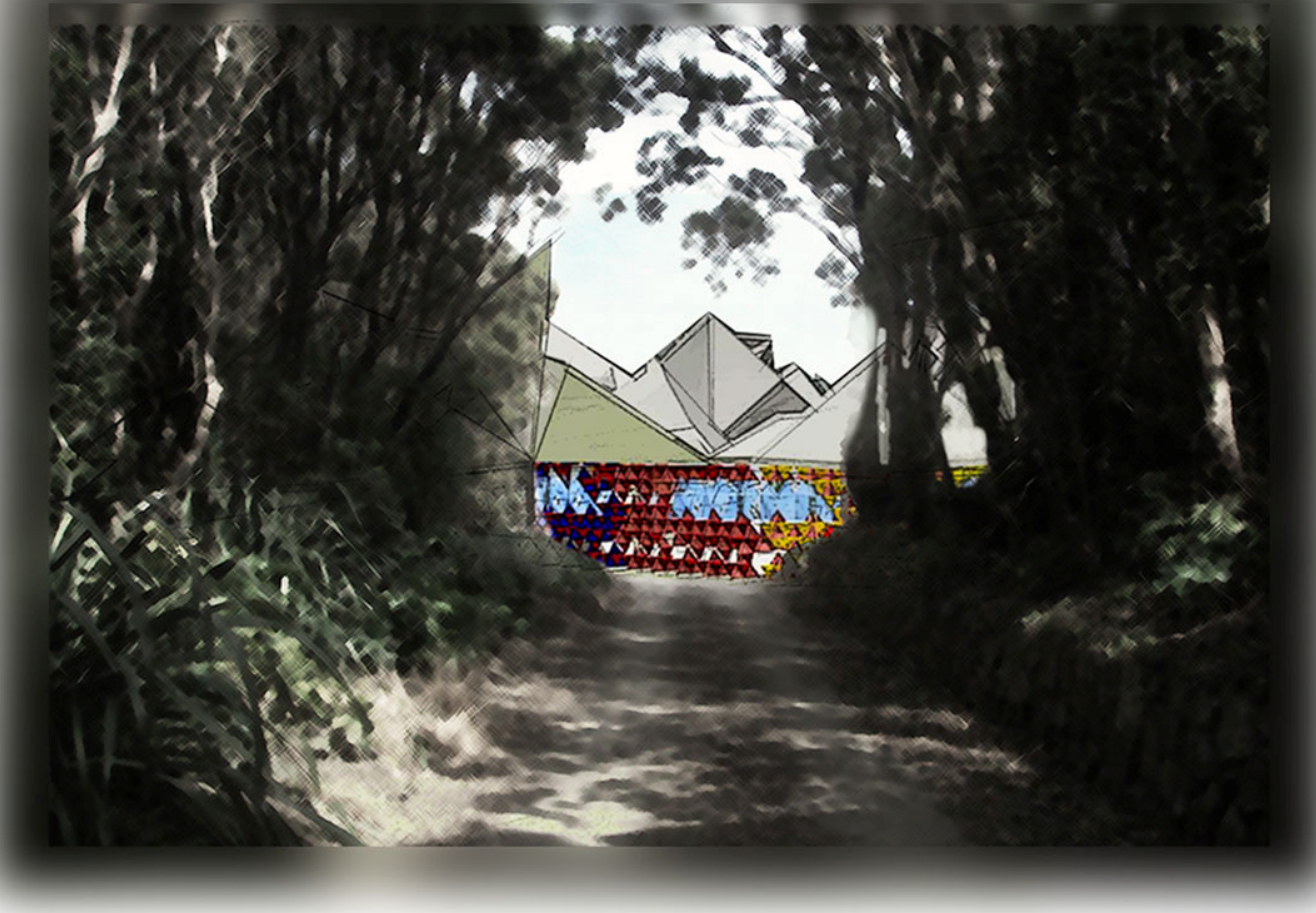

Due to the location of the crematorium deep within the town belt, the intricate architecture is not revealed until you are at its doorstep, when the surrounding trees unveil it 


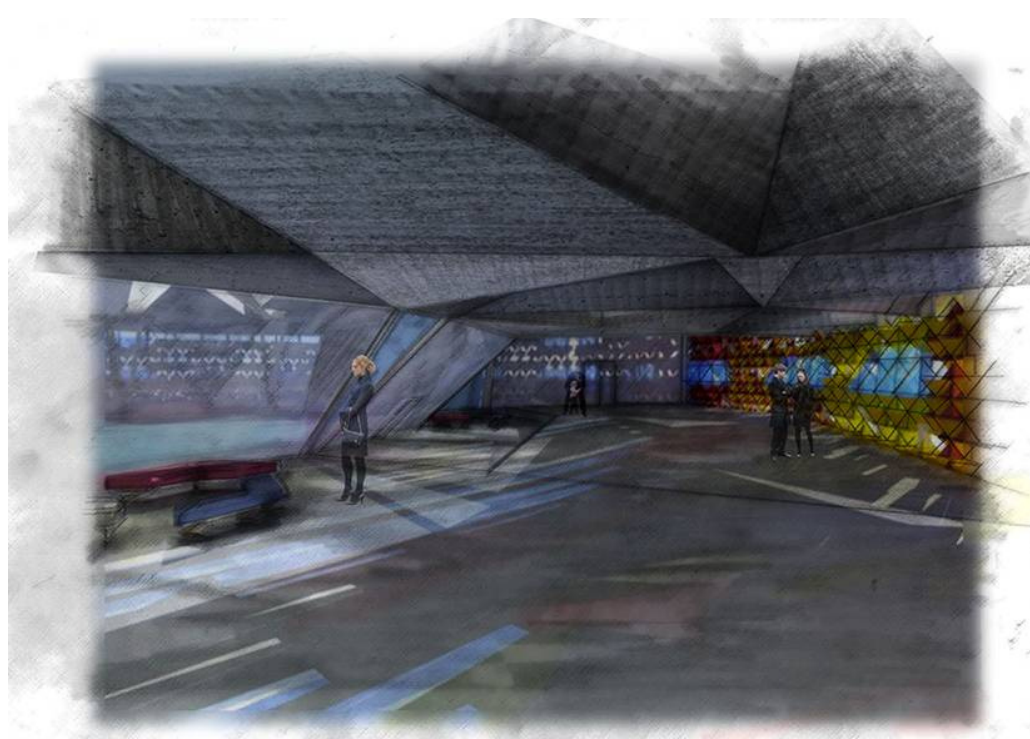

The waiting room overlooks the main pond, and houses the entrance to the viewing platform in case visitors would like to observe the cremation process

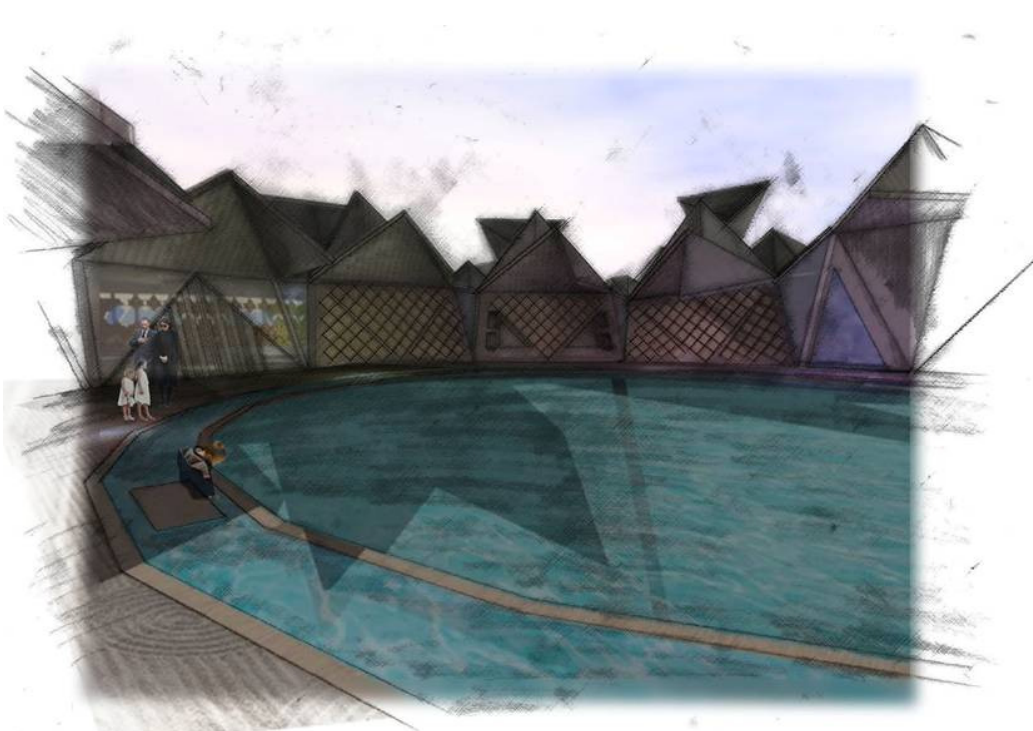

The central pond acts as a focal point and an area of calm and reflection. The space is present to provide a space for pausing. Its sheer size reflects the vastness of life itself.
Joey Goei - Playing with Fire: Analysing the role of Fire in Architecture

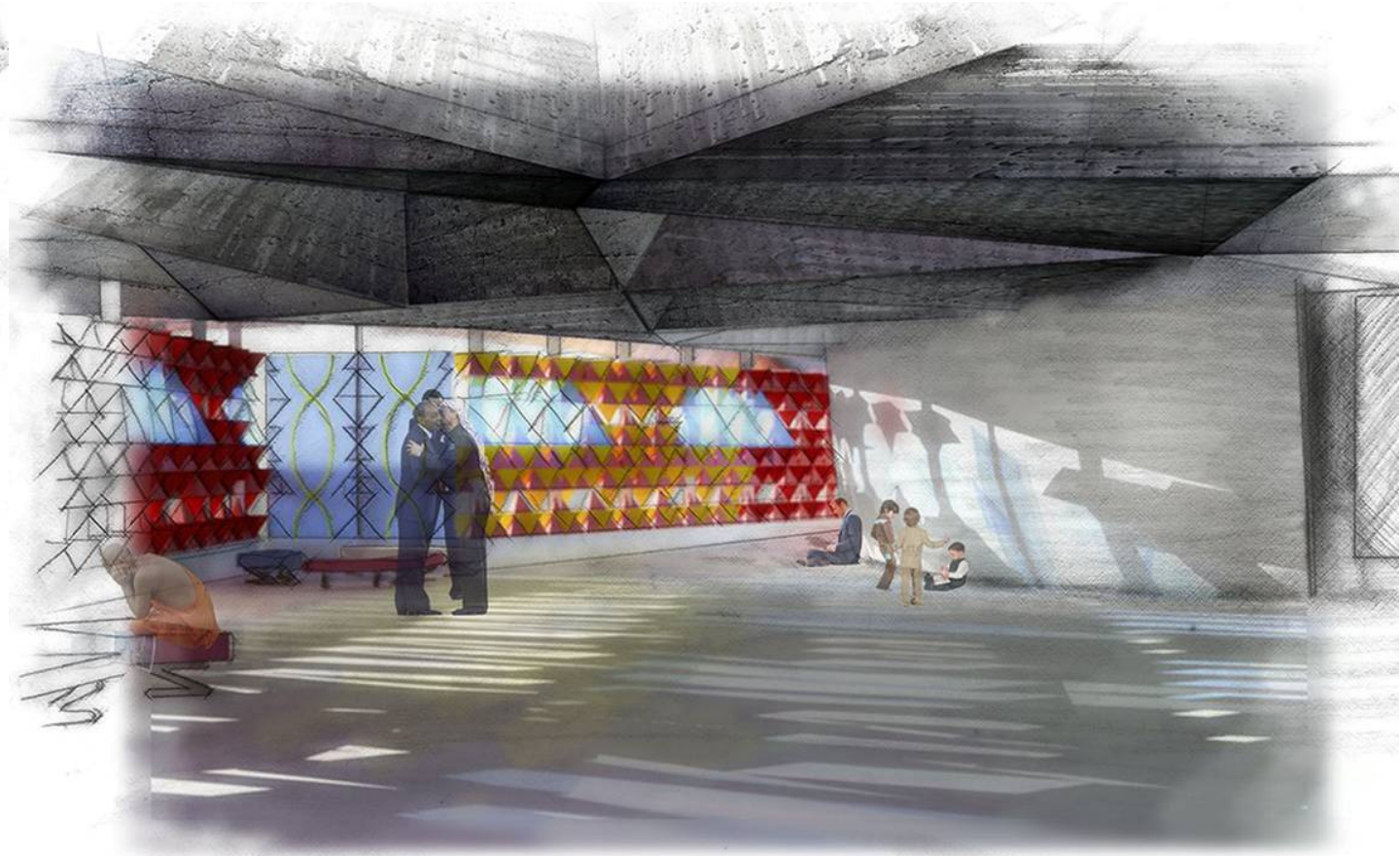

The spacious lobby allows visitors to gather and have time away from the formalities of the main congregation hall. The gem like architectural elements casts shadow on the plain floor and curved interior wall thus luring you to the adjacent congregation hall 


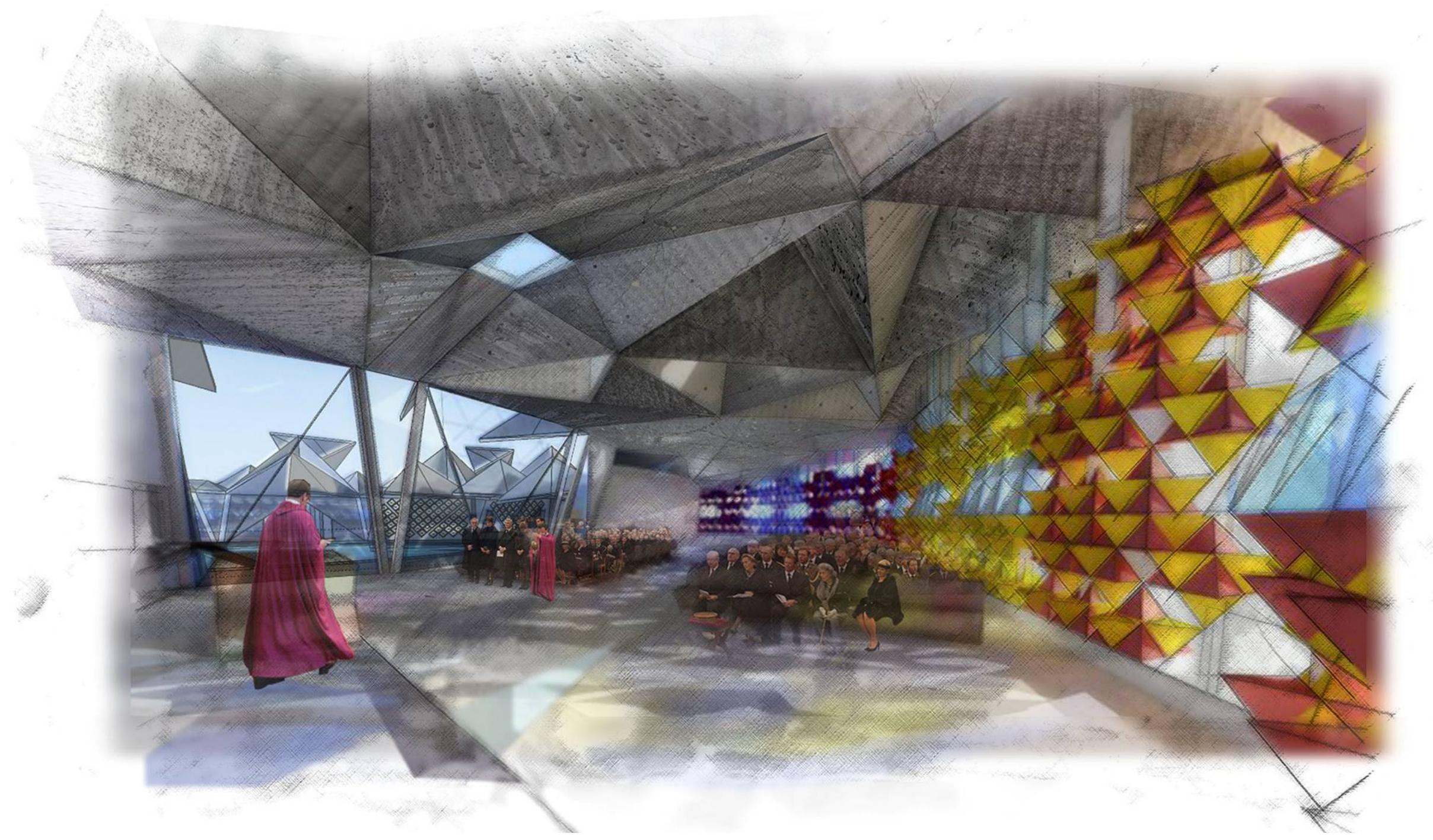

The main congregation hall acts as the climax of the architecture. Its high ceiling and vast space is bathed in light and patterns from the architectural elements. The journey from the safety of the lobby and into the small corridor only highlights the loftiness of the service hall. 


\section{Conclusion}

Fire is one of the most common architectural elements. This research seeks to understand the reason why fire is so important in the relationship between architecture and society. By looking at its use throughout history, and the various meanings people has given the element, we are able to better understand its place in our world. Scientists, anthropologists and philosophers are fascinated by this particular element, due to its complexity and dialectical nature. This is shown in the way Bachelard and many others have studied fire as being an essential part of human life.

Fire's importance in architecture is due to its primal, symbolic and pragmatic functions. However, with the world today focusing mainly on the pragmatics, fire is decreasingly celebrated in architecture. Its importance in society is a sign that we should not simply discard it as architectural elements. There are many primal fulfilments fire provide through architecture that cannot be achieved by modern machines. Therefore an adaptation of fire as an architectural element is searched for so that architecture continually fulfils both our conscious and subconscious selves.

Gaston Bachelard coined the Prometheus Complex, Novalis Complex, and Novalis Complex to explain the way fire allows us to experience the state of reverie, which Bachelard believes is essential in order to become 'whole.' In Bachelard's view society is bound by many 'civilized' rules and restriction thus taking us far from our primal self. Bachelard suggests that fire is the way modern living attempts to touch the primitive. It is proof that "the primitive still lived in the psyche of the modern person." ${ }^{\prime 15}$ His theories on fire and reveries show how fire can often place us in a subconscious realm, one that is primitive, away from the modern world. In other words, Bachelard believes by being in touch with fire we are able to still engage with our primal self. It is important to stay true to our animalistic nature, as it has to do with our overall health. In order to be truly fulfilled, we must accept and embrace our primal subconscious.

\footnotetext{
${ }^{115}$ Chimisso, Christina, pp. 205
} 
Fire's principal ritualistic role in society is not due to its ability to fulfil the needs of people wholly. Not only it is able to fulfil physical needs such as safety and warmth, it fulfils us mentally and spiritually through the way it gathers people and allows us to escape our surrounding through reflection. Its ability to satisfy the pragmatics as well as the poetics is the reason for its constant importance throughout history.

In order to propose a new adaptation of fire in architecture, several case studies were analysed. These cases were contemporary architecture that does not use fire in an obvious manner. The chosen pieces of architecture are the Vanna Venturi House by Robert Venturi, Element House by MOS, Treptow Crematorium by Axel Schultes, Takasugi-an by Terunobu Fujimori and Bruder Klaus Feldkappelle by Peter Zumthor. Although all of these buildings can be considered 'modern,' they all still embrace and celebrate the poetic nature of fire. Fire's connection with community amongst other ideas is highlighted within all five cases. Venturi utilises the fire place as a point of gathering. Although MOS did not literally use fire, they used light shafts in the image of a chimney as the central points of their modular design. The Takasugi-an houses the important Japanese tradition of tea ceremony. In the practice of the ceremony, ideas of acceptance and welcome are represented. Zumthor's design, being a religious building, too automatically allows the gathering of people.

Through the research and case studies, it is apparent that one of fire's primary roles is as a life and death symbol. Fire symbolises life, death, violence and power. Geometric alchemy symbols of these were taken and used for a series of drawings that eventually became the base modules of the proposed crematorium. The chosen proposal of crematorium is due to its linkage with life and death a duality strongly associated with fire. The abstract module created through the drawing experiment is arranged in a variety of ways to further this idea of duality. It resulted in a building with intricate textures juxtaposed against each other in order to replicate the tension that exists within dialectics.

Using fire for civic purposes in architecture is an appropriate step. As fire's role within the home is decreasing, through the historical research and analysis I recommend the move from domestic hearth to a civic hearth. The crematorium is one example where fire in architecture can be utilised for civic purposes. This use of fire in architecture also represents many of its qualities such as 
bringer of life and death, cleansing and passion. Crematoriums in the Western world today mainly serve to provide a space of group reflection for the living. However, I feel that rather than focusing on the loss of a dear one, death is a celebration of life. Many eastern religions such as Hinduism believe that death is not the end but the beginning. Rather than seeing death as an end, it is seen as a renewal or rebirth. The cyclical nature of life is highlighted in both the architecture and meaning of the event. The dialectic of life and death is also closely related to fire as it is seen as a life giving element as well as one that can take life away.

Fire has the ability to bring people together in ritual. In the crematorium proposed, people are able to gather around the fire should they choose to. The universal nature of fire as a symbol leads to the choice of colours. Colours of death from different cultures were taken and applied to decorate the building. Surprisingly the colours that represent death are high-chroma, a character we associate with festivities. In using the colours on the intricate walls, a sense of celebration rather than sadness is achieved.

The intricate architecture is based on a modular pattern. This pattern is based upon alchemy symbols of fire. The simple geometric symbols are repeated and manipulated until it evolved to a complex pattern. From here the same cycle of action is repeated in order to create the architecture of the crematorium. The crystal-like form of the building hidden in the hills makes it an accessible 'hidden gem' located within the city, but without the chaos of the city.

I found the modules to be a great way in utilizing the drawing experiments into the design. However, a further development at detail level is required for a more convincing proposal. Time did not allow for a closer look into scale and presentation of the design. If I was able to do more, I would insert more detail in regards to fire's role as a ritual element within the architecture of the crematorium. Things such as the visitor's connection with fire at the viewing platform should have been highlighted more within the design. Fire when used symbolically in architecture has so many connotations that several layers of treatment should be used. This way the complex nature of fire as an architectural symbol can be further represented especially when today's society prevents fire from being physically present. 
Fire's importance in society should be continued in architecture. Its celebratory and ritualistic functions should be celebrated in architecture just as it has in the past when its purpose was civic. Fire's ability to bring a community together and fulfil our conscious and subconscious needs means it is applicable in many ways outside the home. Crematoriums are just one way of using fire in architecture for civic purposes. The fire within crematoriums allow us to celebrate and honour the life of the dead while to continue our interaction with fire in architecture, we must play with fire. 


\section{Appendix A - History of fireplace:}

"Before men thought of erecting tents, fences or huts, they gathered around an open flame." 116

The role of the fireplace within the home began when people first gathered around an open flame to keep warm. This section will address the evolution of fireplaces from the open fire Semper speaks of to the fireplace we are all acquainted with.

The word fireplace is new in comparison to the use of fire in the home. Historically, fireplaces are called the chimney. The chimney referred "to the complete structure, fireplace and shaft"117 rather than a "structure, usually vertical, containing a passage or flue by which the smoke, gases, etc., of a fire or furnace are carried off and by means of which a draft is created."118 This definition of a chimney as a separate element is a recent development. The chimney as we know it today began to appear during the $12^{\text {th }}$ Century used by the Romans to allow smoke ventilation. Through research and technology, the ventilation shaft used by the Romans developed into the vertical structure we know today.

The concept of a chimney was first formed when fire and hearth were domesticated inside the home. Overtime people began to realise the dangers of breathing in smoke. As fire was essential in heating the home, a system is needed to allow the harmful smoke to get out without losing heat. The Saxons were the first to coin a solution. They simply created an opening on the roof of their shelters above the location of the fire. This way the smoke will rise to the opening. ${ }^{119}$ The Saxons also carefully selected the types of wood used as they realise certain types of wood creates less smoke. ${ }^{120}$ Acknowledging the difficulties of keeping the fire alight in wet weather, the opening is developed into a separate roof placed is higher than the main roof (See image of Medicine House). The gap between the two 'roofs' were filled with set of louvers. McDonald notes that the purpose of the louvers was to "improve the upward draught of the smoke." ${ }^{\prime 21}$ The louver consists of "an often hexagonal opening in the roof, from which a turret was raised, with side outlets for the smoke."122 Today, similar techniques are still used in ventilating barns.

\footnotetext{
${ }^{116}$ Herrmann, Wolfgang, Gottfried Semper: in search of architecture, USA: MIT Press, 1984, pp. 198

${ }_{117}$ McDonald, Roxana, The Fireplace Book, England: Architectural Press Ltd., 1984, pp. 3

${ }^{118}$ http://oxforddictionaries.com/view/entry/m en gb0143820\#m en gb0143820, visited 05 may 2010

119 McDonald, Roxana, pp. 3

${ }^{120}$ McDonald, Roxana, pp.37

${ }^{121}$ Hills, Nicholas, The English Fireplace: its architecture and the working fire, London: Quiller Press Ltd, 1983, pp. 23

${ }^{122}$ McDonald, Roxana, pp. 39
} 


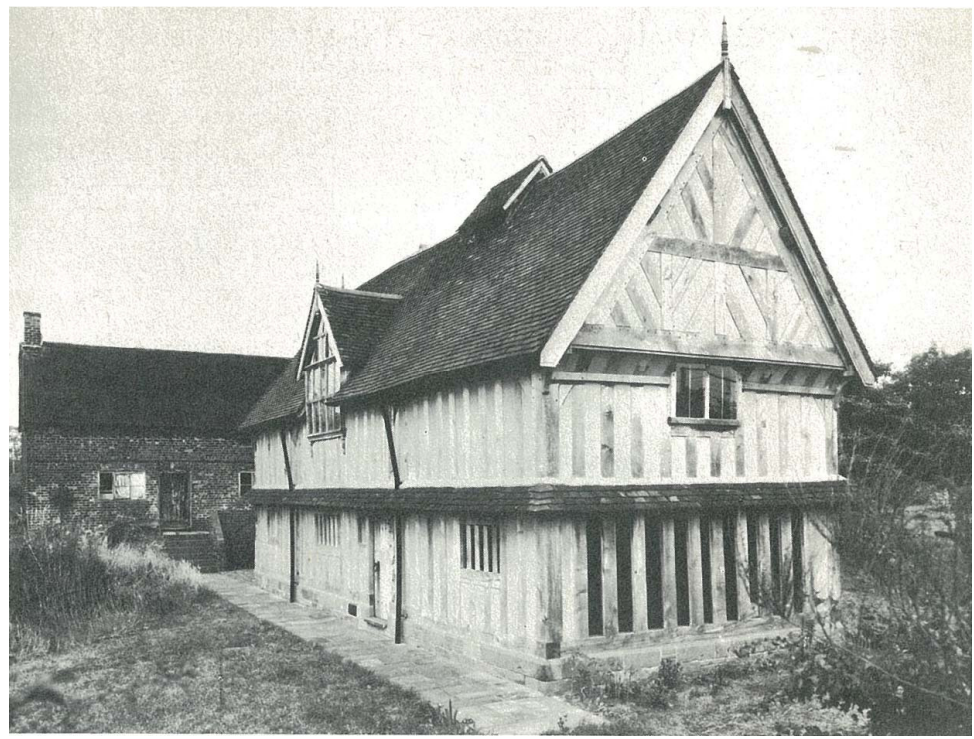

Medicine House 1581 (McDonald, R, pp. 19)

Note the raised section of the roof. This is the louvered system McDonald speaks of.

During the Norman Period ( $11^{\text {th }}$ and $12^{\text {th }}$ century), we see the first move of the hearth from the centre of the home to against the wall. This movement of the hearth first appeared during the middle ages. In medieval hall houses, there was evidence of the first attempt to control the drift of smoke. A type of smoke canopy, referred to as "smoke bay", directs the smoke flow towards the louvers. ${ }^{123}$ This was the first time the hearth, fire and chimney as a whole became a fully integrated elements of a building. This move is due to the Normans' understanding of the flue and stack system. ${ }^{124}$ They discovered that by creating a tunnel like path for the smoke within the wall, they were able to channel the smoke from one or multiple fires and exit it above the house. The Norman chimney was a cylindrical, "open-at-the-top chimney." 125 Despite of its advantages in channelling the smoke out, it is difficult to keep the rain out, therefore the two concepts were combined and chimneys with vertical openings were used in the $13^{\text {th }}$ century.

\footnotetext{
${ }^{123}$ Hills, Nicholas, pp. 23

${ }^{124}$ McDonald, Roxana, pp. 39

${ }^{125}$ McDonald Roxana, pp. 41
} 

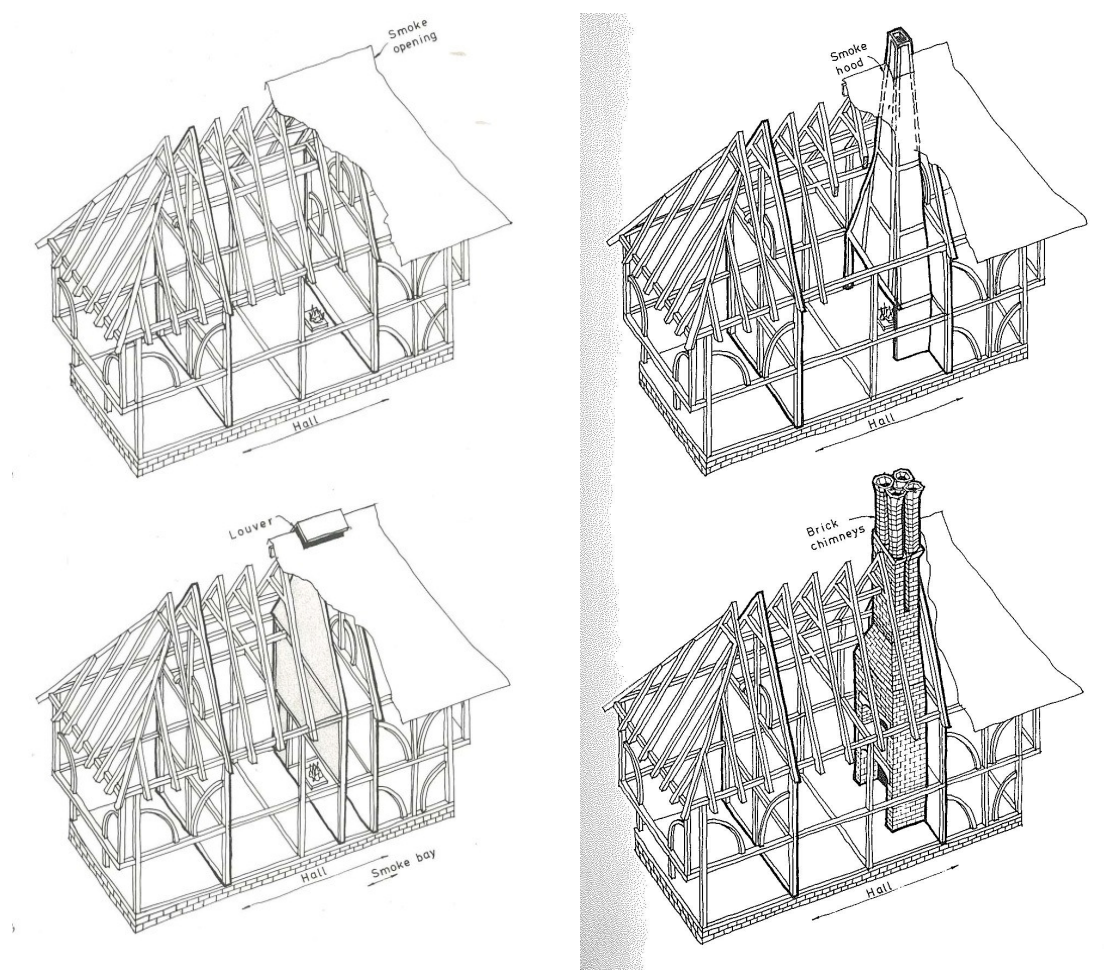

Transition to Masonry Chimney (McDonald, R, pp 14-15)

Often, instead of multiple fires, houses utilise inglenooks. Inglenooks are a kind of inset built into a large fireplace that allows people to sit inside the fireplace. This development is also used to transfer warm air to the floors above. For example a $16^{\text {th }}$ century farmhouse, Pendean Farmhouse, has two back to back inglenooks that when in use, would radiate warmth to bedrooms on the first floor. Should a main bedroom also have a smaller fireplace, another flue exists to "conduct warm air from the back of the inglenooks to circulate in the upper part of the house." ${ }^{126}$ This is the first sign of warm air being transported around the house inside the walls. This development was taken from the Romans, who realized that in smaller rooms, the chimney is

\footnotetext{
${ }^{126}$ Hills, Nicholas, pp. 30
} 
insufficient to take away the soot and smoke as more control is needed. Instead the Romans had "127 hot air ducts under the floor fed by an outside furnace." We can see how even today, similar philosophies are taken in the setting up of our modern heating systems.

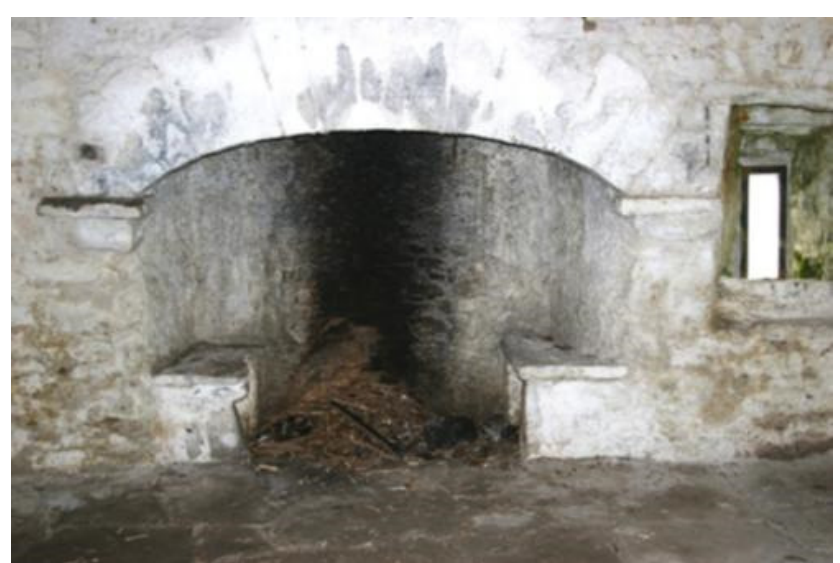

Image of an Inglenook

(Cawley, Frank, 'Granuaile', http://www.castlebar.ie/news/article 2308.shtml)

Chimneys as an architectural element became especially prominent during the industrial revolution. The use of coal on open fires meant that unburnt carbon particles were carried in the smoke. ${ }^{128}$ Being the only heating system of buildings, the chimney became a part of the townscape, spouting out from every building. In 1799 Count Rumford, published an essay 'Upon Fireplaces,' which focuses in preventing "the greatest of all plagues, a smoky fire," proving dark smoke is a sign of unburnt fuel, therefore a waste of resource. ${ }^{129}$ He then allegedly discovered the optimum design for fireplaces. At the same time, continuous developments based on Rumford's findings were made in order to improve the method of smoke disposal. It is discovered that if cold air

\footnotetext{
${ }^{127}$ Hills, Nicholas, pp. 92

${ }^{128}$ Hills, Nicholas, pp. 92

${ }^{129}$ Hills, Nicholas, pp. 94
} 
was introduced into the room, the smoke from open fire will be driven up the chimney more efficiently. ${ }^{130}$ Besides the obvious option of opening windows and doors, inventions such as air supply valves below the fireplace and other air inlets were introduced.

In terms of imagery, the smoking chimney is a sign of life. In literature and films, the smoking chimney is often the first sign of life for those who are lost. As a result, there is a sense of security when we see a smoking chimney. The image of the warm fireplace and the togetherness of the hearth automatically come into mind and all of the associations and feelings inherent within us arise. Just like the fire and the hearth, the chimney was originally a pragmatic solution. However, due to its long presence in our history, associations with other ideas occur. In other words, the chimney has become as iconographic as the fire and hearth.

With the development of the fireplace throughout time, the mantelpiece has gained a prominent position. Being a point of gathering where families shared stories, the mantelpiece also speaks of the owner's history. Its decoration is often adorned with ornaments that speak of the period it was constructed in. On it and above it will be trinkets and other mementoes that reflect the family's values and history. As it adorns important items and messages, the mantelpiece became the more decorated part of the fireplace. Its ornamentation not only highlights the items it holds but also makes the existence of the fire grander. The following diagrams show the way the mantelpiece change according to its period's fashion. Each style of mantelpiece reflects a particular place and time.

\footnotetext{
${ }^{130}$ McDonald, Roxana, pp. 43
} 


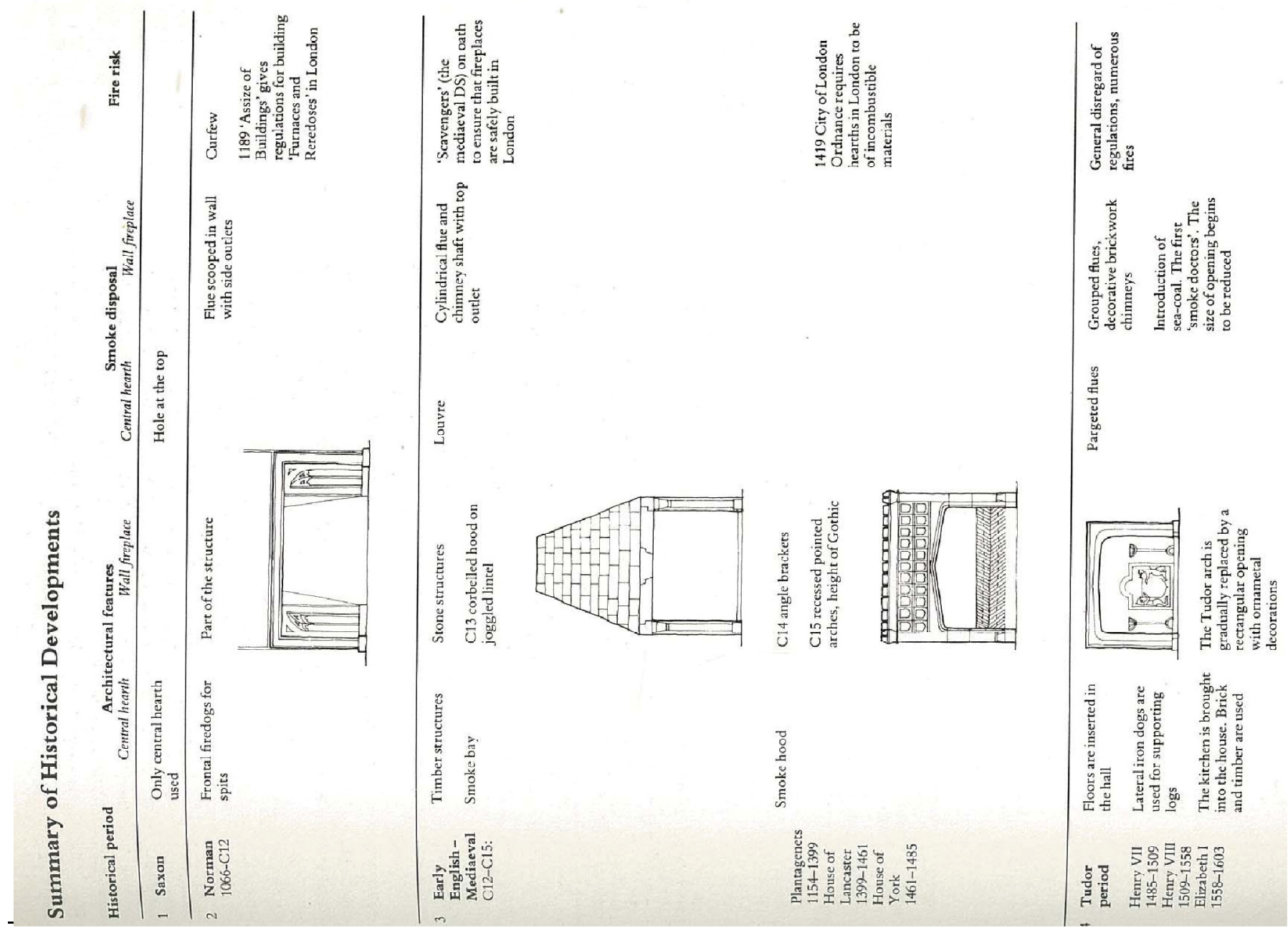

${ }^{131}$ The images above and following are taken from McDonald, Roxana, The Fireplace Book, England: Architectural Press Ltd., 1984, pp. 55-58 

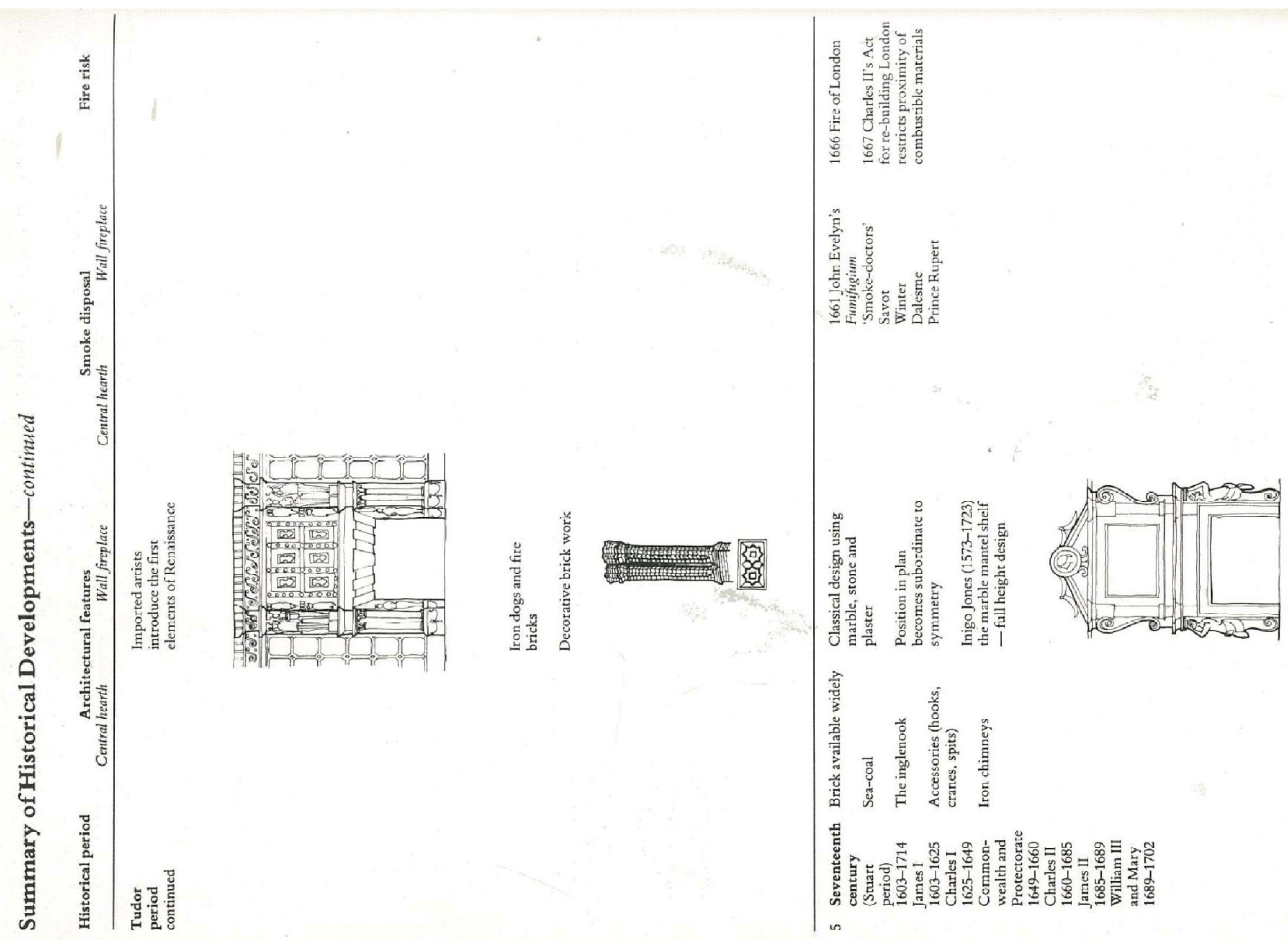


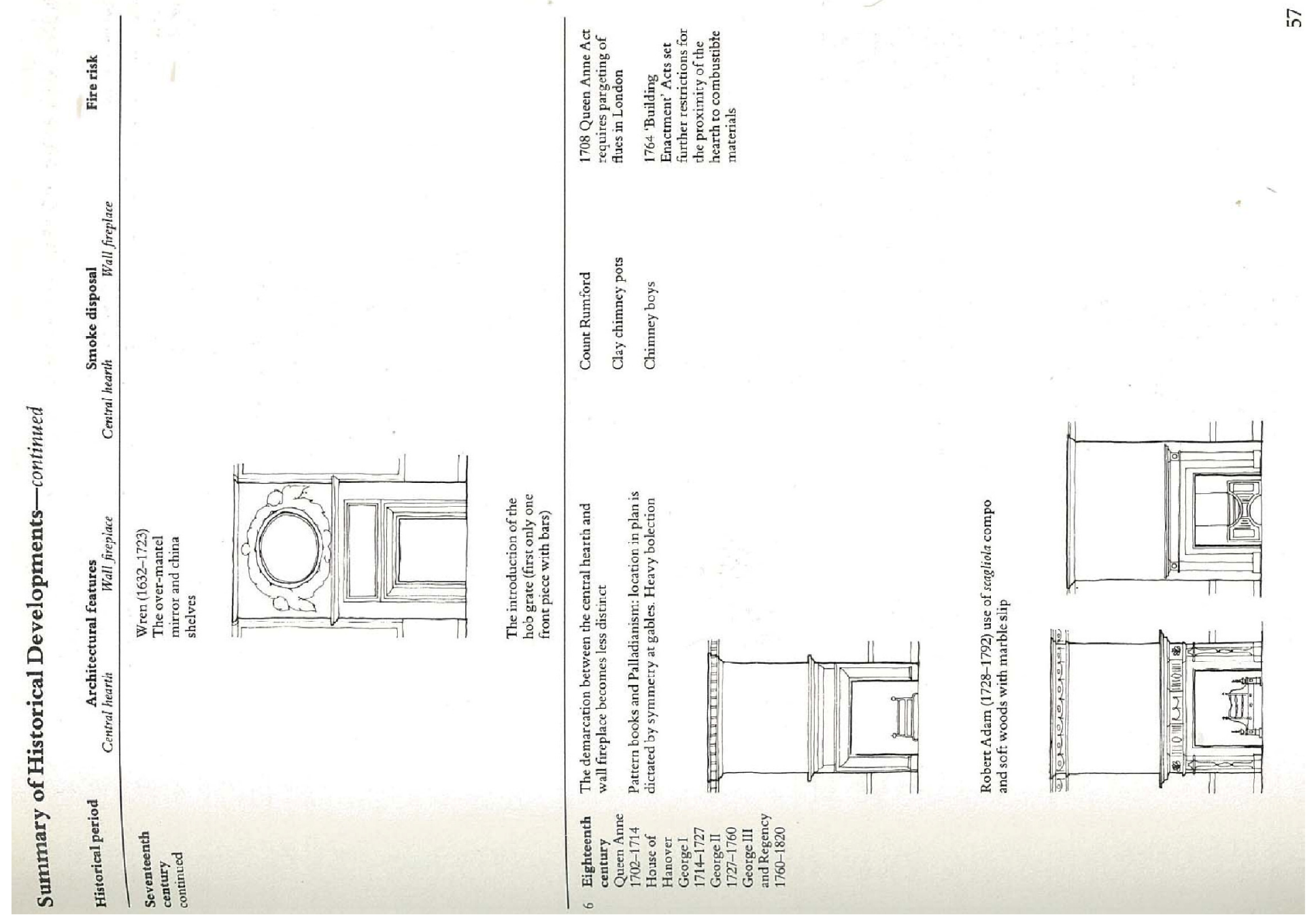




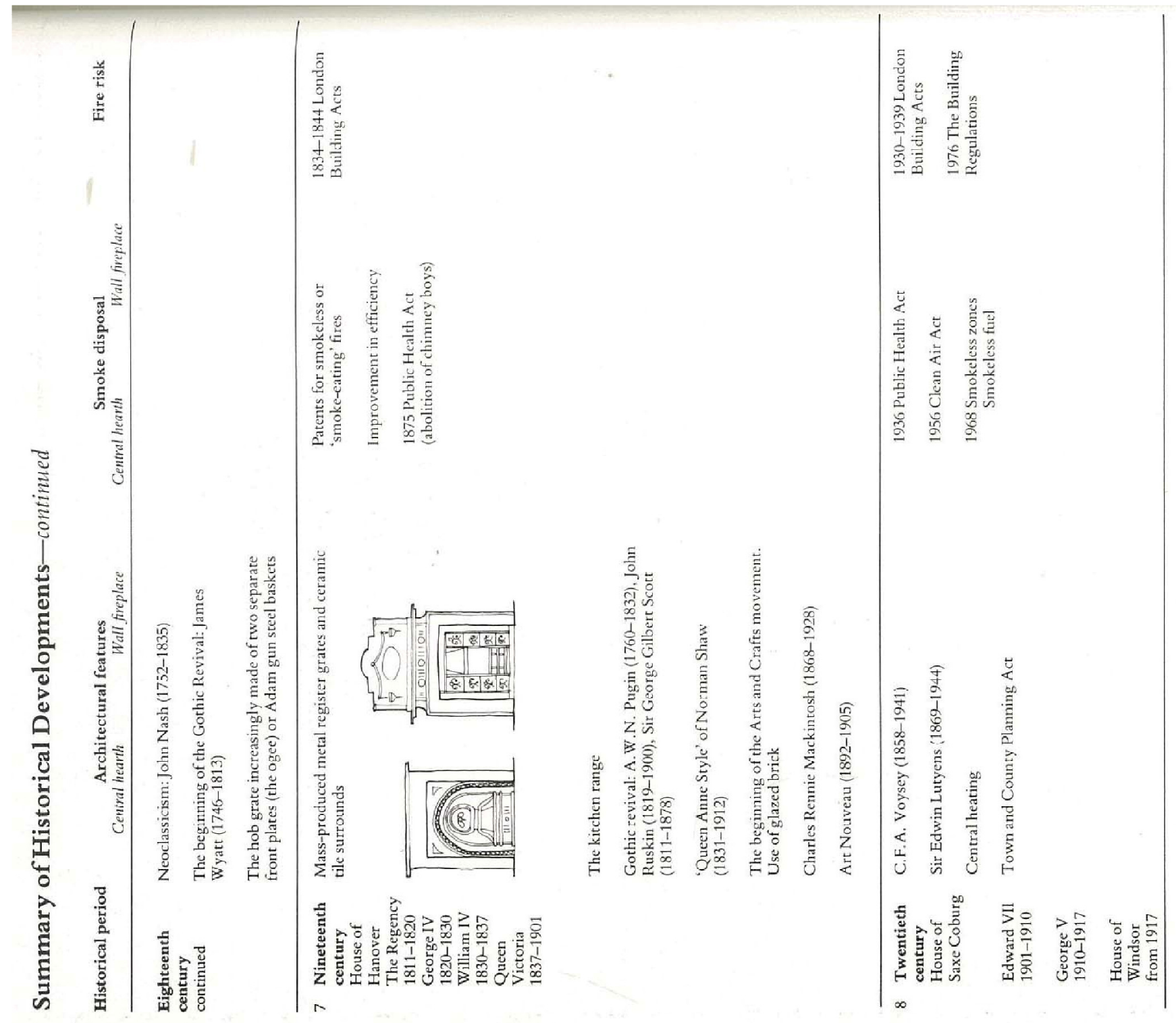




\section{Summary of History:}

\section{- Antiquity:}

Ancient fire pits were positioned in the middle of the room. This allowed for maximum radiation inside space and enabled the maximum number of people to gather around it.

\section{- Medieval:}

When two-storey buildings became common the fireplace was moved into the outside wall, so that outlets can be made on the second floor. This way heat is transferred via the chimney upwards.

- 1678:

Prince Rupert designs a grate for the firewood to rest on. The grate raised the firewood up so that air could get in from underneath and fuel it.

- 1700s:

Benjamin Franklin invented the Franklin stove. Here the hearth is moved back to the centre of the room so that the iron case can radiate heat to all directions.

- 1796:

Count Rumsford published the his first of two papers describing his new fireplace design. The tall, shallow fireboxes reflected heat more efficiently, and the streamlined throats proved excellent at drawing the smoke up and out. This combination-less depth and a decreased risk of chimney fire-allowed the chimney to be incorporated into the wall of the home rather than attached to the outside. This design lasted with adaptations through the 19th century.

- 1950s:

"Ranch houses" and central heating made the fireplace a decoration rather than a heating and cooking device.

- 1970s:

Cost averse homeowners started purchasing cheaper, prefabricated fireplaces.

- 1980s to present:

Environmentally conscious society began seeking wood burning stoves, pellet appliances, and other ways to get the most heat for the least money with the least pollution.

\footnotetext{
${ }^{132}$ Fireplaces Magazine 2005, http://www.fireplacesmagazine.com/fireplace-buyers-guide/history-of-fireplaces.html, visited 7 May 2010
} 


\section{Bibliography}

"myth", Oxford Dictionaries, April 2010, Oxford University Press, visited 1 November 2010

<http://english.oxforddictionaries.com/view/entry/m_en_gb0545790>.

Bachelard, Gaston, Poetics of Space, Boston: Beacon Press, 1958

Bachelard, Gaston, The Psychoanalysis of Fire, Boston: Beacon Press, 1964

Barthes, Roland, Mythologies, Canada: HarperCollinsCanada Ltd., 1972

Boerhaave, Herman, Elements of Chemistry, London: printed for J. Wilford, 1732

Bulfinch, Thomas, Bulfinch's Mythology, London: Spring Books, 1964

Buntrock, Dana (Ed.), Materials and Meaning in Contemporary Japanese Architecture Today, New York: Routledge, 2010

Casciani, Stefano, 'Il Santo e l'Architetto = A Saint and an Architect [Bruder-Klaus-Feldkappelle]', Domus 906 (2007), pp. 52-59

Castle, Helen Ed., 'Poetics in Architecture', $A D$ vol. 72 no. 2, Mar 2002

Chimisso, Christina, Gaston Bachelard: critic of science and imagination, New York: Routledge, 2001

Colomina, Beatriz, 'Domesticity At War', Assemblage vol. 16, 1991

Ciroldi S.p.A, 'Fumes purification', Ciroldi - Technology for People and the Environment, http://www.ciroldi.it/en/spa/fumes_purification/, visited 8 September 2010

Crain, Calib, 'The Artistic Animal', Lingua Franca Oct. 2009

Davey, Peter, 'Ritual of Death', Architectural Review 205/1223, January 1999 
Encyclopaedia of Britannica, 'Concepts of Life after Death', http://www.britannica.com/EBchecked/topic/115240/Christianity/67527/Concepts-of-life-afterdeath, visited 29 January 2011

Fernandez-Galiano, Luis, Fire and Memory: On Architecture and Energy, Cambridge: MIT Press, 2000

Frazer, James, the Golden Bough: A Study in Magic and Religion vol. 3, London: Macmillan, 1933-36

Frazer, Sir James G., Myths of the Origin of Fire, London, Macmillan, 1930

Fujimori, Terunobu, Fujimori Terunobu Architecture, Tokyo: TOTO Ltd, 2007

Gjesdal, Kristin, "Georg Friedrich Philipp von Hardenberg [Novalis]", The Stanford Encyclopaedia of Philosophy (Fall 2009 Edition), Edward http://plato.stanford.edu/archives/fall2009/entries/novalis/, visited 22 January 2011

Grainger, Hilary J, Death Redesigned: British Crematoria History, Architecture and Landscape, Oxford: Spire Books Ltd., 2005

Heehs, Peter, 'Myth, History and Theory', History and Theory vol. 33 No.1

Herrmann, Wolfgang, Gottfried Semper: in search of architecture, USA: MIT Press, 1984

Hersey, George, the Lost Meaning of Classical Architecture, Massachusetts: MIT Press, 1988

Hvatum, Mari, Gottfried Semper and the Problem of Historicism, Cambridge: Cambridge University Press, 2004

Jung, Carl G., Memories Dreams Reflections, London: Collins, 1961

Kahl, Douglas, 'Robert Venturi and His Contributions to Postmodern Architecture’, Oshkosh Scholar vol. 3, 2008

Kajava, Mika, 'Hestia: Hearth, Goddess and Cult', Harvard Studies in Classical Philology, vol. 102, 2004

Louisiana Department of Natural Resources, 'Fireplaces: Energy Dollars Up in Smoke', Energy Efficiency Resource Gateway, http://dnr.louisiana.gov/sec/execdiv/techasmt/educational_resources/bgbb/7/energy/index.html, visited 9 December 2010

Matthews, Emma-Kate, ‘Treptow Crematorium, Baumschulenberg, Berlin’, University of Nottingham Journal, 2007 
Meinhold, Bridget, 'Element Prefab Housing by MOS Utilizes Fibonacci Growth Patterns', Inhabitat, http://inhabitat.com/element-prefab-housing-by-mosutilizes-fibonacci-growth-patterns/mos-element-house-15/, visited 22 April 2010

Meinhold, Bridget, 'Japanese Treetop Teahouse is “Built Too High”', Inhabitat, http://inhabitat.com/fujimori-tea-house/, visited 3 May 2010

Nesbitt, Kate, Theorizing a New Agenda for Architecture: an anthology of architectural theory, Massachusetts: Princeton Architectural Press, 1996

Pilling, Simon, ‘Tea for Three', Architecture Review 223/1335, May 2008

Preziosi, Donald, The Semiotics of Built Environment, Bloomington: Indiana University Press, 1979

Preziosi, Donald, Architecture Language and Meaning, Netherlands: Mouton Publishers, 1979

Raggio, Olga, 'The Myth of Prometheus', Journal of the Warburg and Courfauld Institutes vol. 21 no. 1/2, Warburg Institute, 1958

Russell, Bertrand, History of Western Philosophy, New York: Routledge, 2004

Russell, James S., 'Evoking the Infinite’, Architectural Record vol. 188 no. 5, May 2000

Rykwert, Joseph, The Necessity of Artifice, New York: Rizzoli, 1982

Saieh, Nicoh, 'Multiplicity and Memory: Talking about Architecture with Peter Zumthor', ArchDaily November 2010, http://www.archdaily.com/85656/multiplicity-and-memory-talking-about-architecture-with-peter-zumthor/, visited 16 November 2010

Santamouris, Matheos, Environmental design of Urban Buildings: an Integrated Approach, USA: Earthscan, 2006

Schilbrack, Kevin Ed., Thinking Through Myths: Philosophical Perspective, London: Routledge, 2002

Schwartz, Frederic (Ed.), Mother's House: The Evolution of Vanna Venturi's House in Chestnut Hill, 1992: New York, Rizzoli International Publications Inc Semper, Gottfried, Four Elements of Architecture and Other Writings, Cambridge: Cambridge University Press, 1989

Smith, Lisa, 'Element House by MOS', Core 77, http://www.core77.com/blog/object_culture/element_house_by_mos_, visited 22 April 2010

Spigel, Lynn, Make Room for TV: television and the family ideal in post-war America, Chicago: University of Chicago Press, 1992

Spradley, Todd, Myth, ritual, and Architecture: The Path Toward Architectural Transcendence, Houston: Atrium Press, 1995 
Stegers, Rudolf \& Dorothea Baumann, Sacred Buildings: a design manual, New York: Springer, 2008

Venturi, Robert, Architecture as signs and systems: for a Mannerist time, Cambridge: Harvard University Press, 2004

Venturi, Robert, Complexity and Contradiction in Architecture, New York: MoMA, 1977

Walker, Paul, Semiotics and the Discourse of Architecture, Auckland: University of Auckland, 1987

Zaidman, Louise \& Pauline Pantel, Religion in the Ancient Greek City, Cambridge: Cambridge University Press, 1992

\section{Illustration reference:}

1. Fernandez-Galiano, Luis, Fire and Memory: On Architecture and Energy, Cambridge: MIT Press, 2000

2. Schwartz, Frederic (Ed.), Mother's House: The Evolution of Vanna Venturi's House in Chestnut Hill, 1992: New York, Rizzoli International Publications Inc

3. Matthews, Emma-Kate, 'Treptow Crematorium, Baumschulenberg, Berlin', University of Nottingham Journal, 2007

4. Fujimori, Terunobu, Fujimori Terunobu Architecture, Tokyo: TOTO Ltd, 2007

5. Smith, Lisa, 'Element House by MOS', Core 77, http://www.core77.com/blog/object_culture/element_house_by_mos_, visited 22 April 2010

6. http://otrootroblog.blogspot.com/2009 1201 archive.html, visited 8 November 2010

7. http://commons.wikimedia.org/wiki/File:Heinrich fueger 1817 prometheus brings fire to mankind.jpg, visited 23 May 2010

8. http://karenswhimsy.com/vestal-virgins.shtm, visited 15 November 2010

9. http://firesafetyforchildren.wordpress.com/, visited 13 January 2011

10. http://childproofmyhome.com/store/index.php?main page=index\&cPath=7, visited 14 July 2010

11. Nancy, Trave/wonder, http://www.thewanderkind.com/2010/05/23/the-spirit-of-kecak-fireand-trance-dance/, visited 5 November

12. Rome of the West, http://www.romeofthewest.com/2007/08/photos-of-cathedral-of-saint-peter-in.html, visited 21 January 2011

13. Personal picture, taken August 2007

14. Personal Picture, taken August 2007

15. Tui Beer, http://www.tui.co.nz/default.asp?s1=Cool\%20Shit\&s2=Yeah\%20Right\%20Map, visited 2 December 2010,

15a. http://miyomarinaheritage.wordpress.com/

15b. Colomina, Beatriz, 'Domesticity At War', Assemblage vol. 16, 1991

16. http://www.inanna.virtualave.net/hestia.html, visited 28 August 2010 
17. Schwartz, Frederic (Ed.), Mother's House: The Evolution of Vanna Venturi's House in Chestnut Hill, 1992: New York, Rizzoli International Publications Inc

18. Schwartz, Frederic (Ed.), Mother's House: The Evolution of Vanna Venturi's House in Chestnut Hill, 1992: New York, Rizzoli International Publications Inc

19. Schwartz, Frederic (Ed.), Mother's House: The Evolution of Vanna Venturi's House in Chestnut Hill, 1992: New York, Rizzoli International Publications Inc

20. Smith, Lisa, 'Element House by MOS', Core 77, http://www.core77.com/blog/object_culture/element_house_by_mos_, visited 22 April 2010

21. Smith, Lisa, 'Element House by MOS', Core 77, http://www.core77.com/blog/object_culture/element_house_by_mos_, visited 22 April 2010

22. Smith, Lisa, 'Element House by MOS', Core 77, http://www.core77.com/blog/object_culture/element_house_by_mos_, visited 22 April 2010

23. Matthews, Emma-Kate, 'Treptow Crematorium, Baumschulenberg, Berlin', University of Nottingham Journal, 2007

24. Davey, Peter, 'Ritual of Death', Architectural Review 205/1223, January 1999

25. Davey, Peter, 'Ritual of Death', Architectural Review 205/1223, January 1999

26. Matthews, Emma-Kate, 'Treptow Crematorium, Baumschulenberg, Berlin', University of Nottingham Journal, 2007

27. Fujimori, Terunobu, Fujimori Terunobu Architecture, Tokyo: TOTO Ltd, 2007

28. http://www.artelino.com/articles/japanese tea ceremony.asp, visited 21 January 2011

29. Fujimori, Terunobu, Fujimori Terunobu Architecture, Tokyo: TOTO Ltd, 2007

30. Fujimori, Terunobu, Fujimori Terunobu Architecture, Tokyo: TOTO Ltd, 2007

31. http://otrootroblog.blogspot.com/2009 1201 archive.html, visited 8 November 2010

32. http://otrootroblog.blogspot.com/2009 1201 archive.html, visited 8 November 2010

33. http://farchitecture.tumblr.com/post/182070568/kureator-fotos-auf-www-bruderklaus-com, visited 26 November 2010

34. Casciani, Stefano, 'Il Santo e l'Architetto = A Saint and an Architect [Bruder-Klaus-Feldkappelle]', Domus 906 (2007), pp. 52-59

35. Casciani, Stefano, 'Il Santo e l'Architetto = A Saint and an Architect [Bruder-Klaus-Feldkappelle]', Domus 906 (2007), pp. 52-59

36. http://otrootroblog.blogspot.com/2009 1201 archive.html, visited 8 November 2010

37. Personal drawing

38. http://www.istrianet.org/istria/illustri/non-istrian/jackson tg/index.htm, visited 12 January 2011

39. http://www.life.com/image/imagenotavailable, visited 16 January, 2011 